\title{
THE DEVELOPING ROLE OF THE
}

\section{SPECIAL EDUCATION NEEDS COORDINATOR.}

An evaluation study on the effects of an RTLB project, which provided a wrap around Special Education Needs Coordinator service to all of the schools within its region.

\author{
By Lisa Collinson
}

A thesis submitted in partial fulfilment of the requirements for the degree

of

Master of Education

Victoria University 


\begin{abstract}
The purpose of this mixed methods study was to investigate the systems level intervention which was initiated by an RTLB (Resource Teachers' of Learning and Behaviour) cluster, through EPF (enhancing programming funding) and with local Principals' Association support in order to improve the SENCo (special education needs coordinator) service (outcomes for students) within the region. This intervention based on an inclusive paradigm involved creating dedicated SENCo positions within each of 19 schools involved and assisting in setting up special need's committees, gaining release time for SENCos, negotiating and arranging professional development, developing a reporting system for SENCos, developing interagency collaboration and fostering a community of practise among the SENCos. This study found that the RTLB cluster, working collaboratively with the local principals, successfully initiated the EPF application in order to aid in the creation of the SENCo positions within all of the schools in the region, along with leading the project of professional development and supporting SENCos in schools in order to provide a better service for special education students within the region. New Zealand's education system historically either ignored students with special education needs or placed them into special settings. Special education and the Tomorrow Schools policy provided the next step toward inclusive practices. However, the tools to implement shifts in paradigm are found through; professional development, communities of practice, collaborative-consultative approaches, teacher/school change and the management and facilitation of the transfer of learning. The research clearly indicates that further investigation is needed to understand the role of the SENCo within New Zealand schools. Is there a place for SENCos in our post Special Education 2000 schools? Do; release time, PD, professional support and role development affect the SENCo role and does a SENCo service impact on the service provided to students with special educational needs? There is much scope for future research within this area. It would be interesting to follow what happens with this group of SENCos in the long term. A longitudinal study of this kind would be able to answer questions about the long term implications and outcomes that may arise. Do the systems put in place lead to more inclusive classroom practices within the region and better outcomes of the students? Is this fledgling community of practice maintained and do the SENCos take up the mantle of change agents within their schools? It would also be worthwhile to look at the other two clusters who have initiated their own versions
\end{abstract}


of this project. Undertaking case studies for schools which create SENCo positions would shed further light on what works and what doesn't at the school level and the outcomes for students with special educational needs. 


\section{Acknowledgements}

Firstly I need to acknowledge the support of my family. Thank you to my awesome husband (Chris) and two amazing children (Julia and James) who have shared me with this thesis. Also to my parents who have stepped in to help with my family commitments many times and have always supported and encouraged me every step of the way.

Secondly, to my supervisor Liz Manins whom I hope I have not put off this role of thesis supervisor forever. You took me on in mid-project and have been outstanding in your feedback and guidance. May all your future students be much easier.

Thirdly, I need to thank the RTLB, the SENCos, the families and the schools involved in this project for allowing me access to this project and your time. We are often vulnerable at times of change and I appreciate the way you opened up to me about your experiences.

I would also like to acknowledge the input, guidance and inspiration that I have received from Don Brown and Lottie Thomson/Brown both with regard to this study and also in my personal journey of developing a passion for cooperative, inclusive education. Your legacy is our practise; I pray I do it justice. 
Table of Contents

Abstract $\quad$ ii

Acknowledgements

Table of contents $\quad \mathrm{V}$

Chapter 1 The study 1

1.1 Introduction 1

1.2 Statement of the problem 2

1.3 Definitions of the constructs for this study 2

1.4 Purpose of the study 3

1.5 Research questions 4

$\begin{array}{lll}1.6 & \text { Significance to the field } & 7\end{array}$

$\begin{array}{lll}1.7 & \text { Summary } & 9\end{array}$

$\begin{array}{lll}\text { Chapter } 2 & \text { Literature Review } & 11\end{array}$

$\begin{array}{lll}2.1 & \text { Introduction } & 11\end{array}$

2.2 Historical Development of New Zealand special education 11

$\begin{array}{lll}2.3 & \text { School/Teacher change and transfer } & 13\end{array}$

2.4 Tomorrow Schools Policy 15

2.5 Special Education 2000 and inclusive education 18

2.6 The Wylie Report and SENCo 23

2.7 The SENCo and communities of practice 28

2.8 Summary 33 
$\begin{array}{lll}\text { Chapter } 3 & \text { Methodology } & 35\end{array}$

$\begin{array}{lll}3.1 & \text { Introduction } & 35\end{array}$

3.2 Research design 36

$\begin{array}{lll}3.3 & \text { Participants } & 38\end{array}$

$\begin{array}{lll}3.4 & \text { Setting } & 39\end{array}$

3.5 The project 41

3.6 Data Collection 42

3.7 Data Analysis 43

Quantitative

Qualitative

Validity and Reliability

Trustworthiness

3.8 Ethical consideration 50

3.9 Summary 52

$\begin{array}{lll}\text { Chapter } 4 \quad \text { Findings } & 54\end{array}$

4.1 Introduction $\quad 54$

4.2 How did the initiative impact on the regional SENCo service? 54

4.3 How did release time, professional development, professional support and role development affect the SENCo role? 57

4.4 How did these elements impact on the service provided to students with special educational needs within the region? $\quad 70$

$\begin{array}{lll}4.5 & \text { Summary } & 72\end{array}$ 
$\begin{array}{lll}\text { Chapter } 5 & \text { Discussion and Reflection } & 74\end{array}$

$\begin{array}{lll}5.1 & \text { Introduction } & 74\end{array}$

5.2 How did the initiative impact on the regional SENCo service? $\quad 74$

5.3 How did release time, professional development, professional support and role development affect the SENCo role? 79

5.4 How did the project impact on the service provided to students with special educational needs within the region? 83

5.5 Reflections 83

$\begin{array}{lll}5.6 & \text { Summary } & 86\end{array}$

$\begin{array}{lll}\text { Chapter } 6 & \text { Implications and Recommendations } & 88\end{array}$

$\begin{array}{lll}6.1 & \text { Introduction } & 88\end{array}$

$\begin{array}{lll}6.2 & \text { Reflections } & 88\end{array}$

$\begin{array}{lll}6.3 & \text { Recommendations } & 90\end{array}$

6.4 Further Research and Questions 93

$\begin{array}{lll}6.5 & \text { Summary } & 93\end{array}$

$\begin{array}{ll}\text { References } & 95\end{array}$

$\begin{array}{ll}\text { Appendices: } & 103\end{array}$

$\begin{array}{lll}\text { Appendix A: } & \text { Ethical Approval } & 105\end{array}$

$\begin{array}{lll}\text { Appendix B: Participant Information and consent form } & 106\end{array}$

$\begin{array}{ll}\text { Appendix C: Interview questions } & 119\end{array}$

$\begin{array}{ll}\text { Appendix D: } & 123\end{array}$

$\begin{array}{lll}\text { Appendix E } & \text { The RTLB milestone report format } & 128\end{array}$ 


\section{List of Figures:}

Figure 1: The Ministry of Education's framework for supporting students with special educational needs

Figure 2: $\quad$ RTLB Policy and Toolbox

Figure 3: $\quad$ Types of schools in the region

Figure 4: $\quad$ Teaching experience of the SENCos

Figure 5: Decile ratings of schools within the region

Figure 6: Level of education for those over 15 in the area

Figure 7: National and local level of income for those over

Figure 8: Qualitative and Quantatative data Collection

Figure 9: $\quad$ Gender of the SENCos

Figure 10: SENCos in schools before the project

Figure 11: SENCos in schools after the project 
Figure 14: Job description

Figure 15: Correlation between job description and networking

Figure: 19: Correlation between release time and having a special needs committee

Figure: 20: Correlation between professional development and having a special needs committee

Figure: 21: Correlation between having a job description and having a special needs committee

Figure: 22: Set criteria for special needs referral 
Figure: 28: Parents identifying the SENCo

Figure: 29: Students on the Special Needs Register 


\section{Chapter 1: The Study}

\subsection{Introduction}

In this study the researcher evaluated an RTLB initiated project, which provided a 'wrap around' special education needs coordinator (SENCo) service to all 19 schools within an RTLB region of New Zealand.

Education is a dynamic process which is often buffeted by changing governments and new social, psychological and philosophical ideas. Within this system sits a diverse group of our most vulnerable students, those with special educational needs. Although this group has been recognised and catered for in New Zealand for over 90 years, this has often been as an informal attachment to conventional education. Over the last 10 years, some progress has been made in effectively meeting special educational needs however, this is not yet complete. Tomorrow Schools (Department of Education, 1988) allowed schools the flexibility to be responsive to their communities however, this system of decentralization does not establish itself overnight and the task for early Boards of Trustees was daunting. I believe that we are currently in a place where at least some boards and principals really understand the special education system and have established and entrenched special education policies and procedures in place within their schools. This is a perfect climate, the breeding ground for ingenuity based on good practice. At least some of these self governing Tomorrow Schools have shown themselves as capable of shaking off their fledgling status and blooming into independent entities that can see the need to develop leadership in providing for the needs of all of their students.

This study looked at such a project, whose inception came from Resource Teacher of Learning and Behaviour (RTLB), but with principals' support encompassed all of the schools within the region. Drawing on the established British model which was supported under Special Education 2000 (Ministry of Education, 1996), these schools created Special Education Needs Coordinator (SENCo) positions with release time and access to professional development. This model demonstrated self governing schools working collaboratively and proactively to cater for special educational needs within their region, with the support of contestable funds. This project 
provided a rare opportunity to study the dynamics of educational change. Could self-governing schools, using the resources currently available to them, create systems that nurture and support effective services for those with special education needs?

In 1996 the Ministry of Education stated that “The Government’s aim is to achieve, over the next decade, a world class inclusive education system that provides learning opportunities of equal quality to all students.” (p.5). In light of this, the Wylie (2000) report (commissioned by the Minister of Education as part of a review of Special Education Policy) recommended the use of SENCo positions as an integral part of schools 'special-needs systems'. However, little information is available to school boards or professionals about the use of SENCos within schools in New Zealand.

It is 10 years since the Wylie review and this was an opportune time to evaluate a section of current 'special education' practice in light of this inclusive framework.

Wylie (2000) recommended that the SENCo, “...could work with school staff, Resource Teachers: learning and behaviour, and district centre staff to identify individual students needs, plan programmes, arrange support, professional development and resource materials to support other teachers at the school in their work with special needs.” (p.88). Although not directly created, the SENCo position were seen as an integral part of the schools special-needs system and responsible for overseeing and reporting on: resources, personnel, programmes and equipment provided to students within special education.

\subsection{Statement of the problem}

This study sought to evaluate the outcomes of the SENCo project that was designed to determine the effects of an RTLB led initiative to create and support the development of SENCO positions within schools.

Focus 1: Monitoring and evaluating the development of the collaborative, regional SENCO service. 
Problem: There had not been a collaborative regional SENCo service in this area before and therefore there was a need to consider if and how the RTLB cluster created and supported the role of SENCo within the schools in its region.

Focus 2: Analysing the impact that release time, professional development, professional support and role development had on those working within the SENCo role.

Problem: What was the impact of the professional development provided? We needed to consider the impact of: release time, professional development, professional networking and role development on those who worked within the SENCo role.

Focus 3: Analysing the impacts on the education service provided to students with special educational needs through parent interviews.

Problem: Was there a flow on effect from the creation and support of the SENCo role to the students with special needs within the school?

\subsection{Definitions of the constructs for this study}

The educational terms referred to in this study are defined as follows:

Professional development: A pre-organised opportunity to develop skills or knowledge in line with the role of SENCO

Release time: The non contact time allocated to SENCO within the course of their normal work to spend time working in the role of SENCO.

Professional networking: Communities of practice where people undertaking the same role (SENCo) communicate amongst themselves to share ideas and support.

Role development: the practise of defining the role of SENCo and identifying and creating systems in order to undertake SENCo work.

SENCo: $\quad$ Special Educational Needs Coordinators.

RTLB: $\quad$ Resource Teachers of Learning and Behaviour. 
IEP:

Individual Education Programme.

BOT: Board of Trustees

SMT: Senior Management Team

EPF:

Enhanced Programme Funding

\subsection{Purpose of the study}

The purpose of this study was to evaluate the RTLB initiated project to support the development of an inclusively based region wide SENCo service within all the schools in the region.

In 2007, the members of the RTLB cluster noticed a wide variation in the SENCo service available throughout their region. The RTLB experience supported the idea that, in spite of legislation intended to protect their rights to access mainstream education and participate without discrimination, students with special educational needs in New Zealand were still facing barriers to their successful inclusion (Ballard, 2003; MacArthur, Kelly, Higgins, Phillips \& McDonald, 2005). However while the Ministry of Education has endorsed the use of SENCos in schools, in line with the British model, this has not been supported by the creation of specific positions, training or funding allocations. In order for schools to make informed decisions about the advantages and disadvantages of having a SENCo in a school, more information was needed regarding the role of SENCo within the New Zealand context. This study aimed to evaluate the unique RTLB region wide project which created SENCo positions within all of the regions schools coupled with: professional development (PD), release time, networking and reporting that was developed around these positions.

Prior to 2009 RTLB D (personal communication, February 12, 2008) stated that in 2007 some of the RTLB cluster noticed that within the schools they worked, those who had a dedicated SENCo position identified students with special needs faster and organised inclusively based supports for those children more effectively than those schools which did not have a SENCo position. By having one central link into special needs in a school it allowed a streamlined access for outside agencies and a point of knowledge and expertise within the school. This position was seen by RTLB as adding immeasurably to the philosophy of inclusive special education in schools as well 
as the service to and outcomes of the special education families. This led initially to RTLB discussions and then with their supporting principals groups, which agreed that there may be some benefit in schools within the area having specified SENCo positions. During 2007, the Fernlea and Clovalea RTLB sub clusters realigned themselves and began working as one cluster. This meant that the focus of the SENCo discussion now became region wide. There were six RTLB (and one RTLB Maori who is shared with another cluster) within the cluster with 19 schools in their region.

The initial idea was to provide release time and inclusive based PD for SENCos. This project hinged on the initial financial input from an EPF application in order to release the SENCos and to provide effective and appropriate PD. It meant that a PD programme could be developed in such a way that all of the principals in the area would support it.

In 2007 the RTLB service initiated what was to become a formal EPF application to develop a dedicated SENCo position in each school within their region, encompassing release time and PD over a 2 year period (2008-2009). This application was supported by all of the principals of the 19 schools within the region. A steering group was created which included: two representative principals (one of which was the principal of the EPF fund holding school), two representative RTLB, the local GSE manager, a SENCo representative and myself in my role as researcher.

The EPF covered release day funding for the 19 schools involved, 3 per term with an additional PD release day each term for 2008-2009. The EPF also covered the payment for the PD speakers, venue, and the food for the day. RTLB organised the PD, by sharing coordination and organisational responsibilities. All of the schools involved agreed to create or maintain SENCo positions throughout the project and to provide the release time. The SENCos were encouraged to use some of the release time to work with each other on refining their rolls and procedures and to spend time with RTLB who would assist them to establish committees and ensure registers were developed.

The SENCO role was seen as invaluable to RTLB in schools where it was working well because it gave direct access into schools and increased data that allowed for systems level interventions. 
The RTLB service also recognized that there was high frequency of transience among students with special needs within this region. In the schools with SENCos, the transfer of students and ongoing support flowed more effectively than in schools where there were no defined responsibility. After discussion with the Special Education Advisor, the RTLB considered applying for EPF to address this issue and this EPF application grew to include all of the schools in the region. The proposal was adopted by the local Principals Association with one principal assuming a key role of support and promotion. Eventually all 19 principals agreed to become part of this project, which in some cases meant abandoning EPF applications they had been already considering individually for their schools. An application was put in and once approved a steering group was created to manage the project. It was considered vital that all of the schools in the region be involved in this project because collaboration and school level support were seen as essential to the long term goals.

This project presented the ideal opportunity to evaluate the development of the SENCo role in provincial New Zealand, through a cluster of all of the schools within the region setting up structures to support and steer the development of special education within their schools.

There were four main dimensions to the development of a region wide SENCo service:

1. Relevant SENCo PD designed to provide relevant to SENCos and aimed at the level of change agents.

2. Collaboration closely linked to the PD. The PD was the vehicle through which the SENCos met together and developed working relationships.

3. School release time for planning and implementing changes to support the new learning and allow the SENCos to network.

4. Reporting systems to cover the development of special needs registers and committees. These four areas are discussed in some detail below. 


\subsection{Research Questions}

The research questions of this study were designed to address both the holistic and scientific descriptions of an educational system, the processes, and phenomena within a specific context as well as controlling and explaining variance within that context.

This study sought to evaluate the outcomes of the SENCo project through addressing the following research question:

What are the effects of an RTLB led initiative to create and support the development of SENCo positions within the schools of a region of New Zealand?

This will be investigated via asking three key questions:

- How did the initiative impact on the regional SENCo service?

- How did release time, PD, professional support and role development affect the SENCo role?

- How did these elements impact on the service provided to students with special educational needs within the region?

\subsection{Significance to the field}

There are four major paradigms or world views that underpin educational research. It is these philosophical assumptions that shape and guide the research practice. Mertens (2005) pointed out that early educational research was founded in positivism and post positivism, which emphasises objectives, value free research that studied a fixed reality through empirical, quantitative methods. Constructivist research centres around researcher-participant interactive research, where values are explicit, and it studies socially constructed realities in a qualitative manner. Transformative research considers the relationship between researcher and participants 
within many (social, political, cultural, economic, ethnic, gender and disability) realities using a mixed methods analysis. A pragmatic paradigm is driven by the researcher who considers anything useful. Therefore, useful relationships are explored and the methods match the questions being investigated (Tashakkori \&Teddlie, 2003).

Traditional special education research methodology has been based on positivist paradigms, where differences are viewed through a medical model. Skritc (1991) stated that:

Real progress in special education, of course, will require a different frame of reference, a different set of assumptions, theories and metatheories. At a minimum, it will require the special education community to take seriously the critics of its theoretical and applied knowledge. It will require a self-reflective examination of the limits and validity of special education knowledge and its grounding assumptions. (p. 116)

Historically, special education research has been about fixing or reducing the deficit within the child. However, within an inclusive system the emphasis is on the ecological factors and the research needs to adjust to this change in paradigm, away from a deficit model to an inclusive model.

In contrast, this study is based on a pragmatic paradigm. Because of this, the study does not try to search for truth in the real world, but rather looks at the effectiveness with regard to the specific problem studied (Mertens, 2005). It assumes that the research question is of more importance than the method employed or the worldview underpinning it. Tashakkori and Teddlie (1998) described pragmatic researchers as;

Pragmatists decide what they want to research, guided by their personal value systems; that is, they study what they think is important to study. They then study the topic in a way that is congruent with their value system, including variables and units of analysis that they feel are the most appropriate for finding an answer to their research question. They also conduct their studies in anticipation of results that are congruent with their value systems. This explanation of the way in which researchers conduct their research seems to describe the way in which researcher in the 
social and behavioural science actually conduct their studies, especially research that has important social consequences. (p. 27).

The two main forms of data collection within education are qualitative and quantitative. Quantitative research uses numbers in statistical methods that tend to be based on numerical measurements of specific aspects of phenomena that abstract from particular instances to seek general description to test hypotheses that seeks measurements and analysis that are easily replicable by other researchers (Creswell, 1994). In quantitative research, the researchers' role is to observe 'in niche', and care is taken to keep the researchers from contaminating the data through personal involvement with the research subjects. Researchers' objectivity is of utmost concern (Glesne \& Peshkin, 1992). Quantitative research is seeking explanations and projections that will generalise to other persons and places. Careful sampling strategies are aspects of methods aimed at producing generalizable results (Patton, 1990).

The very nature of the project made the sampling easy, because the population entailed the entire 19 schools within the region. The sample for the project therefore involved the entire population of schools, SENCos and principals and although one school chose not to be directly involved in the study they were still part of the project. Of the 19 schools in the region each had a SENCO involved in the project. The 19 principals from the region's schools were also involved in the project and 18 were involved in the study. In addition to this one school allowed access to two sets of parents.

For the 'parent interviews' the sample was 1 school out of 19 from within the region. It was deliberately selected because it represented an age range from year 0 to year 8 (inclusive) in a medium sized urban school. The participants were the SENCo, the principal, and two families selected at random by the SENCo, from students on the special needs register at that time. All participants underwent a discussion around informed consent and what their involvement entailed as well as signed consent forms. The researcher conducted the interviews to minimise interviewer differences. 
The study does not aim to provide a generalizable study but rather an evaluation of a specific project within a specific region.

This thesis makes an important contribution to the current knowledge of special education practise within New Zealand. It provides a rare opportunity to study the dynamics of change within this field. The initiative built on the recommendations made by the Wiley report (2000), which were never implemented officially within New Zealand schools. This study took advantage of the opportunity to investigate the effects of this RTLB led initiative to create and support the development of SENCo positions within the schools of a region of New Zealand. Therefore, contributing knowledge about: the regional impact of having a SENCo service, how release time, $\mathrm{PD}$, professional support and role development affected the SENCo role and how those elements impacted on the service provided to students with special educational needs within the region?

\subsection{Summary}

This study was based on a constructivist and ecological perspective. It provided a rare opportunity to evaluate an RTLB project which provided a wrap around Special Education Needs Coordinator service to all of the schools within its region. Three key research questions concerning; the impact on the regional SENCo service, the affect on the SENCo role and the impact on the service provided to students with special educational needs within the region, were used to focus the gathering of both qualitative and quantitative data. 


\section{Chapter 2: Literature Review}

\subsection{Introduction}

This study is based within the broad umbrella of the education in New Zealand and more specifically the field of special education within this sector. It is therefore useful to have a brief history of the international educational systems and social movements which have helped shape the New Zealand system, as well as the more specific development of education within New Zealand with particular emphasis on the development of special education. This information allows us to understand the broader context into which this study fits. The literature review also provides the research framework around; inclusive education, teacher/school change and the management and facilitation of the transfer of learning that supports the given ecological perspective.

\subsection{Historical Development of New Zealand Special Education}

Formal, European-based education in New Zealand started with the early missionary schools and led to state education in New Zealand in 1877. However, students with special education needs were excluded and left to the care of churches and other voluntary organisations. In 1907, the Education Amendment Act provided for the education of 'defective' children in separate special schools (Mitchell, \& Mitchell, 1985). The Act defined a 'defective' child as;

a child who, not being idiot or imbecile and not being merely backward, is by reason of mental or physical defect incapable of receiving proper benefit from instruction in an ordinary school but is not incapable by reason of such defect of receiving benefit from instruction in a special school or class (cited in Mitchell \& Mitchell, 1985, p.172).

In 1927 education policy stated that children with an intellectual handicap should attend either special schools or special classes in ordinary schools. This institutionalisation of students deemed as having more severe sensory, intellectual or physical needs became accepted practice. 
Mitchell and Mitchell (1985) discuss how special education in New Zealand expanded between 1930 and 1960 with special schools and units. They go on to state that this period was also marked by a number of consumer and charitable organisations providing services for disabled people. These include: The Hearing Association in 1982, the New Zealand Crippled Children's Society in 1955, the Dominion Association for the Blind in 1935, the Handicapped Children's Association in 1939 and the New Zealand Epilepsy Association in 1956. The Foundation for the Blind was established as a charity to provide for the care, relief, education, and training of blind persons in New Zealand.

In 1959 the Department of Education stated that the separation of children from their peers was done only reluctantly, however between the late 1950s and the mid-1970s segregated special education was wide spread and the rationale for this was centred upon the medical model of disability. This mirrored international trends of segregated systems for special needs students. Hall (1997) found that the emphasis was on remediating the student rather than changing the system and that this model firmly planted the deficit within the child. This perspective encouraged the development of special schools with specialised resources and teaching staff. Skrtic (1991) argued that the lack of capacity and capability in regular schools also led to special schools for students with special needs. Teachers who considered themselves ill-prepared to meet the needs of these students in the regular class, were often prepared to pass their students on to 'experts' in a system which offered to fix the deficit. By 1977, Kimberley Hospital in Levin had 700 clients and was considered the largest hospital for the intellectually handicapped in the southern hemisphere - it cared for 15\% of all identified intellectually disabled people in New Zealand (Hunt, 2000).

In the late 1950s to early 1970s there was the development of an international movement that emphasised human rights and this slowly flowed into the area of special education. The main factor in this change is attributed to the American civil rights movement in the 1950s and 60s. In 1953, in a then landmark decision by the United States Supreme Court, Chief Justice Warren ruled that separate was not equal (Stainback, Stainback \& Bunch, 1989) and in the late 1960s normalisation theory was developed in Sweden. Normalisation postulated that "patterns of life in 
conditions of everyday living which are as close as possible to the regional circumstances and ways of life of society” should be made available to disabled people (Nirje, 1976, p.231).

Although within New Zealand the education of these students with special educational needs continued outside mainstream schools until the late 1970s, a change in disability strategy paralleled the world wide civil rights movement (Skerrett, 2008). With persistent agitation the rights and needs of people with disabilities began to receive more recognition (Fine \& Ash, 1988). In 1981 the International Year of the Disabled Person (IYDP) culminated years of challenges, and slowly legislation and policy began to change and individuals with disabilities begin resisting the treatment they were receiving. (Morris, 1991). In 1987 the New Zealand Draft Review of Special Education (Department of Education, 1987) advocated for the closing of special schools and units. It emphasised that special education should provide support within the mainstream rather than a separate system with its own facilities. Although the report was not formally ratified, many of the keys ideas were contained in Special Education 2000.

In the late 1970s and early 1980s New Zealand's education system was influenced by the mainstream movement which lead to many special education facilities being closed and responsibility for the education of these students being given to regular schools. The 1980s was a time characterised by inflexibility in decision-making and a lack of responsiveness when dealing with those with diverse needs (Greaves, 2003). In 1983 the Ministry of Education Curriculum Review encouraged input from the public. It took 2 years of consultation with 21,000 submissions before the review was published in 1986 (NZCER, nd). This document was not specific to special education; however it was one of the areas which were highlighted by public submissions. The momentum for change in special education continued with the Draft Review of Special Education in 1987 which recommended mainstreaming for New Zealand education. However, the Draft Review was not ratified and education became subject to political reform as a new Labour Government came to power in 1987. This government commissioned a report on education now known as the Picot report (Department of Education,1988) which then developed the philosophy of Tomorrow's Schools. This report backed the decentralisation of educational decision-making within a framework of national objectives. The reforms which ensued were based on the principles of equity, quality, efficiency, economy and effectiveness. 


\subsection{School/teacher change and transfer}

The definition of professional development has evolved over time as various models have grown as researchers have tackled the task of identifying which strategies are most effective. These models have highlighted the importance of; reflection, observation, mentoring, coaching, knowledge and conceptual growth, personal development and social learning opportunities. They have also shown that practice can change and that there are strategies that can support successful professional development. Current thinking identifies the systematic nature of professional development and Villegas-Reimers (2003) sum it up by saying that "the process of professional development has a significant impact upon teachers' beliefs and practices, students' learning and on the implementation of educational reform” (p. 19).

McDonald (2009) identified a variety of significant issues relating to the professional development process. He classified four factors affecting this process; teachers learning and motivation in professional development programmes, the quality of the programme, the educational systems openness to change and professional demands. However he also found that fundamental to professional development improving students' learning is that it changes values, belief systems and skills and the principle that learning can be transferred from one situation to another. Further to this, suggests that while many variables assist in promoting effective professional development the most important factor is having programmes that meet the needs of the learners and their specific contexts.

Professional development can lead to enhanced teacher performance. An important part of this is transfer of learning, which relates to the degree that past and new leaning is repeated in similar new situations. Haskell (2001) states that transfer of learning is the basis of knowledge and problem-solving. It is a central concept in effective education and the key to all effective instruction and learning, including professional development. McDonald and Melchior (2007) have developed 14 principles that have important implications for both the facilitators and participants in professional development programmes. These are; an extensive knowledge base 
and expertise in the subject area, a knowledge base in peripheral and unrelated subject areas to draw analogies, similarities, differences, background and context, highly motivated, an understanding about transfer, higher-level thinking skills, support, theoretical knowledge of the area under consideration, practice and drill activities, allowing time for the learning and the experiences of other people.

This body of research has highlighted significant considerations associated with the transfer of professional development knowledge which need to underpin effective professional development programmes.

\subsection{The Tomorrow School's Policy}

Under Tomorrow School's policy, Boards of Trustees were elected to govern the school. The Ministry of Education sets the National Administration Guidelines (NAGS) for school administration, which set out statements of desirable principles of conduct or administration for schools and Boards of Trustees. The National Administrative Guidelines state that schools must develop and implement teaching and learning programmes for all students, that it is good practice for schools to have policies and procedures to support all students and that the Education Review Office (ERO) would expect a special needs policy and ensure that Special Education Grant (SEG) funding was used to benefit students. There was an expectation that schools would identify students were at risk of not achieving or who had special education needs. It was the schools responsibility to create strategies that address these needs. National Education Goals (within the National Education Guidelines or NEGs) calls for “...success in their learning for those with special needs by ensuring that they are identified and receive appropriate support” Ministry of Education (n.d). The RTLB service is one of the school-based resources supporting schools to meet these responsibilities (see Figure. 1).

Under Tomorrow Schools the school Board of Trustees takes the responsibility of providing staff with PD under the guidance of the principal. Moore et al. (1999) recommended two important issues when considering PD for professionals required to apply effective inclusive practices in schools. These two issues were: the acknowledgement that teachers need help to access effective 
and appropriate PD, and that the interventions need to be developed collaboratively at the school level.

For teachers to develop and apply effective inclusive practices literature and in-service training programmes are insufficient sources of assistance. Furthermore, Korthagen and Kessels (1999) found that teachers generally do not use research to develop the philosophy of their work because this process is just too complex and time consuming. They also found a need to link research and teaching practice and suggested the need for research to be seen as a reciprocal questioning and exploration. But as Hubermann (1993) stated, reflection of own practice is not an easy skill to develop in isolation

Beattie, Jordan and Algozzine (2006) state that "PD that empowers both special education and general education teachers and encourages them to work together is critical to successful inclusion” (p. 157). They suggest the best way to provide students with great education is to give them skilled teachers. Darling-Hammond (2003) showed the single greatest impact on student achievement is teacher quality.

In August 2005 the Ministry of Education (2004) released the Draft Report of the Literature Review for the Enhancing Effective Practice in Special Education Research Programme (EEPiSE). This included the 2004 literature review carried out by the Donald Beasley Institute, and used to inform the subsequent phases of the project. Auckland Uniservices inferred the following indicators of effectiveness from the 21 Pilot study schools:

Effective pedagogy for students with special needs requires effective PD for all teachers and specialist staff.

The Pilot study also identified five key characteristics for effective PD and learning: Professional learning opportunities must be based on immediate needs and build upon existing knowledge. 
Teachers become facilitators and begin owning the process of professional learning and development.

Support to meet the needs of diverse learners is required.

Support for teachers needs to be built into school wide planning for raising student achievement.

Collaborative planning leads to goals that require ongoing monitoring, adaptation and review. (p.1)

In 1989 the New Zealand Education Act was passed, which entitled all children to a free, full time education from the age of 5 to the age of 19 at any state school in New Zealand (Education Act, Section 8). This was followed 4 years later, in 1993 when section 57 of the Human Rights Act prohibited educational establishments from refusing or failing to admit a student with a disability.

In 1991 the Special Education in New Zealand: Statement of Intent was released by the New Zealand Ministry of Education. Its aim was to ensure that all learners could have equal access to quality educational environment. The Ministry established a consultative body, the Special Education Policy Implementation Team to gather feedback about the implementation of the statement of intent policy but the report was never released to the public.

New Zealand's Special Education Policy Guidelines (Ministry of Education,1995) were developed in partnership with parents and students on the ideal that students with special education needs have the same legal right to in enrol and attend school on the same basis as other learners. However the guidelines also stated that some children with special educational needs may need to be taught in different learning environments than regular classrooms (Ministry of Education,1995, p.1). 
In 1995 and National Advisory Committee was set up to consider special education policy. In 1995/1996 a new policy, Special Education 2000 (SE2000) (Ministry of Education, 1996) in New Zealand was introduced. As expressed by the government, the overall aim of this policy was to: “...achieve over the next decade, a world-class inclusive education system that provides learning opportunities of equal quality to all students.” (p. 5). This policy reflected a most profound shift in educational thinking in New Zealand's history, a paradigm shift toward inclusive education in New Zealand. It’s aims were to; “...improve educational opportunities and outcomes for children with special education needs, ensure a clear, consistent and predictable resourcing framework for special education and to provide equitable resourcing for those with similar needs irrespective of school setting or geographical location” (Ministry of Education, 1996, p. 4).

The move towards inclusive education was considerable step forward to ward more equitable services within special education. However inclusion is not an easy term to define within education but it does signify a significant change in thinking from a medical model of diagnosis and deficit to an ecological evaluation of the match between the student and the instruction (Bines (2001); Karagiannis, Stainback \& Stainback, 1996). Cole (2005) suggested that while inclusion is a basic human right, it has not been well defined. She suggests that inclusion is a process. Gartner and Lipsky (1987) argue that inclusion isn't about how we fit students with special needs into our curriculum and classrooms but rather how we develop schools that scaffold and foster each student through adaptive environments.

Inclusion has become a catchword within education. Because it has been difficult to define it has been open to misrepresentation and abuse (Burstein, Sears, Wilcoxen, Cabello \& Spagna, 2003). This in turn has made it harder to achieve change. Undoubtedly a clear definition of such an important concept hinders developing effective policy change and more importantly practice in both schools and classrooms. However any term being used by such a wide and varied population will have inherent differences in definition and will also be subject to ongoing development (Luster \& Ouder, 1993). This means that a definitive definition is problematic and perhaps the best we can hope for is a consensus on the essence of the idea. Some terms can only be fully 
defined after they have completed their journey of evolution, and inclusion is very much still in its infancy.

The Ministry of Education defines inclusion as being threefold. Firstly, as a process that values all members, secondly it implies support to all students to fully participate in all levels and aspects of school life and thirdly it should imply an active searching for, and reduction in barriers to learning. The aim is a sense of belonging for all. The Ministry uses the term for ethnicity and disability. However, perhaps it is actually the opposite that really embodies inclusion. It is not about working optimally despite differences but working optimally because we are embracing and welcoming of those very differences. It is in effect those very differences which make us strong (Ministry of Education, 1991).

Miller and Katz (2002) offered a glimpse of inclusion from an industry platform, and supported the idea of inclusion embracing differences. They discussed “capitalising on diversity” (p. 1) where a workplace doesn't just have a varied employee base but where that diversity is the very building block of the company. Inclusion was a means of capturing this diversity and making it profitable. Again the focus in on a real sense of belonging, valuing and supporting while actively removing barriers (Lindsay, 2003).

The idea of removing barriers may on the surface appear redundant in a truly inclusive environment, and maybe it would be a greatly reduced need, however barriers can occur anywhere and collective vigilance and being prepared to address issues that arise is vital in maintaining the best atmosphere. Lipsky and Gartner (1992) address the need to eradicate the labels in special education and how inclusion achieves this end by acknowledging everyone as individuals and not simply diagnoses and deficits. They quote a public school superintendent who stating, “inclusion is about ownership. They are all our students” (Lipsky \& Gartner, 1997, p. 134). They go on to note that inclusion is a whole school based approach. It must be the cornerstone of educational philosophy, infiltrating every aspect of policy and practice if education is to meet its potential. 
When all of these ideas and definitions are considered it is apparent that there are several core threads which encompass the essence of inclusion. Drawing on all of these ideas the following description defines inclusion in education as valuing, fostering and supporting the diversity of all individuals in every aspect of their education through a whole school approach which actively seeks to reduce barriers to learning, in order to create a school and community wide sense of belonging.

A paradigm shift is never easy. Many people do not like change. The dual system of regular and special schools of the 1950's and 1960's was flawed and change was long overdue. However change that merely returned these students from their separate environments into regular classrooms which remained largely unchanged in the process was never going to work well (Lipsky \& Gartner, 1992). Such an arrangement is not inclusion. Special education schools and units were closed and students placed into regular classrooms primarily because of the Commission of Human Rights. However, the diversity that these students brought was not sufficiently valued, fostered or supported for an inclusive foundation (Ministry of Education, 2004). There was no whole school approach, no sense of belonging and very little done to reduce barriers to learning.

It is easy in retrospect to concur that inclusion which held such potential for change and life altering opportunities for so many ran the risk of being implemented hastily by those inside the system who did not understand the basis of the change. However, perhaps it could not be rushed through quickly enough for those students who were languishing under the old system.

It is important to clearly understand the differences between inclusion and its forerunner, the mainstreaming movement because, although they are different processes sometimes the two terms have been blurred. Karten (2005) stated that, "the Latin root of inclusion is include, meaning to embrace, while the Latin root of exclusion is excludo meaning separate or shut out” (p. 2). Embracing is very different from tolerating, it encompasses: warmth, affection and closeness. Mainstreaming within education is the practice of combining students from special classes with mainstream classes for specific classes. The ownership of these students' progress remained with special education. It was not a full inclusive model, but a step in that direction. 
Initial mainstreaming was about equity in human rights. The ideals were right, but they didn't include a clear way of getting from rights to best practice.

There needed to be a clear research based process between the concept and the implementation of inclusion. The issues of; up-skilling staff, changing attitudes, gaining resources, changing physical structures and transitioning students and families were far too complex to simply take students out of special settings and place them into regular classrooms (Ainscow,2000). Our educationalists were to naïve in believing that vague ideals (no matter how noble) could be smoothly imposed on entrenched school systems. In their enthusiasm they forgot about consultation and collaboration. They failed to take into account human nature and the fear and opposition to change and they also neglected o supply the tools with which to make this transition successful. Possibly mainstreaming needed to occur before inclusion could fully evolve and it is just an ongoing process of educational development. Perhaps the physical shift needed to happen before the philosophical one could. What we do shapes our belief's far more, than what we say we believe does (Myers, 2009. The very visible implication has been, and will continue to be the change in special education from a special programme (Lipsky \& Gartner,1992). Another more implicit benefit would be the empowerment of teachers (Gerber, 1998). Inclusion is about collaboration and valuing of all parties.

It is important to remember that schooling is a relatively new institution in the evolution of humankind and one might venture to say it is not yet mature. In the Western world the Industrial Revolution and child labour laws saw the development of the education system based on Western cultural values and a factory model (Deschenes, Cuban, \& Tyack, 2001). It was far from a perfect system but it was a step along the path of development. Over the last twenty plus years that path has been steered by research to look at education through an ecological eyepiece (Lipsky \& Gartner, 1992; Tilly, 2002, Bronfenbrenner, 1979). The deficit ideas that a school can be culturally unbiased and that there is something inherently wrong with children themselves if they don't learn has been eroded and we have realised that we cannot escape our own worldviews and be culturally neutral (Deschenes et al.. 2001; Norwich \& Lewis, 2001). Educationalists have realised that in order to move forward we need to actively accept individual differences and 
actively include culture, ethnicity and all diversity within our system rather than naïvely pretend that this diversity can be left at the classroom door (Reschly \& Ysseldyke, 2002).

Special education 2000 was gradually introduced in 1996. It lays out procedures governing special education resources. Mitchell (1999) refers to SE2000 as a set of complex interlocking provisions with the aim of producing a world-class inclusive education system in New Zealand by 2005. These complex interlocking provisions provide: special education resources for children from birth to school entry, an ongoing resourcing scheme to school students with high or very high needs, a newly created special education grant for schools based on size and decile rating, and the provision of services to students with moderate needs who are not catered for by other components of the policy. Three major components of the policy were a severe behaviour initiative for students with extreme behaviour difficulties, a communications initiative for students with speech language difficulties, and the creation of a mostly itinerant based school resource, Resource Teachers of Learning and Behaviour (RTLB) who would support schools in assisting students in Years one to ten with moderate to mild behaviour and learning needs (see Figure 1).

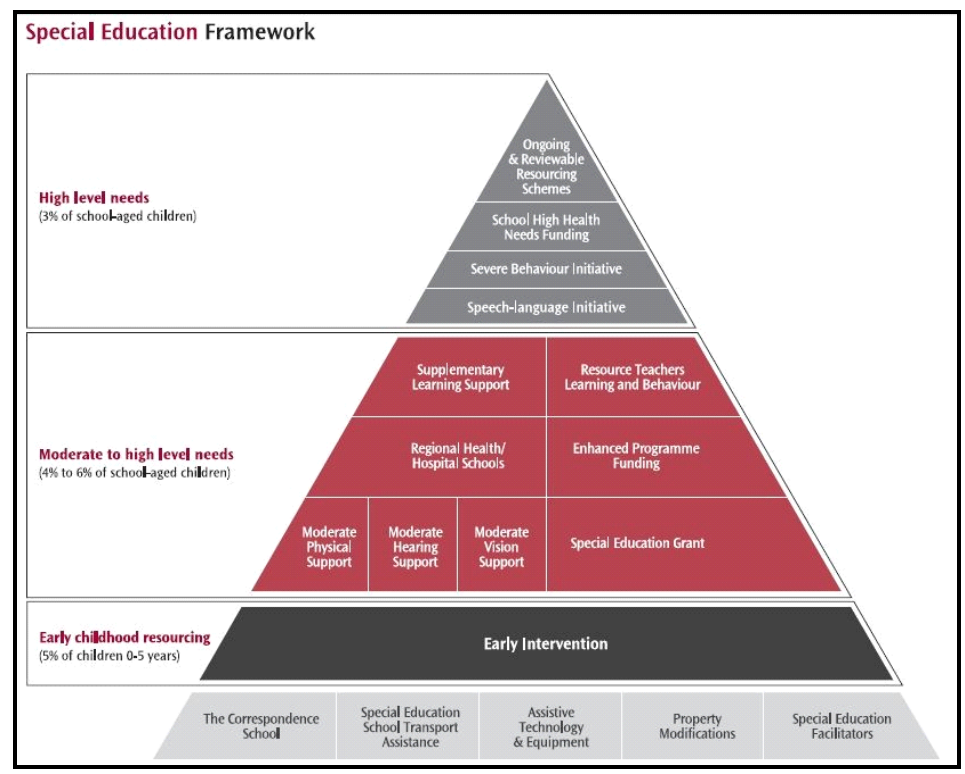

Figure 1. The Ministry of Education's framework for supporting students with special educational needs. From the Controller and Auditor-General, by the Office of the AuditorGeneral, Audit New Zealand,2001. Retrieved from the Auditor-General's website: www.oag.govt.nz/2009/special-education/part2.htm 
As can be seen in Figure 1, the Enhanced Programme Fund (EPF) is a supplementary, group based contestable grant available from the Ministry of Education to schools that have a disproportionate number of students with moderate special education needs who are not receiving targeted funding support from any other source. It was implemented in 2003 and ceased under the new National Governments review in 2009.

Three years after the Special Education 2000 (SE2000) policy was introduced McAlpine (1999) looked at data which evaluated the learning outcomes and educational provisions of children who were outside the criteria of acceptance for the ongoing resourcing scheme (ORRS). He then found that these students changed school often and because the funding did not follow them they could be denied funding in a new school environment. The data also linked transience to low decile schools. He also found that teachers required more release time to develop the curriculum, to communicate with others and for PD opportunities.

A year later in 2000, Brown and Wills considered that the New Zealand market model of education where schools compete for students detracts from schools ability to deliver appropriate services to students with special needs.

\subsection{The Wylie Report and SENCos}

In 2000 and Minister of Education commissioned a review of special education policy from Cathie Wylie at the New Zealand Council of Education Research. This report highlighted fragmented service provision but said that the SE2000 policy was sound in principle. It showed; school students on the margin between moderate and high needs (see Figure 1), faced issues and problems associated with staffing special education units and problems with the allocation of the Special Education grant. It went on to recommend; SENCo positions in all schools, providing ongoing support and PD to schools, keeping resources up-to-date, and networking with other special education professionals and organisations. 
Wylie (2000) recommended that the SENCo, “could work with school staff, Resource Teachers: learning and behaviour, and district centre staff to identify individual students needs, plan programmes, arrange support, PD and resource materials to support other teachers at the school in their work with special needs” (p.88). Although not directly created, the SENCo position was seen as an integral part of the schools special-needs system and responsible for overseeing and reporting on; resources, personnel, programmes and equipment provided to students within special education.

The position and title of SENCo is taken from the British education system. Although many British schools have had SENCos for quite some time, in 1993 the SENCo role became official and the role was explained in the Code of Practice, within the United Kingdom. The code of practice placed a statutory obligation on schools to have a special teacher to coordinate special educational needs (Layton, 2005). The British Teacher Training Agency published the National Standards for Special Educational Needs Coordinators in 1988. The 2001 Code of Practice was developed alongside the SEN toolkit which gave practice advice (Crowne, 2003).

SE 2000 (Special Education 2000), Education Guidelines for Implementing Special Education 2000 define special education as “...the provision of extra assistance, adapted programmes or learning environments, specialised equipment or materials to support young children in school students with this accessing the curriculum in a range of settings” (p.24). This provided special education funding to schools in the form of the Special Education Grant (SEG). All schools receive SEG as part of their operations funding towards funding special education programmes. The SEG is given to all state schools to help them support students with moderate to high levels of learning and/or behaviour difficulties. It is allocated on the basis of a school's decile rating and roll number. It may be spent on PD, staffing, resources and materials to support those students with special education needs who do not receive assistance through any other special education initiative. Therefore schools, parents and communities were left to determine how to spend this money in order to meet the special education needs of their students. While the role of RTLB was specifically created, the SENCo role was not. 
Without direct guidance from the Ministry of Education (and prior to the project) a few schools within the region of the study created SENCo positions as proposed by the Wiley report in order to oversee the special education needs within the school. This has lead to the situation (prior to the intervention) where there was a wide variance in the service that was offered between schools even in the same region. (RTLB D, personal communication, May 12, 2009).

The SENCo position within New Zealand is a difficult one in that SENCos take responsibility for special education needs within an inclusive framework while having little or no control over funding and having to deal with administration and legislation (Cole, 2005). In New Zealand this is compounded by the lack of any clear guidance or conformity in the role.

Liberty (2009) found that trainee teachers in New Zealand were not trained to work with diverse students and that this provided a barrier to inclusion. She felt that teachers had, themselves, learned helplessness. She also noted that there was a widespread belief that instructional strategies for children with special education needs was different and requires special teaching methods which only a few knew how to implement.

The Organisation for Economic Cooperation and Development (OCED, 2003) state that:

Meeting the educational needs of students is part of the development of equitable provision in an inclusive society where individual rights are recognised and protected. Failure to provide education and create the conditions for individual progress may be seen as a denial of a child's rights (p.8).

The role of the SENCo in British schools is the responsibility for the day-to-day implementation of legislation supporting children identified as having special educational needs within mainstream schools (Cole, 2005). However Cole (2002) and Cole and Johnson (2004) demonstrate that the culture of the school and values of senior management impact on the SENCo role, and power to effect inclusive practices within a school. 
A research project in 2005 found that British SENCos felt that the key people and agencies need to see them in a leadership role rather than just as Special Education Needs (SEN) managers (Layton, 2005). “The challenge...is to explore how SENCos might be newly valued and empowered in this pivotal role so that we can effect sustainable transformations in education systems that operate for the benefit of all learners” (Layton, 2005, p. 138). The need to keep records within special education is not a new idea however deciding where to start and what data to keep and who to keep it on are complex questions. Although the schools involved in this study were diverse there is an overall need for systems that identify, record and monitor student achievement within special education. These systems may look very different between schools however these underlying requirements are very similar. Hutchison (2001) described registers as, “... as a list of individuals with chosen characteristics in common. It is a record kept for a period of time and systematically updated” (p.253). While this is a good start it is also necessary to not only use the register to record information but also as a means to oversee planning and goals. It becomes apparent that it is important to have an objective for the register. These are often improving the care for individuals and improving the planning of services or interventions (Colver \& Robinson, 1989).

The Department for Education and Skills (DfES), 2003 said, "We want schools to see the SENCo as a key member of the senior leadership team, able to influence the development of policies for whole school improvement.” (p. 2).

Kearney and Poskitt (2001) found that there was a need for ongoing special education and PD within schools. It is hard to differentiate between collaboration and PD in practice. Whilst traditionally learning was seen its acquisition of knowledge, that has now changed to a more modern approach of participation within an inclusive environment.

Thus, successfully inclusive schools have teachers and other staff members who work together collaboratively (Guzmán,1997). Each professional brings their particular perspective to the programme. Teachers are experts on the curriculum, SENCos are specialists in the unique learning and behaviour requirements of students who have special learning needs and RTLB 
bring additional resources and expertise to support inclusive practices. This is a team effort and no one professional can carry it off alone successfully.

There are two distinct definitions to the term collaborate. In the first collaborating is working jointly with others. In the second it involves working with an enemy force that is occupying one's country. Both of these definitions seem to fit well when working collaboratively in special education within schools. Beattie, Jordan \& Algozzine (2006) indentify the goal of collaboration in schools as having teachers work together in an effort to meet the needs of all students in the general education classroom, and Gable, Korinek \& McLaughlin (1997) showed that teachers use collaboration as a tool that facilitates effective inclusive programmes. However sometimes classroom teachers can see collaboration as a threat to their territory, the classroom. Auckland Uniservices inferred the following indicators of effectiveness from the 21 Pilot study schools:

Effective practice requires collaborative planning between those teachers, specialists and family members important in the life of the student. Collaboration is an important tool and support.

Effective assessment involves knowledge of strategies involving families and working within a team.

Adapted curriculum and adapted teaching strategies need to align with student need for outcomes to be effective and successful.

School settings need to promote policies and structures that are flexible in accommodating difference (Education Counts, nd).

Release time for SENCos is necessary. This is time when they can carry out coordination, management and leadership duties. It should not be part of their allocated planning, preparation and assessment teacher release time. The English data shows that many SENCos, particularly those working in primary schools struggle to have access to adequate non-contact time to carry out their essential duties. The British National Union of Teachers (NUT, n.d) states that: 
Teachers with leadership and management responsibilities should be awarded additional time for (PPA), equivalent to $10 \%$ of their timetabled teaching time remaining after deduction of leadership and management time.

To illustrate what this might mean for a SENCO, the following example is also presented in their pamphlet:

A SENCO currently has one afternoon a week to undertake specific SENCO duties. This leaves 20 hours' timetabled teaching; the SENCO is, therefore, entitled to two hours for planning, preparation and assessment purposes. The SENCos total hours spent on teaching per week would then be reduced to 18 hours (National Union of Teachers, n.d).

\subsection{The SENCo and communities of practice}

Crowne (2003) states that; “... one of the SENCos key roles is getting to know and working with various support services and agencies that are available locally.” and another key role as, “...leading other staff and ensuring that continuing PD opportunities are appropriate and regard the various aspects of SEN, including working in partnership with those beyond the school (p. $55 / 56)$.

The formalized idea of a community of practice is a relatively new concept, and possibly even more so within education where often sections and sectors are competitive rather than collaborative. Although these types of groups often develop within schools the cross school clustering is a somewhat new idea. It is therefore important to clearly identify what is meant by a community of practice in this context and the dynamics within a community of practice as set up by this project. Wenger (1998) found that a community of practice is a group that works together through a shared commitment in a common endeavour. The negotiation of individual identities within communities of practice, are central to Wenger's thinking about communities of practice. He argued that an individual's identity is fluid. It is shaped and transformed throughout their lives. Community members are continuously negotiating their identity and moving from the periphery towards the heart of the community. 
Within any community there is a changing ebb and flow of those at the heart and on the periphery, it is a two way interaction between the group shaping the knowledge of the individual and the individual shaping the knowledge of the group. Wenger et al. (2002) describes communities of practice as providing; informality, diversity and shared knowledge where geographically dispersed members can reconnect through mutual engagement, joint enterprise and repertoires. They state that a community of practice is a group of people “... who share a concern or a passion for something they do and learn how to do it better as they interact regularly” (p. 75). These communities build a shared commitment through the process of interacting and learning together.

Lave and Wenger (1998) found that within any community of practice there are both ends of the spectrum. At one end you have fully active participants who fashion the identity within the community and at the other extreme are the novices within the practice of community. The novice's legitimately exist on the boundaries of the community. They are engaged in the learning of the community and draw from the community indicators of identity and meaning of the role with the shared practice. These positions are not fixed and everyone within the group is in a state of flux. The path taken to change people's participation is the learning path of the individual within the wider community. This view of learning through a community of practice as a twoway interaction in which the group both shapes the knowledge of the individual as well as the individual having a role in shaping the knowledge of the group. The expert and the novice are both moved and changed through participating in the community.

Billett (1998) discusses how novices are not short of capability but they lack the knowledge which is accessible from experience within any discrete field of knowledge. An 'expert' on the other hand demonstrates capability in the field of knowledge. In this way a community of practice can be viewed as a bridge between working and innovating as both the community and its practise changes. As participants become experts in the community they develop knowledge and ability in the practice of the field. However they also change their own identity both inside and outside of the group. This leads them to find opportunities to develop along the new lines of their learning and changing beliefs and practices. Campbell (2010) shows how the newcomers to 
a community are connected to their identity within the group and what they bring with them. Learning is a process where we grow and change and become a decoupage of experience and knowledge.

Fuller et al. (2005) found that communities of practice are established to build capacity in “developing the collective ability - dispositions, skills, knowledge, motivation and resources - to act together to bring about positive change”(p.4). While Timperley, Wilson, Barrar \& Fung (2007) found that "Participants are supported and challenged to think through new ideas and there implications for their current theories, knowledge and practices” (p.11).

Spillane (2002) identifies that communities of practice provide an essential part of intelligent activity where mutual understanding drive practice. Ki Te Aoturoa (2008) talked of improvement through inquiry of practice and the therefore student outcomes.

Communities of practice have a life cycle. Typically the formation stage is where a common commitment is clear and the value of the group drives it and the transformation stage where the community may expand or fade. These groups are specific in that they have a diverse membership and are about shared practice and are not task orientated.

In 2001 New Zealand Disability Strategy (Ministry of Social Development, 2003) stated that it will be successful when disabled people can say that they live in, "a society that highly values our lives and continually enhances our full participation” (p.3). Objective three of the strategy concerns education for those with disabilities. It states that; every child with a disability can go to their local school, teachers and educators need to understand the learning needs of disabled people and schools must meet the needs of disabled students.

In 2002, the then named Specialist Education Services (SES) was integrated into the Ministry of Education. Since then all divisions of the Ministry of Education became responsible for implementation activities relating to the Disability Strategy (Ministry of Social Development, 2003). Funding to support learning for children and young people with special education needs increased by 33\% between 2002 and 2007. 
This leaves New Zealand schools in the unenviable situation of having to cater for special educational needs in an inclusive environment without the Ministry of Education endorsing or financially supporting an in-school role dedicated to working with and for special education needs. The use of discretionary management units in schools to address this issue has fuelled inequalities between schools.

As seen in Figure 2, RTLB provide itinerant specialist support to schools, to advance the educational outcomes for year 0-10 students with moderate learning or behaviour difficulties. Refer to the diagram below. The position of Resource Teacher of Learning and Behaviour (RTLB) within New Zealand education was created in 1999, under SE2000.

Figure 2 shows the support available to students with special needs within New Zealand. As can bee seen the RTLB service bridges the gap between school support and GSE support.

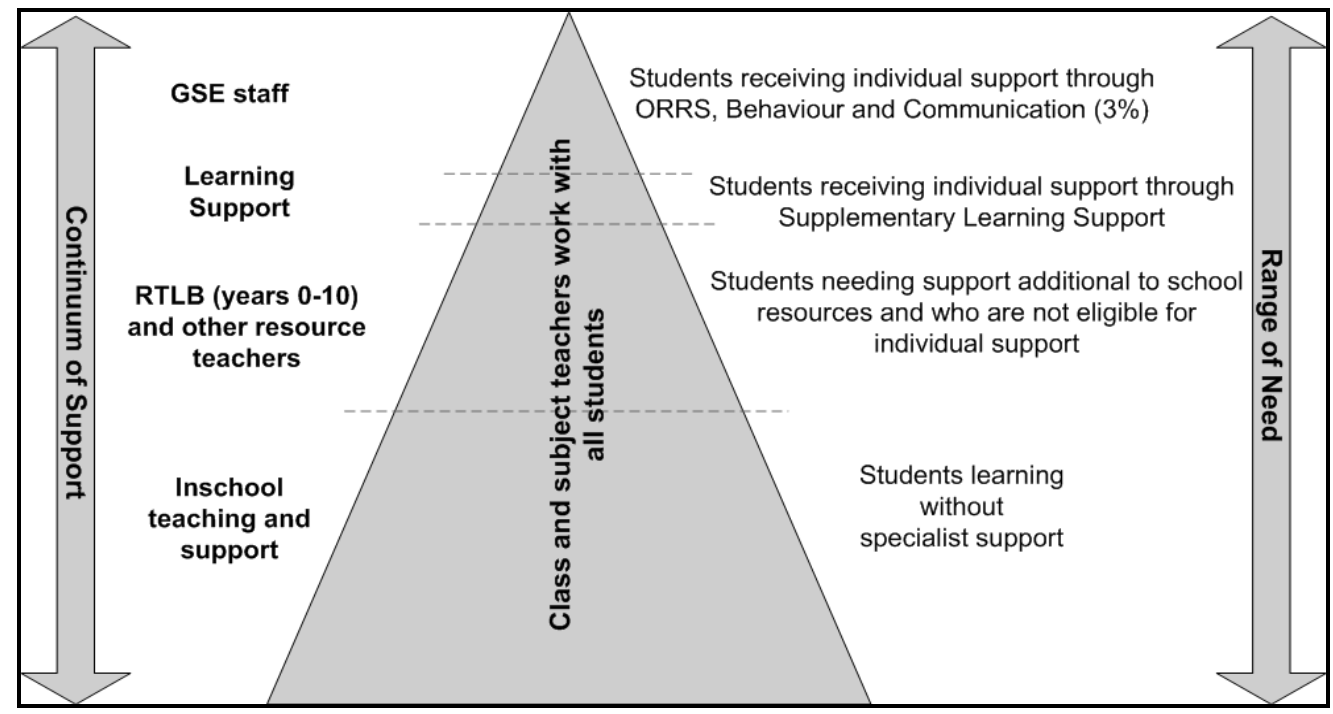

Figure 2. The support available to students with special needs within New Zealand. MOE, RTLB Policy and Toolbox, p.5.

Glynn (1998) explains the RTLB role as being an advocate for students with special needs through collaboration and consultation with teaching colleagues as well as supporting colleagues to modify the curriculum, teaching practices and school systems in order to meet the needs of 
students with learning and behaviour difficulties (Brown, Thomson, Anderson, Moore, Walker, Glynn, Macfarlane, Medcalf \& Ysseldyke,' 2000) he RTLB Policy and Toolbox (Ministry of Education, 2007 states that

The intent of Special Education Policy is that all students who require specialist services and teacher support receive them. Support and resources are prioritised to those students with the highest needs. RTLB have a pivotal role to play in assisting cluster schools to meet the needs of their students with moderate learning or behaviour difficulties” (p.9).

RTLB work in clusters of school within a designated area. The RTLB Policy and Toolbox, (MOE, 2008) states that;

Effective RTLB support is likely to provide a school with systems and practices that: maintain an educational focus in inclusive classroom environments adapt the curriculum to meet the needs of diverse learners achieve positive, measurable outcomes for all students, including those with learning and behaviour difficulties (p.10).

RTLB set goals in the domains of; participation, social/behavioural, learning achievement, and teacher/school capabilities. Examples of teacher/school capability goals are; increased teacher knowledge/skills relating to diverse learners and enhanced teacher effectiveness. These promote school systems that support improved outcomes for students with learning or behaviour difficulties.

A three-year action research programme labelled, Enhancing Effective Practice in Special Education (Ministry of Education, 2004). focused on developing teacher knowledge and identifying effective teaching practice for students with special education needs. It involved 24 schools, and although the project was not long enough to examine the impact of reflective practice on student outcomes, it demonstrated the power of professional collaboration. 
In 2006, the Minister of Education released for consultation a draft curriculum for New Zealand schools, which became the New Curriculum in 2007 which became effective in schools from 2010. A key concept was personalised learning, with the idea that, “... all students can reach their potential and strive for excellence, but not necessarily on the same day, at the same time, or in the same way" (Maharey, 2006, p.16). The goal of schooling is for all students to achieve their potential. To achieve this goal, schools must ensure that: all students are taught effectively and that teaching practice benefits from assessment for learning and evidence of student outcomes. Schools aim to improve social and academic outcomes for all students and encourage families and whanau to nurture children's learning.

As I write this we are currently poised for further change in education with the National Governments new National Standards being unrolled during 2010 and 2011 and the 2010 Special Education Review. National Standards are being introduced against a backdrop of unprecedented dissent from; teachers, principals and national educationalists. No doubt these will also lead to further considerations and changes within Special Education.

\section{$2.8 \quad$ Summary}

New Zealand's education system stems from the European style of industrial revolution based mass education. It historically either ignored students with special education needs or placed them into special settings. The international human rights movement was a major factor in normalisation which spilled into education and led to the mainstreaming movement. Special education and the Tomorrow Schools policy provided the next step toward inclusive practices. However, the tools to implement shifts in paradigm are found through; professional development, communities of practice, collaborative-consultative approaches, teacher/school change and the management and facilitation of the transfer of learning.

The research clearly indicates that further investigation is needed to understand the role of the SENCo within New Zealand schools. Is there a place for SENCos in our post Special Education 2000 schools? Does release time, PD, professional support and role development affect the 
SENCo role and does a SENCo service impact on the service provided to students with special educational needs? 


\section{Chapter 3: Methodology}

\subsection{Introduction}

This project was a mixed method approach with an interpretive/constructivist emphasis. This method of research is essentially concerned with meaning and it seeks to understand participants own perceptions within situations (Schwandt, 1994). It was conducted in order to investigate a systems level intervention initiated by a RTLB cluster to establish a region wide SENCo service in schools. All of the SENCos within the designated local area participated in the study and two family groups from one school provided data.

The independent variable measured by this study was the RTLB project. An independent variable is a factor that is manipulated in an experiment. The experimenter controls whether or not subjects are exposed to the independent variable. The dependent variable is measured to determine if the manipulation of the independent variable has had any effect. The dependant variables measured by this study consisted of the development of the collaborative, regional SENCO service, release time, PD, professional support and role development and the education service provided to students with special educational needs.

The research question asked, "What are the effects of an RTLB led initiative to create and support the development of SENCo positions in schools within a region of New Zealand?” The methods will be further discussed alongside data collection under the sub questions which seek to answer this main question. 


\subsection{Research Design}

The methodology for this study is quasi-experimental and it is founded within a pragmatic world view, reliant on a parallel mixed method approach. This study involved pre-intervention, intervention and post-intervention data in an ABA design. A mixed methods design is a procedure for collecting and analyzing both qualitative and quantitative within a single study.

The value of a mixed method approach for this project lies in the complex educational context of the study. Therefore by using a mixture of research strategies the dimensions and scope of the study can be expanded, hence getting a fuller picture of what is happening and allowing the best foundation to guide design, data collection and analysis (Morse, 2002).

While mixed methods mean that both qualitative and quantitative data has been gathered and analysed, the parallel relates to the way quantitative and qualitative data are collected at the same time, concurrently. Also by its very nature a pragmatic philosophy uses the tools that best suit, irrespective of their philosophical basis. From this paradigm a researcher uses whatever methods will answer the questions, and because of this, mixed methods is not unusual within social sciences and education.

As stated above quasi-experimental designs are often used in the evaluation of educational programmes when random assignment of the participants is not possible. The fundamental aim of an experimental design is to test the impact of an intervention on an outcome, controlling for all other factors that might influence the outcome (Trochim, 2006). Of course educational settings do not easily lend themselves to such strict boundaries and quasi-experimental designs have been 
developed to allow for studies where there can be no random assignment. They provide a design framework for researchers investigating realistic everyday settings, while recognising the lack of researcher control that this can involve. Usually quasi-experimental designs have an intervention group and a comparison group. However for this study the entire population was already part of the intervention group and the researcher had no control over the independent variable (the RTLB project). This falls into the sub category of 'natural experiments' when the researcher has to exploit naturally occurring conditions rather than investigating a programme that they have set up themselves (Coolican, 1999).

Mixed methods research is an approach to enquiry that combines or associates both qualitative and quantitative forms. It is more than simply collecting and analysing both kinds of data; it also involves the use of both approaches so that the overall strength of the study is greater than either qualitative or quantitative research can be alone (Cresswell, 2009). It has also been known as 'multi-trait / multi-method' research (Campbell \& Fiske, 1959) and 'quantitative \& qualitative' methods (Fielding \& Fielding, 1986b). It is based on the assertion that a combination of qualitative and quantitative methods gives better insight than either approach could give alone. By means of using this mixed-methods approach, the researcher was able to obtain the advantages of both quantitative and qualitative approaches and overcome their limitations. It is believed that in this case a mixture of qualitative and quantitative methods of inquiry would form a solid basis to guide design, data collection and analysis. A mixed method approach allows the dimensions to be extended along with the scope of the study and therefore gives a full picture of what happened. 


\subsection{Participants}

The sampling procedure used for the study was convenience sampling. The participants were restricted to those SENCos and principals within the EPF proposal region. For the parent interviews the SENCo at the participating school asked the families on her special needs roll if they would be prepared to be part of the study. Two families indicated to the SENCo that they were happy to participate and their contact details were passed on to the researcher. Participants of this research study included 18 SENCos, 18 principals and two families from within a single school.

In this study the sample was the entire population of nineteen schools within the region. There were three high schools, one intermediate, 11 full primary schools and four primary schools. There was one SENCo from each school involved in the project (although one high school abstained from the study). The schools ranged from decile one to decile six and included urban and rural schools. At the beginning of the project only one SENCo was male. Two SENCos had been teaching for less than 10 years and seventeen had been teaching more than 20 years. Three worked in secondary schools, one worked in an intermediate school, twelve worked in full primary schools and three worked in primary schools.

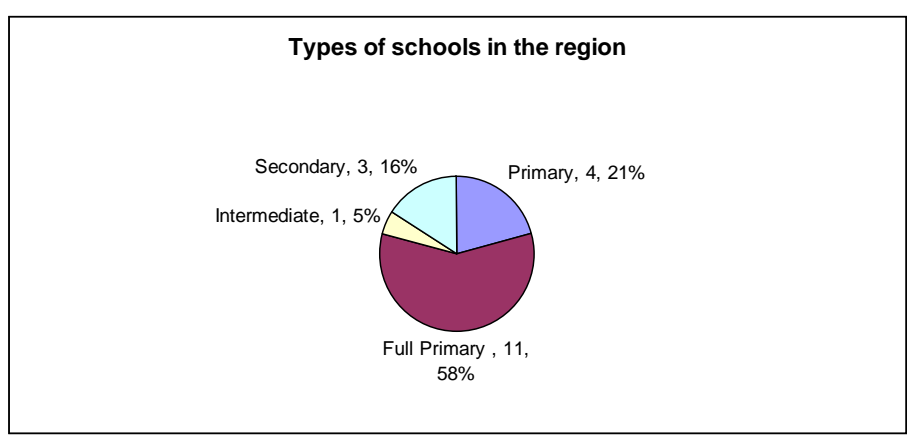

Figure 3. Types of schools in the region 
94.7\% of the SENCos were female and although there were staff changes throughout the project this statistic remained unchanged.

There were $63 \%$ of the SENCos who had over twenty years teaching experience, 32\% with between ten and twenty years experience and 5\% with less than ten years experience.

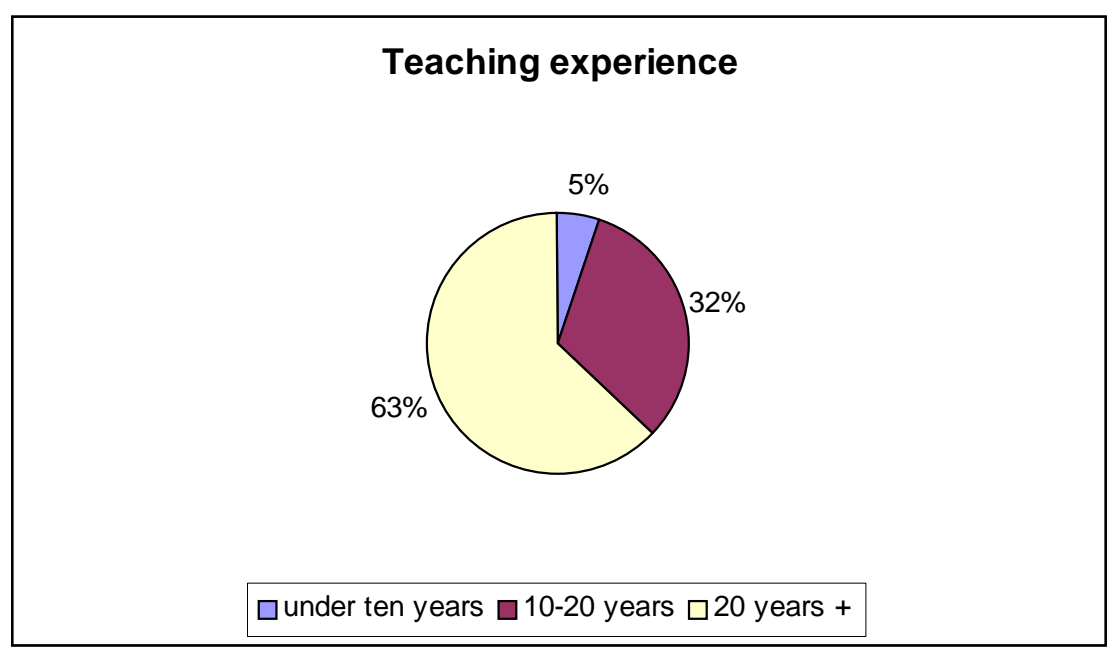

Figure 4. Teaching experience of the SENCos

\subsection{Setting}

This study took place within an RTLB cluster region of New Zealand, for which the EPF application was made.

The region used for this study is a low socio-economic area. Figure 3 shows that at the commencement of the study all of the schools in the region fell below decile seven, with three decile one schools and fifteen out of nineteen schools being below decile five. 


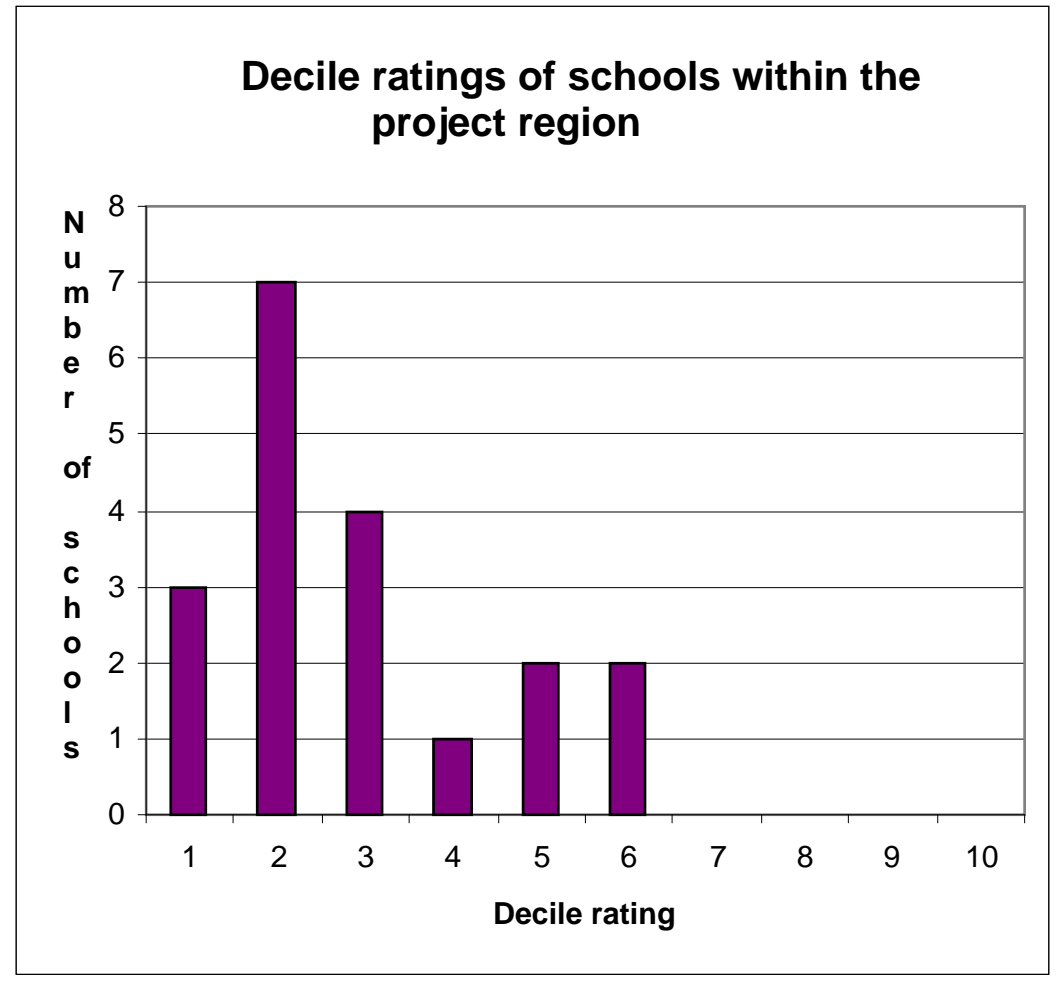

Figure 5. Decile ratings in the schools

The region has sixteen primary schools and three colleges. Before the project only two primary schools had an identified SENCO while all three colleges had a Head of Learning Support (HOD). One primary school had removed the SENCO position two years previously.

Figure 4 and 5 show that within the region 15\% more students over the age of fifteen have no qualification than for that of the national average. The income levels in the area are well below the national average. 


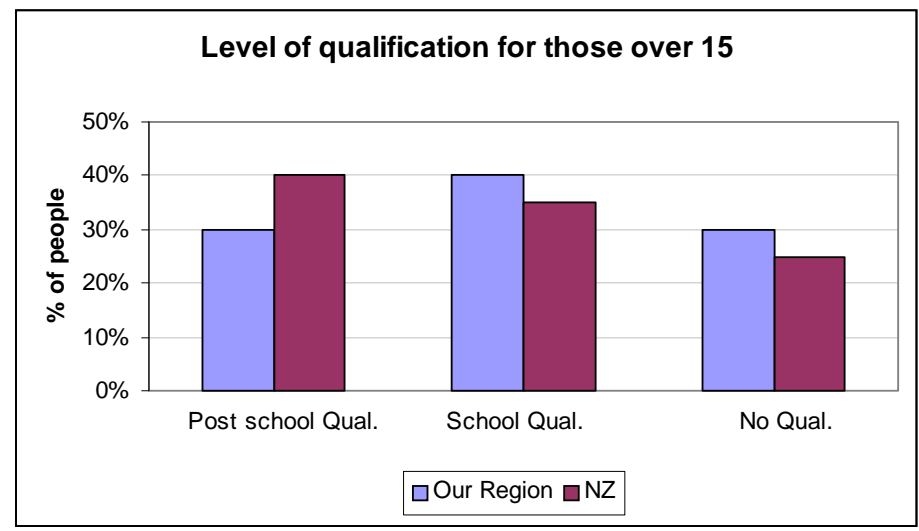

Figure 6. Level of education for those over 15 in the area

As seen in Figure 4 and 5, the income levels in the area are well below the national average.

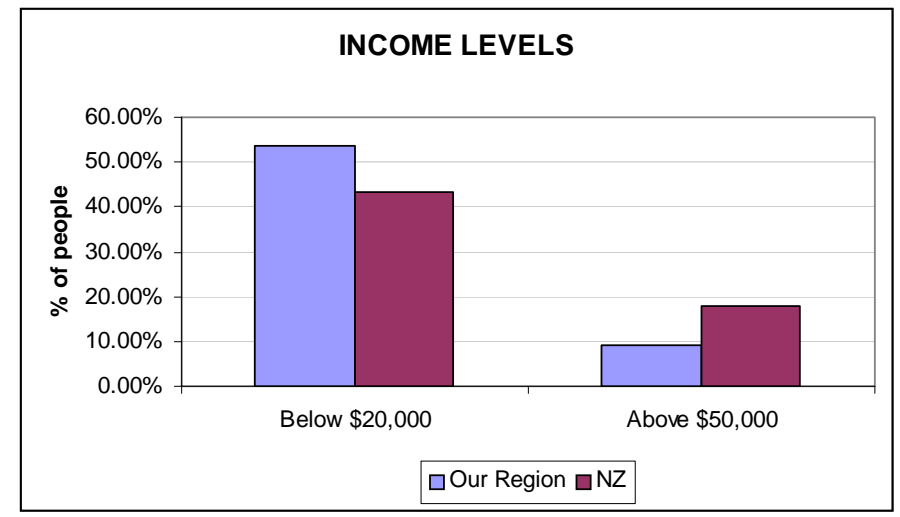

Figure 7. Income levels, both nationally and in the area

\subsection{The project}

There were 8 PD days held in the 2 years of the RTLB initiative. Each day lasted from 9am until 3pm. There was an introductory day, the main aim being to allow the SENCos a chance to meet each other in a non-threatening environment and hence this could set the tone for the programme. The 2nd day was concerned with policy and procedure and the 3rd day was based around information relating to the social work agencies available in the region. Day 3provided details about the effective use of teacher aides and curriculum adaptation and day 5 was centred around 
the different support available to schools through Group Special Education. Day six was on skills for effective facilitation. Day seven involved workshop sessions run by RTLB, SENCos and outside providers looking again at some of the core activities of SENCos such as: procedures, individual education programme's (IEP’s), registers, and measurable goal setting. (See Appendix D for further details on the PD days).

\subsection{Data Collection}

The researcher used pre and post-interview questionnaires which were designed to provide both quantitative and qualitative data simultaneously from the SENCos and parents.

The pre and post data collection interviews for the study involved interviewing the SENCos from each of the 19 schools within the region. The information obtained came directly from those interviewed rather than allowing time to discuss the questions with others or review school documents. The interview consisted of 15 questions (for a complete schedule please refer to Appendix C).

\section{The SENCo questions related to:}

Q 1,2 release time,

Q 3 other roles in the school,

Q 4,5,6,7 identifying and recording student data,

Q 8 the special needs committee,

Q 9 PD,

Q 10, 11 role definition,

Q 12, 13 role development, 
Q $14 \quad$ outside agencies

Q 15 communities of service.

The researcher also used pre and post data collection interviews which provided both quantitative and qualitative data from the two sets of parents. The interview consisted of 8 questions (for a complete schedule please refer to Appendix C).

\section{The parent questions related to:}

Q1 number of schools the child attended;.

Q 2,3,4the special needs register;

Q 5,6 the practise of the SENCo;

Q 7,8 the way in which the school had met the needs of the child.

\section{$\underline{3.7 \quad \text { Data Analysis }}$}

\section{Quantitative Data analysis}

Responses to the interview questionnaires were recorded, exported in an excel spreadsheet, and transferred to the statistical software package, the Statistical Package for Social Science Software (SPSS), for in-depth analysis. Descriptive statistics were calculated and data relationships were analyzed.

The quantitative data collection methods centred on the quantification of relationships between variables, in this way the instruments allow data to be gathered in order to establish if there is a 
relationship between measured variables. Quantitative data is viewed as being objective, quantifiable, generalizable and based on numbers. A quantitative approach is useful as it helps the researcher to prevent bias in gathering and presenting data. It is based on the assumption that social reality has an objective ontological structure (Morgan \& Smircich, 1980). Quantitative research involves counting and measuring events and using statistical analysis (Smith, 1988). The belief is that there an objective truth existing in the world that can be measured and explained scientifically.

Two methods of quantitative data analysis were used in this study. The results were analysed using descriptive and inferential statistics. Descriptive statistics summarise patterns in the responses of people in the sample. Inferential statistics provide an idea about whether the patterns from any sample are likely to apply in the population from which the sample was drawn. Statistical analysis using the Statistical Packages for the Social Science’s (SPSS) software was then conducted on these to identify the range mean and standard deviation for each set of data. An independent samples t test was then conducted to compare the mean scores and to indentify if there was a significant difference between the two groups' mean scores.

Quantitative methods establish very specific research problem and terms which allow for longitudinal measures. This is based upon developing scientific hypotheses, free of researcher bias and proving it empirically (Frankfort-Nachmias \& Nachmias, 1992).

The observations and surveys were coded. The quantitative data that was gathered in this study was; SENCo, RTLB, and parent interview questionnaires, SENCo behavioural observations, 
SENCo, RTLB, principal and parents comments, feedback sheets, and SENCo self ratings forms. See figure 8 below.

\begin{tabular}{|l|l|}
\hline $\begin{array}{l}\text { QUALITATIVE DATA } \\
\text { QUESTIONS }\end{array}$ & $\begin{array}{l}\text { QUANTITATIVE DATA } \\
\text { QUESTIONS }\end{array}$ \\
\hline communities of service & $\begin{array}{l}\text { number of schools the child } \\
\text { attended }\end{array}$ \\
\hline role development & the special needs register \\
\hline outside agencies & the practise of the SENCo \\
\hline $\begin{array}{l}\text { number of schools the child } \\
\text { attended }\end{array}$ & $\begin{array}{l}\text { the way in which the school } \\
\text { had met the needs of the } \\
\text { child }\end{array}$ \\
\hline $\begin{array}{l}\text { the special needs register } \\
\text { the practise of the SENCo }\end{array}$ & outside agencies \\
\hline $\begin{array}{l}\text { the way in which the school } \\
\text { had met the needs of the } \\
\text { child }\end{array}$ & communities of service \\
\hline role definition & release time \\
\hline the special needs committee & other roles in the school \\
\hline $\begin{array}{l}\text { identifying and recording } \\
\text { student data }\end{array}$ & $\begin{array}{l}\text { identifying and recording } \\
\text { student data }\end{array}$ \\
\hline other roles in the school & the special needs committee \\
\hline release time & PD \\
\hline
\end{tabular}

Figure 8. Qualitative and quantitative data collection

\section{Qualitative Data analysis}

A Qualitative approach differs from quantitative approach in that it generates verbal information rather than numerical values (Polgar \& Thomas, 1995). Qualitative researchers are concerned with accurately describing, decoding, and interpreting the meanings of events occurring within normal social contexts and natural settings rather than through numerical data and statistical analysis (Fryer, 1991). Qualitative research is therefore less likely to use restrictive classification processes on the collection of data and more likely to use flexible data collection methods. It is less concerned with specific hypotheses than with emergent themes and can therefore provide a more holistic view (Cassell \& Symon, 1994). It also allows the researcher to interact with the research subjects. 
In the qualitative analysis, data was analysed using content and thematic techniques (Ryan \& Bernard, 2000). The data was collected, read and analysed using word counting methods, where the frequency of words was collected in order to ascertain the key words and ideas (Dey, 1993). It was also analysed for themes and coded. In this way the implicit and explicit ideas within the data were identified and described. Codes were then developed for these themes and then these were used in the analysis by comparing the frequencies of themes and considering the relationships between themes (Namey, Guest, Thairu \& Johnson, 2007).

Two trends within the data were used to code the results as 'parental knowledge of the schools systems' and 'parental perceptions'.

\subsection{Validity and Reliability}

Reliability and validity are very important in quantitative research because they decrease the errors which may arise from measurement problems. Reliability refers to the precision of a measurement process and validity refers to how much the study accurately assesses the construct that is being measured (Thorndike, 1997).

\section{Validity}

Validity asks how you really are measuring what you think you are measuring. Reliability refers to how consistent that measurement is. Correlation coefficients are often used to evaluate validity and reliability (Farmer \& Rojewski , 2001). Validity has two parts: internal validity relates to whether the effects would have occurred irrespective of the intervention, and external 
validity which refers to whether an effect can be generalised to other populations than those in the study.

This data by its very nature has low external validity, meaning that is does not generalize well to the population outside of this study, however it does have higher internal validity in that it measures more effectively the effect of the intervention and therefore shows that the project was more likely to have caused the changes than for them to have happened without it.

The main threat to the internal validity of this quasi-experimental study was whether extraneous events affected the measured changes in the dependent variable. Another consideration must be statistical regression, the participants all came from high performing groups but they comprised the entire sample. Some participants also left during the study and this will have affected the results.

Quasi-experimental designs may have weaknesses in controlling for threats to internal validity, but they can be quite strong in controlling for threats to external validity since the research takes place in a natural setting and therefore may have wide applicability to other similar settings.

External validity deals with knowing whether the results are generalizable beyond the immediate case. However, that criticism is directed at the statistical and not the analytical generalization that is the basis of case studies. This study is not offered as a case to generalize to the general population but rather as a snap shot of what is happening in one situation. 
Construct validity refers to the kind of confidence there is in the research constructs in relation to the real tangible concept investigated. It has been a source of criticism because of potential investigator subjectivity (Yin, 1994). For this research the risks have been minimised by using multiple sources of evidence, establishing a chain of evidence, and having draft questions reviewed by those involved. It can also be improved by using pattern-matching to show patterns between the construct and the concept and by precisely specifying the theory of the constructs.

In order to enhance validity, triangulation of data was used. Validity has also been increased in this study because the entire population was studied across deciles, genders, location, size of school and age ranges. The observations were collected under natural, non-manipulated settings. The observation of the participants occurred in the PD setting. The researcher was a nonparticipant observer and sat at a distance from the participants to avoid any interference. The data collection process occurred over a 2 year time period with 1 PD day each term during this time. The interviews were conducted at the school sites and the procedure did not disrupt the participant's normal daily activities. Validity has also been increased in this study because the entire population was studied; across deciles, genders, location, size of school and age ranges. (Miles \& Huberman,1994).

\section{Reliability}

Reliability is about consistency. It refers to the extent that a measure, would deliver the exact same results no matter how many times it is was applied to random members of the same target group. Reliability and validity are affected in part by the research design. Quantitative methods tend to have high internal validity and low external validity coupled with high reliability. 
Qualitative methods tend to have low internal validity, high external validity and low reliability. Reliability and validity are also affected by the instruments used in data collection.

Reliability was addressed in this study by triangulation of data to see if the same information that was obtained from the interviews also came through in the observations and discussion during the professional development days. This data shows higher reliability demonstrating that it is consistently measuring what it set out to measure.

Ideally the interviews could have been conducted more frequently to measure the smaller changes over time, however with the high workloads of the participants it was not possible to organize.

\section{Trustworthiness}

There are two main epistemologies which underpin data analysis. Realism is the view that the world has an existence independent of the observer whereas idealism believes the external world is itself a representation or concept and the result of human cognition. With reference to this, qualitative methods have different criteria for judging trustworthiness.

Trustworthiness aims to show that the findings are "worth paying attention to" (Lincoln \& Guba, 1985, p.290). There are four aspects of trustworthiness: credibility, transferability, dependability, and conformability.

In qualitative research the researcher seeks to establish if the finding give a credible interpretation of the data (Eisner, 1991 \& Lincoln \& Guba, 1985) through verification rather than traditional reliability and validity. Four methods were used in this study to determine credibility: 1) 
triangulation - gathering data in different forms (interviews, observation, documents), 2) member checking, obtaining feedback from the participants on what was observed and interpreted, 3) thorough description and 4) outside review, getting the RTLB to review the themes and report back.

Transferability considers whether the findings apply or transfer beyond this study. The qualitative viewpoint sees transferability as the responsibility of the person generalizing the data.

Transferability was enhanced in this study by describing the research context and the assumptions that were central to the research. Therefore anyone who wishes to "transfer" the results to a new situation is responsible for this decision.

Dependability is an assessment of the quality of the integrated processes of data collection, data analysis, and theory generation. Therefore the researcher needed to account for the changing context of the research by relating the changes that occur in the setting and how these changes affected the way the researcher approached the study.

Conformability is a measure of how well the inquiry's findings are supported by the data collected. (Lincoln \& Guba, 1985). The researcher has tried to document the procedures for checking and rechecking the data throughout this study to help establish conformability as well as examining the data collection and analysis procedures after the study was completed to evaluate any possible bias or misrepresentation.

\subsection{Ethical Considerations}

Ethics is a significant part of any research process, and this is even more important when working with human participants. Ethical considerations exist to decrease the likelihood of harm being 
experienced by anyone involved in the research process. Therefore a full application was made to Victoria University's Human Ethics Committee in relation to this research and the Human Ethics Policy was adhered to at all times (Victoria University, n.d). Oliver (2003) states that the main considerations in research involving people are: to treat them with respect, make sure that no harm occurs (physically and emotionally) and that they should be fully informed about what is happening.

The research did not use language or words that were biased against persons because of gender, sexual orientation, racial or ethnic group, disability or age.

Informed consent is one of the most imperative values in research ethics. Victoria University code of ethics (Victoria University. n.d.) states that, "Participation of a human subject in any research project, course work project, or teaching activity or laboratory class must be voluntary and obtained through informed consent. Subjects or human tissue must be reviewed by, and receive the approval of, the HEC prior to initiation.” (p. 2).

Full information was given to all of the participants in the form of written information sheets. These adhered to the guidelines as detailed by Victoria University's human ethics committee. As well as this clear contact details were provided to participants in case they wished to clarify or discuss anything about the research with the researcher or supervisor.

Confidentiality and anonymity are the foundations of research ethics. For the purposes of this research, the term anonymity is used to mean that any data gathered during the process of the 
research would not be linked with names, or with any other factors that would identify the research participants. In order to guarantee the anonymity of the participants in the study a number of safety measures were used. Information that was gathered was stored in a locked cabinet within a locked office and identification codes were used. No real names were used on any material as all participants were assigned a number or letter. When describing any background information about participants, care was taken not to give any information that could identify them or others. The names that have been used within this study around the cluster involved are pseudonyms.

For the purpose of this research, confidentiality was used to mean that data that was discussed was not repeated or published in any way. Therefore confidentiality was not offered to research participants within the study.

Ethical approval was gained through Victoria University of Wellington Ethics committee (see Appendix A). Participants were informed of the project and gave written informed consent.

\subsection{Summary}

The methodology of this study was selected in order to support answering the research question "What are the effects of an RTLB led initiative to create and support the development of SENCo positions in schools within a region of New Zealand?”

The use of a mixed-methods design was used to gather a wide and varied range of data that could be analysed to help answer this question. It was also used to help address the issues of reliability, 
validity, and trustworthiness because it broadens the scope of the study, incorporating the strengths of both qualitative and quantitative methods. 


\section{Chapter 4: Findings}

\subsection{Introduction}

This study was concerned with the impact of the creation of a region wide SENCo service. The core research question of this study was; 'What are the effects of an RTLB led initiative to create and support the development of SENCo positions within the schools of a region of New Zealand?'. This section seeks to present the results in relation to the three guiding research questions that seek in turn to inform the core research question.

The first section presents the findings in regard to the first guiding research question: 'How did the initiative impact on the regional SENCo service?'. The second section presents the findings in regard to the second guiding research question; 'How did release time, PD, professional support and role development affect the SENCo role?'. And the third section seeks to present the findings in regard to the remaining third question; 'How did these elements impact on the service provided to students with special educational needs within the region?'.

\subsection{How did the initiative impact on the regional SENCo service?}

In order to identify the impact that the RTLB led SENCo initiative had on the regional SENCo service data were collected from SENCo, principals and the RTLB service on changes: the provision of service available amongst the regional schools, the role status of SENCos in the schools and policy and practice changes. According to this section the changes in the provision of SENCo service available amongst regional schools, role status, policy and practise are identified.

Prior to the project each of the three secondary schools within the region already had a Head of Learning Support, doing (among other things) the SENCo role at the secondary level. This remained constant throughout the project (see Figure 9). Five of the schools in the primary sector also had staff (excluding the principal) within SENCo positions. At the beginning of the project this increased to $100 \%$ of schools having a dedicated SENCo position for this was a pre-requisite of the EPF grant (see Figure 10). 


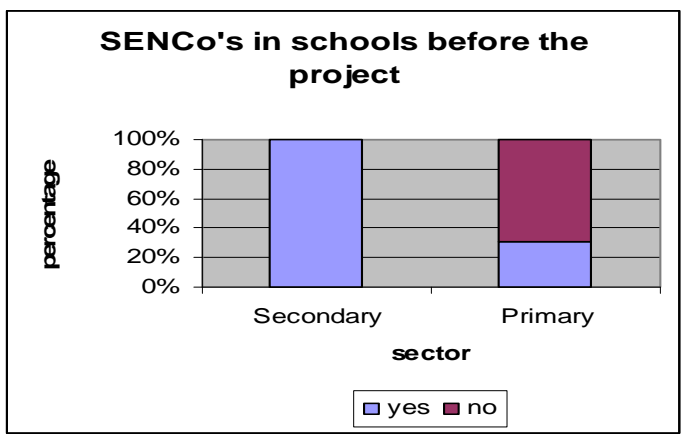

Figure 9. Before the project

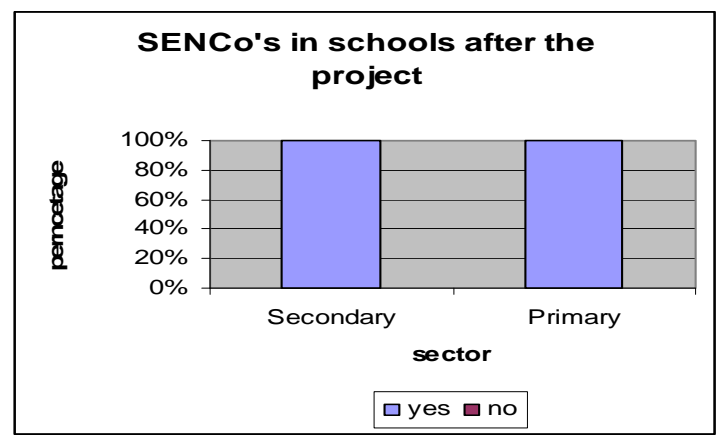

Figure 10. After the project

One RTLB commented that, "having a SENCo in each school now gives a clear contact person for us to work through when needing information around a referral or when students transfer between schools. The project has also meant that we are developing relationships with all of these key people within our schools”. (RTLB A, personal communication, June 1, 2009).

The SENCo positions across the region were developing both networks and special needs committees and therefore a better managed, collaborative special education service was emerging. This led to a change in SENCo role status. This change in the role status of SENCos in schools was an important issue.

The RTLB cluster developed a 'milestone’ report (see Appendix E) which they used as a 'measure of change' half way into the study. The questions were worked through between the SENCo and their principal during the last PD day of the 1st year of the project.

This report showed that out of the 17 schools that completed this report 53\% were now using the special needs committee to give PD to the school staff. A further 59\% of the schools had started giving regular special needs reports to their BOT. $88 \%$ of the schools had developed a job description which was agreed to by the SENCo and principal. 94\% had designated release time each term and $71 \%$ believed they would get the same release time after the project had finished. Also 2\% had discussions around their special needs role in their appraisal process. 
Changes in the policy and practice of SENCos was also an important theme. The RTLB cluster 'milestone' report showed that $94 \%$ of the schools responding had written a special needs policy, and $76 \%$ of these had it signed by the BOT. One hundred percent of the schools were using a standard template for IEP's. One hundred percent of the SENCos and their principals thought that they had had PD that was appropriate to SENCo needs. Eighty two percent of the SENCos were giving guidance and advice around programme planning in their schools. Eighty two percent believed they could support class teachers to use teacher aides effectively. Ninety four percent had a special needs register. Eighty two percent had a special needs committee in place. One hundred percent had students with high needs on IEP's. Seventy six percent of schools had the principal on the special needs committee, with eighty eight percent having the SENCo on, fifty three percent having the DP on and twenty four percent having other representatives on the committee.

For the first time the SENCos were initiating development of their own PD and shaping their practice by clearly indentifying the skill areas they wanted development in, as well as the desired knowledge and experience they decided they needed (see Figure 11).

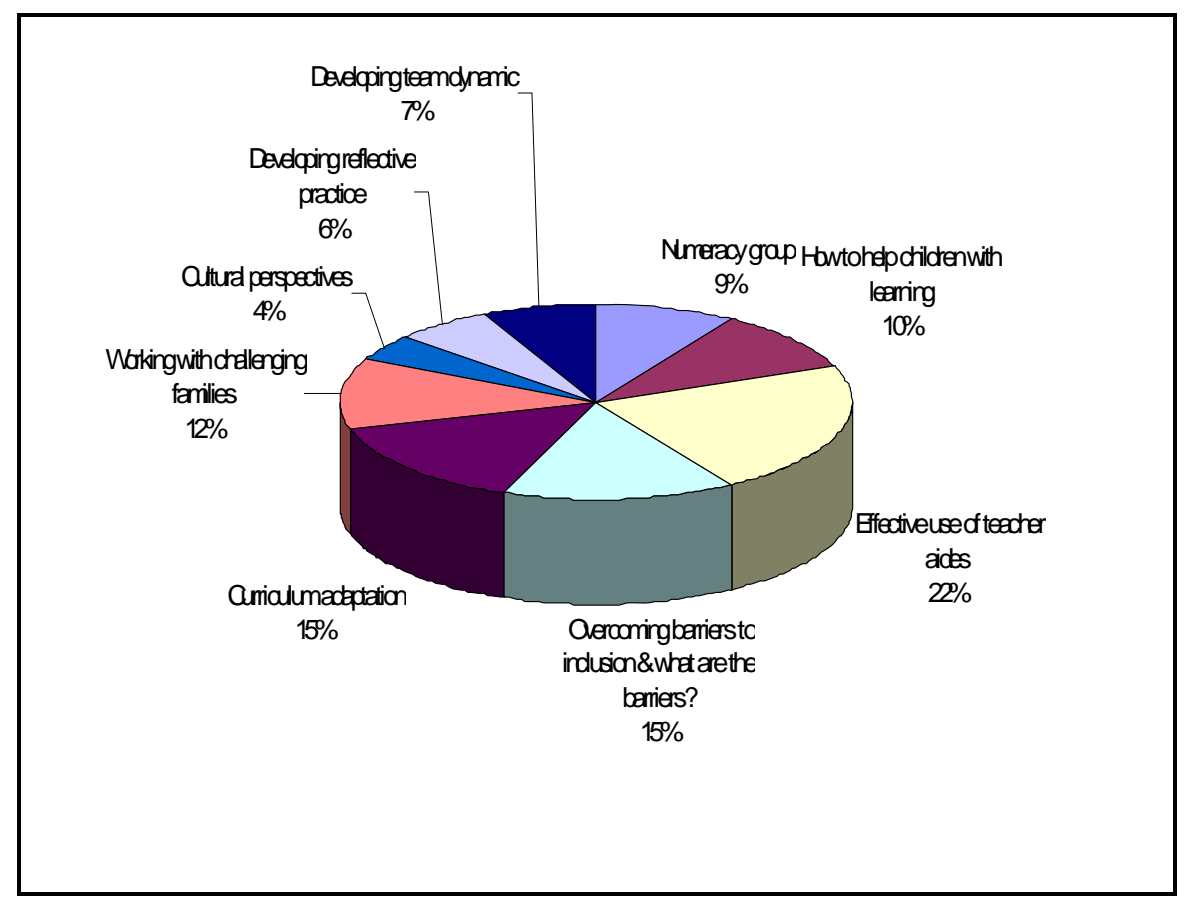

Figure 11. What the SENCos wanted to learn more about. 
An RTLB stated that the impact of the project on the regional SENCo service was that; "Schools now have Special Needs registers, improved communication between SENCos and each other as well as other professionals, improved knowledge of services available and improved data collection” (RTLB C personal communication, August 7, 2009).

\subsection{How did release time, professional development, professional support and role development affect the SENCo role?}

In order to identify the effect of PD, professional support, role development and release time (through the RTLB led SENCo initiative) on the SENCo role, data were collected via questionnaires completed by the SENCos before and after the project.

The qualitative responses to these questionnaires were analysed and coded into the following patterns: 1) conditions within the school, 2) processes within the school and 3) professional learning.

\section{Conditions within the school.}

It was important to consider the impact that the RTLB led SENCo initiative had on the regional SENCo service by considering the changes in the conditions of the SENCo positions within the schools.

Question 1 considered release time. It asked if the SENCo had release time to do the job of SENCo. At the pre-data stage of the project forty seven percent of the SENCos indicated yes, however of these only twenty nine percent indicated that they had release time before the EPF project was mooted. Both during the intervention and at the post-data stage of the project, one hundred percent of the SENCos were receiving release time (because this was paid for throughout the project by the EPF money) however one hundred percent of the SENCos indicated that they believed they would receive some form of release time after the project ceased (Figure. 12). 


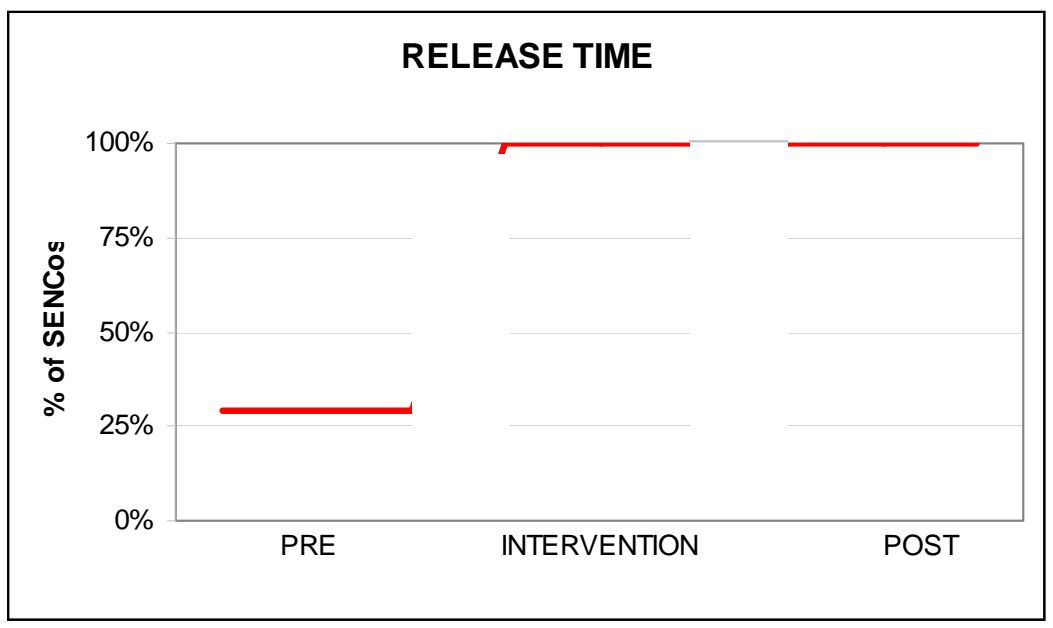

Figure 12. Release time

Participant C said, "It was amazing to have time to set up the special needs register” and Participant F said, "It gave me the chance to see how other people were working” however 13 of the 19 participants indicated to the RTLB that the release time was too much time out of class and that they didn't want to take all of it.

Question 11 considered whether the SENCos had a job description and was seeking information about role definition. During the pre-data collection for the project, seventy four percent of the SENCos had a specific job description for their role as SENCo distinct from their other roles (Figure 8). At the end of the project this had increased by six to eighty percent.

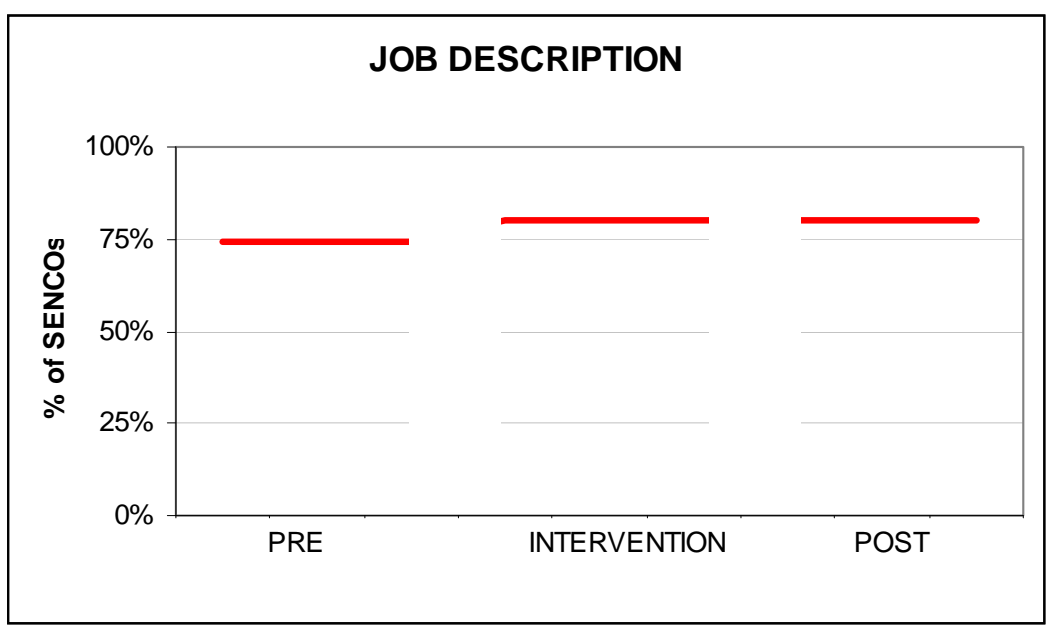

Figure 13. Job description 
Participant D (who didn't have a job description in the pre-data but did in the post-data) stated that, "creating a job description with the principal helped me clarify the role in my own head. It was a really useful exercise”.

A two tailed Pearson Correlation analysis found that there was a positive correlation between having a job description and networking with other SENCos (see Figure 14). 


\begin{tabular}{|ll|l|l|}
\hline & & JOB.DESCRIPTIONNETWORKING \\
\hline JOB. & Pearson Correlation & 1.000 & .015 \\
DESCRIPTION & Sig. (2-tailed) & & .950 \\
& $\mathrm{~N}$ & 19 & 19 \\
\hline NETWORKING & Pearson Correlation & .015 & 1.000 \\
& Sig. (2-tailed) & .950 & 19 \\
& $\mathrm{~N}$ & 19 & \\
\hline
\end{tabular}

Figure 14. Correlation between job description and networking

$\mathrm{df}=17 ; \mathrm{p}<0.001$ critical value $=.0693$ (2 tailed)

There was a correlation between the two variables $[\mathrm{r}=0.693, \mathrm{n}=19, \mathrm{p}=0.001]$.

The analysis also showed that there was also a positive correlation between having a job description and having set criteria on the special needs register (see Figure 15).

\begin{tabular}{|c|c|c|c|}
\hline & & $\begin{array}{l}\text { JOB. } \\
\text { DESCRIPTION }\end{array}$ & SET.CRITERIA \\
\hline JOB.DESCRIPTION & $\begin{array}{l}\text { Pearson } \\
\text { Correlation } \\
\text { Sig. (2-tailed) } \\
\text { N }\end{array}$ & $\begin{array}{l}1.000 \\
19\end{array}$ & $\begin{array}{l}.205 \\
400 \\
19\end{array}$ \\
\hline SET.CRITERIA & $\begin{array}{l}\text { Pearson } \\
\text { Correlation } \\
\text { Sig. (2-tailed) } \\
\text { N }\end{array}$ & $\begin{array}{l}205 \\
400 \\
19\end{array}$ & $\begin{array}{l}1.000 \\
19\end{array}$ \\
\hline
\end{tabular}

Figure 15. Correlation between job description and set criteria

$\mathrm{df}=17 ; \mathrm{p}<0.1$ critical value $=.0 .389(2$ tailed $)$

There was a correlation between the two variables $[r=0.389, n=19, p=0.1]$. 
Question 3 considered the number of positions the SENCo held within the school. At the predata stage forty two percent of the SENCos had one or two other positions in the school, another forty two percent had an additional 3 or 4 positions, while sixteen percent had 5 to 7 additional roles in the school (see Figure 16).

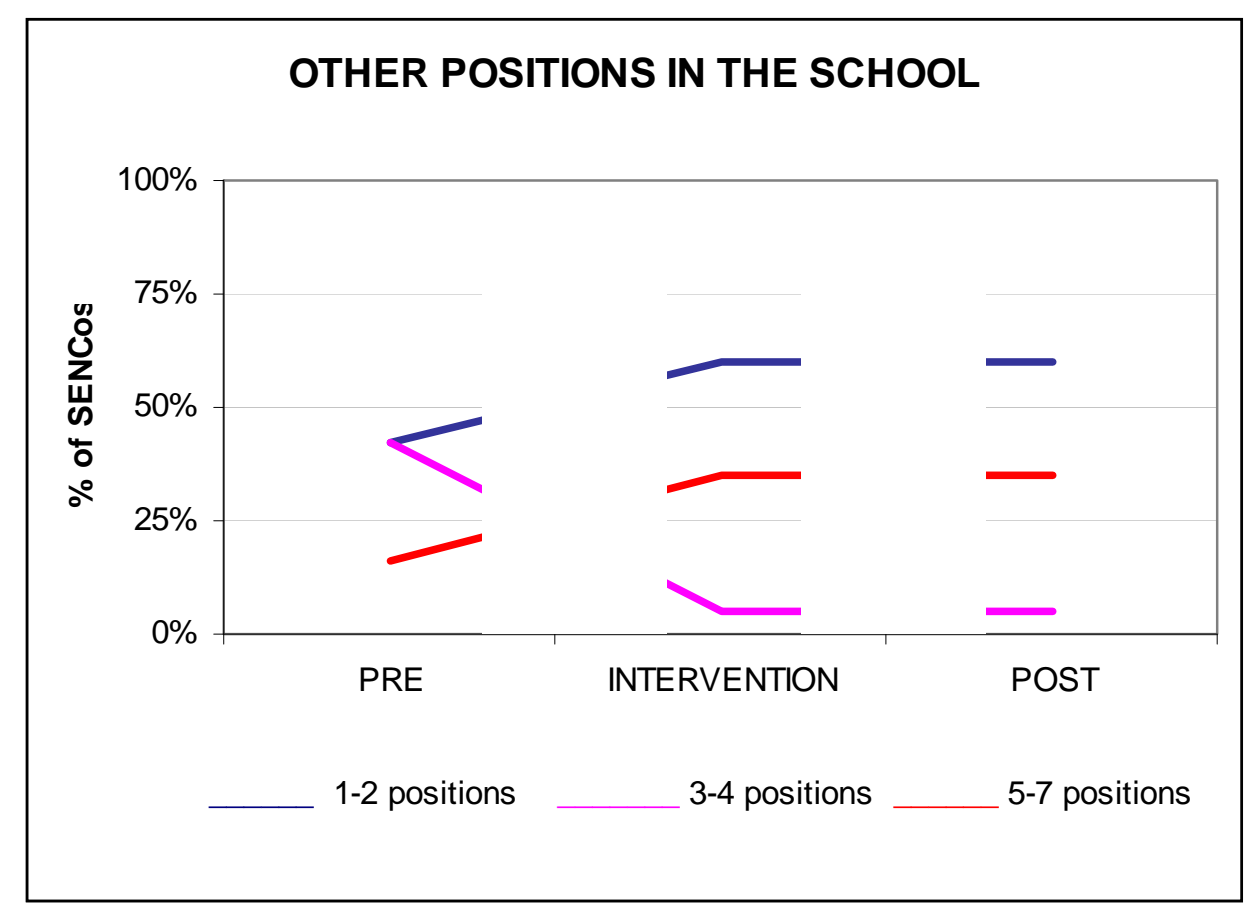

Figure 16. Other positions held in the school

\section{Processes within the school.}

It was important to consider the impact that the RTLB led SENCo initiative had on the regional SENCo service by considering the changes in how the SENCo processes work within the schools. These processes are the keys aspects of the SENCo role, including special needs committees, identification and referral systems, PD, networking with other SENCos and community agencies.

Question 8 asked if there was a special needs committee in place at the school. While at the predata collection stage of the project it was estimated that forty six percent had a special needs committee (Figure 17) (although when this was investigated many of those committees were the SENCo and the principal meeting together). Only thirty two percent had established a full special 
needs committee. By the post data collection stage eight five percent had a special needs committee, ten percent didn't and five percent had one with two members.

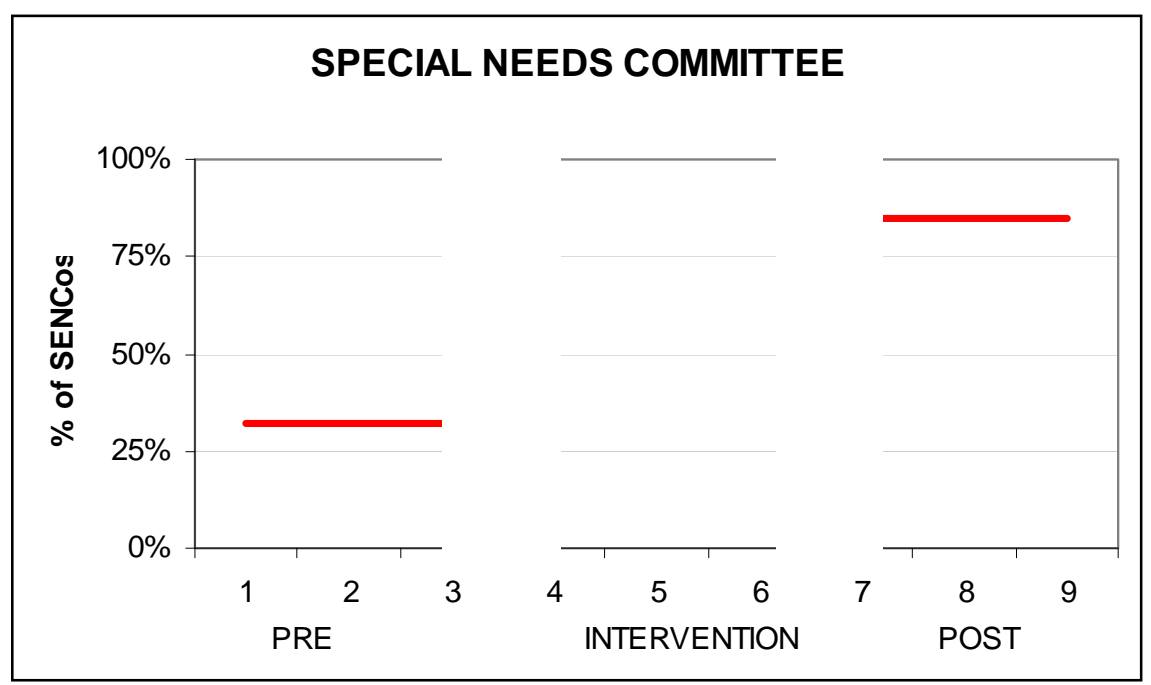

Figure 17. Special needs committee

Participant F commented on her newly established committee at the end of the project: "Having a special needs committee has made a real difference. Now I am part of a team that makes decisions. It is seen as something important”.

A Pearson Correlation analysis showed that there was a positive correlation between having a special needs committee and receiving release time (see Figure 18).

\begin{tabular}{|ll|l|l|}
\hline & & $\begin{array}{l}\text { S.N. } \\
\text { COMMITTEE }\end{array}$ & $\begin{array}{l}\text { RELEASE. } \\
\text { TIME }\end{array}$ \\
\hline S.N.COMMITTEE & Pearson Correlation & 1.000 & .045 \\
& Sig. (2-tailed) & & .855 \\
& $\mathrm{~N}$ & 19 & 19 \\
\hline RELEASE.TIME & Pearson Correlation & .045 & 1.000 \\
& Sig. (2-tailed) & .855 & 19 \\
& $\mathrm{~N}$ & 19 & \\
\hline
\end{tabular}

Figure 18. Correlation between release time and having a special needs committee $\mathrm{df}=17 ; \mathrm{p} 0.001$ critical value $=.0 .693$ ( 2 tailed $)$ 
There was a correlation between the two variables $[\mathrm{r}=0.693, \mathrm{n}=19, \mathrm{p}=0.001]$.

The Pearson analysis also showed that there was a positive correlation between having a special needs committee and receiving PD (see Figure 19).

\begin{tabular}{|ll|l|l|}
\hline & & S.N. & \\
& & COMMITTEE & PD \\
\hline S.N.COMMITTEE & Pearson Correlation & 1.000 & -.130 \\
& Sig. (2-tailed) & & .595 \\
& $\mathrm{~N}$ & 19 & 19 \\
\hline PD & Pearson Correlation & -130 & 1.000 \\
& Sig. (2-tailed) & .595 & \\
& $\mathrm{~N}$ & 19 & 19 \\
\hline
\end{tabular}

Figure 19. Correlation between professional development and having a special needs committee

$\mathrm{df}=17 ; \mathrm{p} 0.01$ critical value $=.0 .575$ (2 tailed)

There was a correlation between the two variables [ $\mathrm{r}=0.575, \mathrm{n}=19, \mathrm{p}=0.01]$.

It also showed that there was a positive correlation between having a special needs committee and having a job description (see Figure 20). 


\begin{tabular}{|ll|l|l|}
\hline & & $\begin{array}{l}\text { S.N. } \\
\text { COMMITTEE }\end{array}$ & $\begin{array}{l}\text { JOB. } \\
\text { DESCRIPTION }\end{array}$ \\
\hline S.N. & Pearson & 1.000 & .088 \\
& Correlation & & .720 \\
& Sig. (2-tailed) & & 19 \\
& $\mathrm{~N}$ & 19 & 1.000 \\
\hline DOB. & Pearson & .088 & \\
& Correlation & & 19 \\
& Sig. (2-tailed) & .720 & 19 \\
\hline
\end{tabular}

Figure 20. Correlation between having a job description and having a special needs committee

$\mathrm{df}=17 ; \mathrm{p}<0.001$ critical value $=.0 .693$ (2 tailed)

There was a correlation between the two variables $[r=0.693, n=19, p=0.001]$.

A focus of the data was processes relating to data used for identifying and recording students' needs.

Question 6 found that at the pre-data collection stage of the project twenty one percent of the SENCos identified that they had set criteria for entry onto the special needs register which increased to ninety percent by the post-data collection stage. 


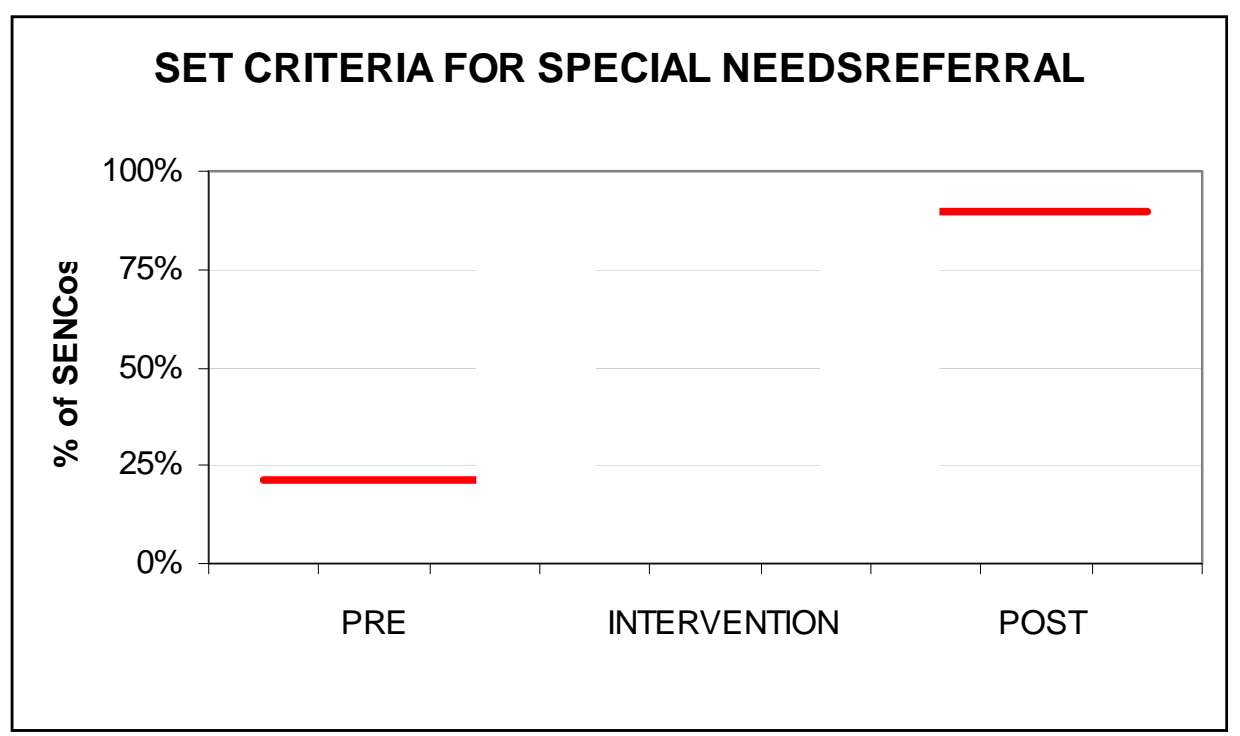

Figure 21. Set criteria for special needs referral

Question 2 was concerned about how the release time for the position was funded. All of the SENCos were aware of the EPF and the allocation of release days through this money, however none of the SENCos, (for whom release time was funded prior to the project) could identify how release time was funded. At the end of the project little had changed in this respect, only 3 SENCos knew how ongoing support for release time was to be funded.

Information was sought about what data was collected and recorded for the school regarding students with special needs (Question 4) but this was a difficult question for SENCos to immediately answer. Thirty two different assessment tools were listed. Schools contributing (to secondary schools) had 'standard' tests which provided norm referenced information. These were developed through the EHSAS (enhancing higher standards among schools) cluster which had been operational within the region for several years prior to this project. On the whole SENCos had a clear idea of what tools they used themselves but not what tools were used within the schools at different levels. However at the end of the project the SENCo had a much clearer idea of specific assessment tools that formed a bank of resources they felt comfortable discussing and an idea of where to go to access further resources should the need arise. 
Student identification for the special needs register (Question 5) was undertaken via two main processes. All 19 of the SENCos indicated that this was done through a mixture of test scores and teacher referral. This remained constant at the end of the projects.

Question 14 asked about which agencies the SENCos had been involved with previously in their SENCo role. The SENCos listed a number of agencies but found it difficult to think of agencies without thinking about individual student cases. At the beginning of the project the SENCos could list an average of 7.4211 outside agencies (see Figure 22), while at the end of the project the SENCos could list on average 11.3158 agencies (see Figure 23) without referring specifically to agencies accessed by their actual students.

\begin{tabular}{|l|l|l|l|l|l|l|l|}
\hline & \multirow{2}{*}{} & Range & Minimum & Maximu & & $\begin{array}{l}\text { Std. } \\
\text { Deviation }\end{array}$ & Variance \\
\hline $\begin{array}{l}\text { OUTSIDE. } \\
\text { AGNECIES } \\
\text { Valid N (listwise) }\end{array}$ & 19 & 6.00 & 5.00 & 11.00 & 7.4211 & 2.19382 & 4.813 \\
\hline
\end{tabular}

Figure 22. Pre-data number of outside agencies named.

\begin{tabular}{|c|c|c|c|c|c|c|c|}
\hline & $\mathrm{N}$ & Range & Minimum & Maximu & Mean & $\begin{array}{l}\text { Std. } \\
\text { Deviation }\end{array}$ & Variance \\
\hline $\begin{array}{l}\text { OUTSIDE.AGEN } \\
\text { CIES } \\
\text { Valid N (listwise) }\end{array}$ & $\begin{array}{l}19 \\
19\end{array}$ & 13.00 & 7.00 & 20.00 & 11.3158 & 3.38383 & 11.450 \\
\hline
\end{tabular}

Figure 23. Post-data number of outside agencies named.

\section{Professional learning.}

In order to address the research questions, it was important to consider the impact that the RTLB led SENCo initiative had on the regional SENCo service by considering the changes in professional learning. The literature review showed that professional development has a large 
role to play in shaping teacher's thinking and practise and also in driving educational reform (Villegas-Reimers, 2003)

As Figure 24 shows, the SENCos clearly identified the agencies which they wanted more information about and this directly fed into the PD days.

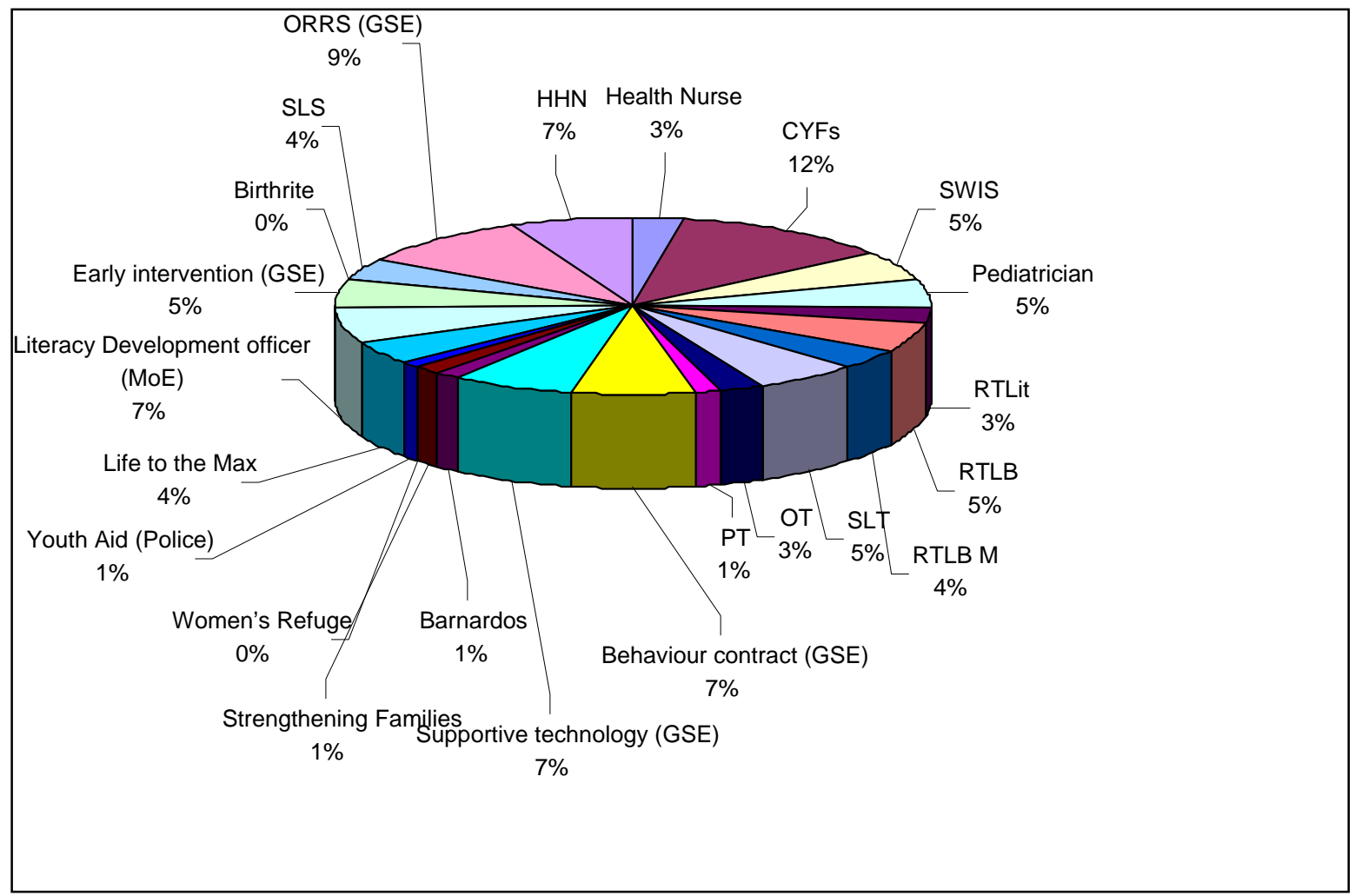

Figure 24. Agencies which the SENCo wanted to learn more about.

One of the questions (number 15) was about communities of service. At the pre-data stage of the project 21\% of the SENCos meet with another SENCo in the region (refer Figure 9), however only 6\% actually met specifically with another SENCo to discuss SENCo matters. The others either had other roles in other schools which meant they ran across other SENCos in the course of their employment, or they socialized with them outside of school hours. During the intervention and post data collection stages of the project, one hundred percent of the SENCos met regularly to network. 


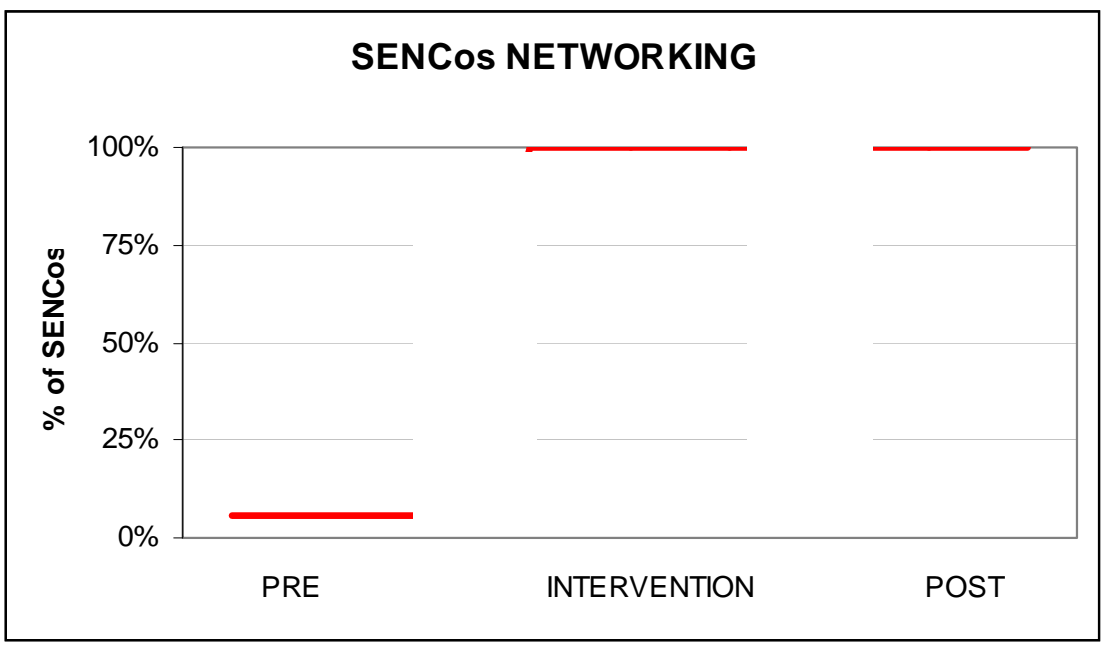

Figure 25. The number of SENCos networking before, during and after the project

Question 9 was about PD. The SENCo interview considered the PD (PD) access available to SENCos had had access. At the pre-data stage of the project fifty three percent of the SENCos said they had had access to PD specific to their role (Figure 6), however only thirty one percent had actually accessed any within the last two years. Many of the SENCos (seventy eight percent) had completed special needs study earlier in their careers and had had little access to ongoing PD regarding special education. During both the intervention and post-data stage of the project $100 \%$ of SENCos were accessing regularly, appropriate PD (Figure 26).

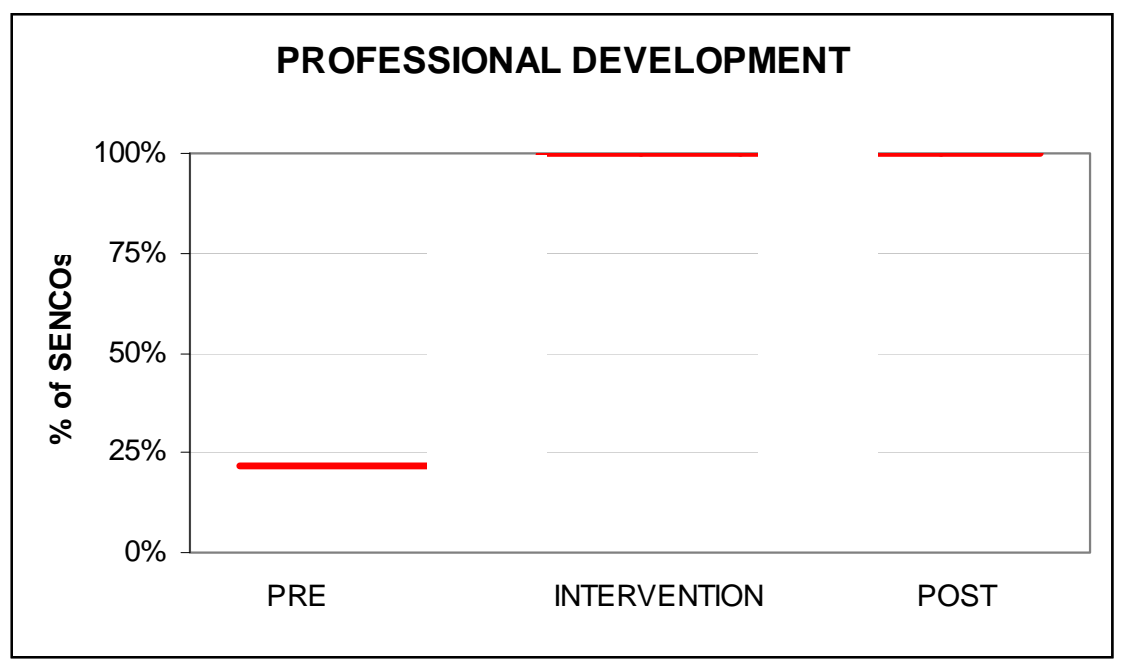

Figure 26. The number of SENCos involved in Professional development before, during and after the project 
Participant F stated: "It is quite isolating being a SENCo, however when we started meeting I felt part of something bigger”, and Participant B said, "It was great to be able to talk to other people who understood the problems I was having and could help”.

Participant B stated, “The professional development was so useful”, Participant E stated, “I learned more than I thought I would”, and Participant L said, “I really hope it will continue”.

Two other professional learning questions centred on how the SENCos wished to see their role developed (Q 12) and what skills and knowledge they wished to develop to assist them in their roles as SENCo (Q 13).

Eight PD days were held during 2008 and 2009, one for each term (see Appendix D). Sufficient funding remained to continue the project into 2010 and the RTLB cluster agreed to continue until at least until the end of 2010, providing schools could cover the release time. These additional four PD days were already organised by February 2010.

The attendance detailed in Figure 22 shows the attendance rate over the 8 days across the 19 schools.

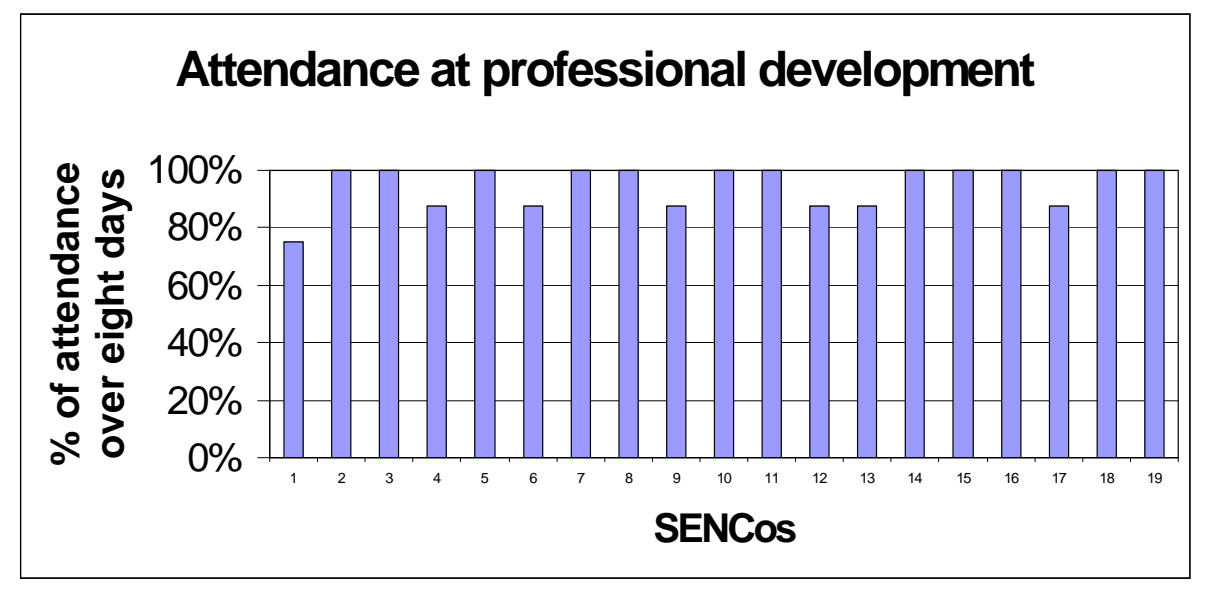

Figure 27. Attendance at the professional development

4.3 How did these elements impact on the service provided to students with special educational needs within the region? 


\subsection{How did these elements impact on the service provided to students with special educational needs within the region?}

The purpose of the parent interviews was to collect more specific data concerning the effects the initiative had on service delivery for students with special educational needs. This was assessed by considering parental awareness of the special educational services and professional special educational processes at the school level (see Appendix C).

It was important to consider the parents’ perceptions of the special needs service, as well as their knowledge of the school systems.

At the beginning of the study neither family knew the term SENCo or the purpose of the role who the SENCo was in the school. One family however did identify the SENCo as the person who they contacted within the school about their child, while the other identified the teacher and assistant principal. By the end of the project both families could identify who the SENCo was and one family knew what the acronym represented while the other family had the key idea about the role..

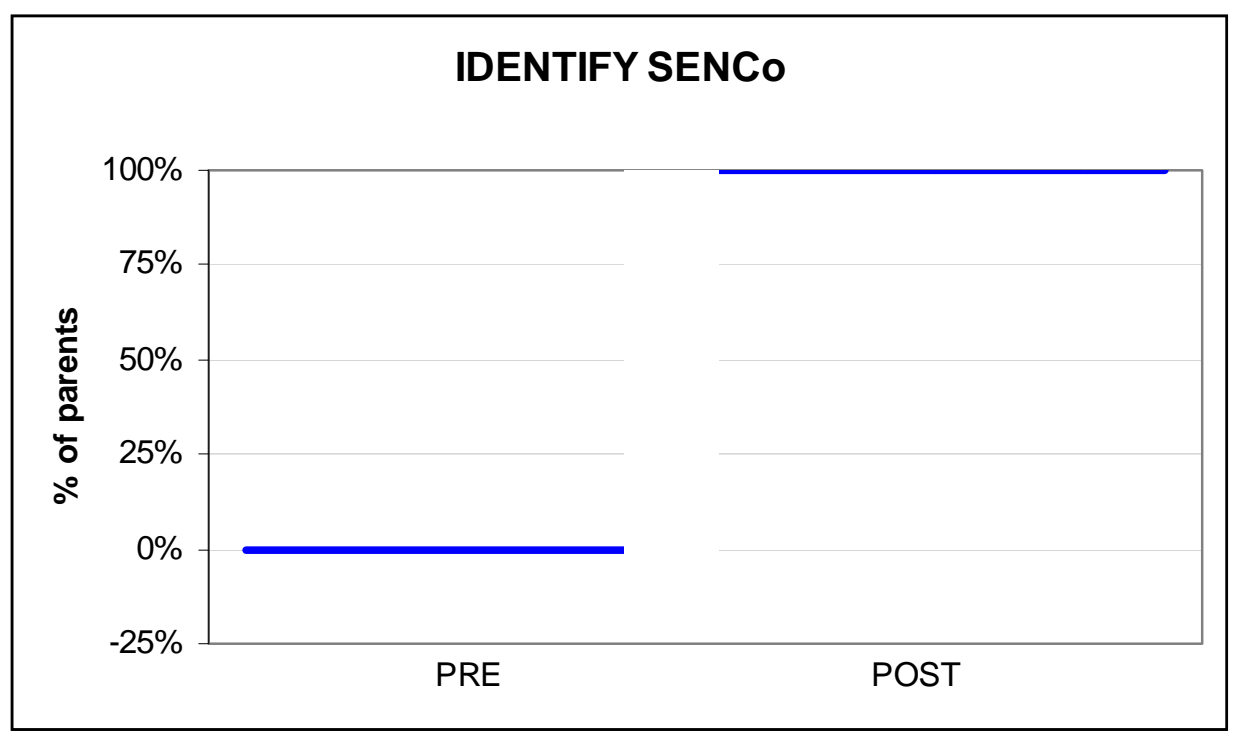

Figure 28. Parents identifying the SENCo. 
At the beginning of the project both families had vague ideas around what the school was doing to assist their child. They discussed the school reporting system as the way they received feedback. By the end of the project both families identified the use of IEPS (individual education plans) around their child with specific meetings to look at goals and progress.

By the end of the project the number of students on the special needs register had grown from 26 to 75 .

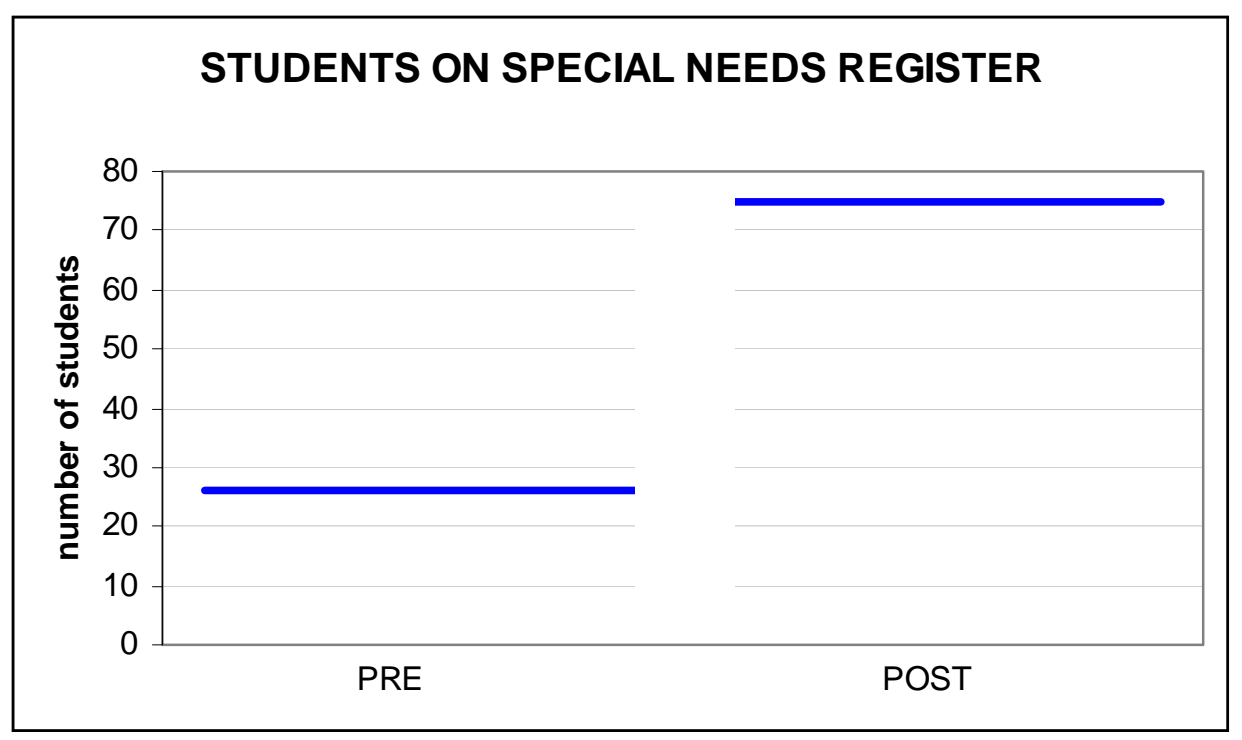

Figure 29. Students on the special needs register.

Over the course of the project the school used for the parent interviews developed a special needs policy which was signed by the Board of Trustees (BOT). They also initiated regular BOT reports regarding the schools activities and the Special Needs Policy. There was also a standard format developed for administration, management and recording of IEP meetings. During the course of this study the SENCo role changed within this school and a new SENCO was appointed. This SENCo had a job description which was written and agreed to by the principal and SENCo. The SENCo received 3 days release time per term and the school had agreed to continue funding this at the end of the project. The SENCO had attended specific PD concerning the SENCo role. Furthermore the SENCO displayed knowledge of a range of standardised and diagnostic tests and was able to, analyse and interpret them in a meaningful way. A special needs register was developed and maintained and student placement on it was linked to agreed set 
criteria. The SENCo had access to assessment data from class teachers for students who were on the special needs register. A special needs committee structure was established and it included the principal and the SENCo who met 6 times a year. The SENCo was to report to the BOT and refers to appropriate outside agencies as needed. The school has accessed the services of; Group Special Education (GSE), RTLB, Supplementary Learning Support (SLS), Speech Language Therapist (SLT), Social Workers in Schools (SWIS), other social workers, Strengthening Families and 'Life To The Max' during this time. Since the projects commencement, students with high needs have regular IEPs that organise their in-school programmes. Teacher aides have job descriptions and they work with students inclusively within classrooms when possible. However, if a teacher aide needs to work in isolation with a student it is on work that is clearly linked to the child's classroom programme. The class teachers plan the teacher aide's programme for children in their classes and the teacher aides have access to PD.

In this parent interview school, the deputy principal has responsibility for the teacher aide timetabling not the SENCo. The teacher aide appraisal process is currently being established. The school is actively seeking to enlarge the membership of the special needs committee, to build capability within the school. The school is planning to use the data to provide information to the BOT for use in making decisions related to governing the school as well as to help in the school budgeting process. The SENCo is working towards being able to support class teachers in discussing a range of options for best use of the teacher aide resource and advice around programme planning. The school is considering a process for appraising the SENCo and it is also considering PD for the staff to provide information on the schools Special Needs Policy.

\subsection{Summary}

This section has detailed the effects of the creation of a region wide SENCo service, through answering the core research question; 'What are the effects of an RTLB led initiative to create and support the development of SENCo positions within the schools of a region of New Zealand?'. The data that was collected has been presented under the headings of; creating a region wide SENCo service, the creation of release time, $\mathrm{PD}$, professional support and role 
development and the impact on the service provided to students with special educational needs within the region.

The first section presented the findings in regard to the first guiding research question: 'How did the initiative impact on the regional SENCo service?'. The second section presented the findings in regard to the second guiding research question; 'How did release time, $\mathrm{PD}$, professional support and role development affect the SENCo role?'. And the third section seeks to presented the findings in regard to the remaining third question; 'How did these elements impact on the service provided to students with special educational needs within the region?'. 


\section{Chapter 5: Discussion and Reflections}

\subsection{Introduction}

The aim of this study was to evaluate the outcomes of the SENCo project through identifying the affects of an RTLB led initiative to create and support the development of SENCO positions within schools in this specific region. The core question of this study was to identify: What are the effects of an RTLB lead initiative to create and support the development of SENCo positions within the schools of a region of New Zealand? This chapter seeks to discuss the findings and their implications in relation to the guiding research questions.

The first section discusses the findings in regard to the first guiding research question: How did the initiative impact on the regional SENCo service? The second section seeks to discuss the findings in regard to the second guiding research question; How did release time, PD, professional support and role development affect the SENCo role? And the third section seeks to discuss the findings in regard to the remaining third question; How did these elements impact on the service provided to students with special educational needs within the region?

The three guiding questions overlap each other to some degree but have been identified in order to enable a specific focus on independent variable (the project) which may affect outcomes and the dependant variable (changes in special needs service) which may have shown affect.

\subsection{How did the initiative impact on the regional SENCo service?}

The overall impact of the initiative on the regional SENCo service was considerable. The SENCos presence in schools provided a key person in each school who was working within special education with an inclusive paradigm perspective. This created a better managed, collaborative special education service within the region. In this section the changes in the provision of SENCo service available amongst regional schools, role status, policy and practise are discussed in detail. 
The changes in the provision of SENCo service available amongst the region's schools, was significant. There was a seventy four percent increase in the number of SENCos within the studied region. Prior to the project there were 5 SENCos within the region and the project directly enabled all of the 19 schools to create these positions. This in itself is a significant change that could lead to an improved regional SENCo service. As part of the EPF application, all of the schools within the region had to commit to creating a SENCo position and the funding for this came from the EPF. However all of the schools indicated that they would keep the positions once the project was completed. While this is a small sample, the impact on the region was that there was a total coverage of SENCo service and the implications are both school and region wide. All of the schools in the region now have an identified position that is responsible for coordinating special educational needs within an inclusive framework and accordingly inclusive special education is a focus and an area highlighted as being important. Moreover, these schools fit into a broader picture of a region whose principals see this initiative as important and worthwhile enough to have collaboratively decided to support these positions. This has led to regional collegiality and a valuing of the SENCo role. This was identified by the community of service that has led to SENCos supporting other SENCos (refer later discussion on PD).

The RTLB cluster’s 'milestone' report (see Appendix E) which was used as a midpoint evaluation of the project, demonstrated an increase in the region's schools number of special needs policies and special needs committees. This was a major development for special education within the region.

The fundamental advantage of having networked SENCo positions across the region with effective special needs committees was the development of a better managed, collaborative special education service which could focus on providing inclusive practices and developing inclusive policies and procedures within the regions schools. One RTLB (A) noted that, The network grew out of recognition that special needs referrals are more easily managed when a school employs a SENCo. The idea of schools working together expanded through discussion among RTLB's, SENCos and principals, it's like ripples in a pond, we threw in a stone and it rippled out. (personal communication, 6 April 2009) 
The changes in the role status of the SENCo position also impacted on the regional service. Szwed (2007) suggested that in England the publishing of the Teacher Training Agency standards meant that the role of the SENCo there was better defined and the status of special needs had been enhanced. However Szwed went on to qualify this by saying,

This may be true where the SENCO is given the time, resources and opportunities for development to carry out the role, but in many cases ..., this is not so thus leaving the SENCO trying to juggle too many balls and feeling inadequate. (p.74)

This project tackled those obstacles from the outset by not only enabling the creation of the positions but also providing release time, $\mathrm{PD}$ and a community of practice. The off-shoot of this has been the enhanced status of the SENCo position from the outset. Having a system of support and PD has legitimized the position. One RTLB (L) described it as a change - previously the SENCo position was not highly valued but now it was becoming a sought after and prized role (personal communication, 8 April 2009).

The milestone report also showed that SENCos were giving regular reports to the Board of Trustees (BOT). They were now documents that had significance as each report was now directly part of the governance system.

Another change was that the special needs committees were planning to provide PD to the staff. This in itself shows that the school perception was that the SENCo had something worth sharing and were being given the time and opportunity to share their knowledge and experience. The SENCos also had specific job descriptions for their roles as well as release time and access to appropriate PD.

SENCos also now had the skills to support teachers in an inclusive manner and to utilize teacher aides effectively within this paradigm. They were also developing a view of how their positions impacted directly on student outcomes. A SENCo (F) said, 
It is important to think about our role and this is allowing SENCos to not just get together but to share all our skills. It's ensuring that students don't fall through the cracks. (personal communication, 6 November 2009)

For the first time the SENCos were in a position where they could guide and shape their own PD and practice by clearly indentifying the skills in which they wished to gain more knowledge and experience.

As one principal (M) put it,

We're empowering and increasing the capability of our SENCos greatly and creating another learning community in our area. People might have individual roles in schools but they are no longer working in isolation. (personal communication, 9 April 2009)

The changes of policy and practise that came from the project also impacted on the regional SENCo service. The statistical analysis showed a positive correlation between the SENCo having a special needs committee in place and the SENCo receiving PD. This makes sense as the special needs committee could identify areas and knowledge to develop and support the SENCo in finding and attending PD related to these needs. However it is also logical that it is through exposure to PD within special education that the value of the support and collaboration of the special needs committee is recognised. Therefore, through increasing the access of SENCos to quality PD and supporting them to develop special needs committees, the project was experiencing a positive flow on effect in other areas.

Other positive correlations found in the data can be viewed in a similar way. For example, consider the positive correlation between having a special needs committee and having a job description. If there is a committee this body can provide the job description based upon accumulated knowledge and understanding of the role by committee members. Alternatively, if there is a job description there is the mandate to develop a committee to maintain the role. It is however, also possible that a common factor was impacting on either or both of these factors. 
The positive correlation between having a job description and having set criteria on the special needs register can also be viewed either way. Having a job description gives the SENCo status and a mandate to do their job so it can impact on the detail they then bring to the job. Likewise, if the school decides to initiate set processes, they must consider who holds the knowledge so that this can be achieved. The SENCo can then oversee the process and this can drive the need for a job description and the recognition that it brings. Again it is possible that a common factor was impacting on either or both of these factors.

The positive correlation between having a special needs committee and receiving release time works in a similar way. A special needs committee shows a commitment and valuing from the school to the special needs process which can lead to the recognition of the need for time for the SENCo to undertake their tasks. If the SENCo has a specific, set time to undertake their tasks, they have more opportunity to devote to developing a special needs committee.

The same is true also for the positive correlation between having a job description and networking with other SENCos. If SENCo have a job description they have the mandate to develop their role and this may well lead them to network and discuss the role with others who do the same job in the area. Likewise if SENCos are meeting together and discussing their role, the importance of the job description would be an issue that would come up for discussion.

What these correlations imply is that by developing one aspect of the SENCo role it may lead to change other areas or it is possible that an unknown common factor was impacting these factors. The correlations tell us that for these areas discussed, those changes are positive. Therefore if we increase the number of SENCos with job descriptions it is possible that the number of SENCos networking will also increase. However, if we increase the number of SENCos networking then the number of SENCos with a job description will also increase. The statistical analysis for the entire data showed that there was no trade off between increasing one area at the expense of another. This is a valuable insight because it means that when initiating changes through the project, there is little risk in decreasing a valuable component inadvertently while trying to increase other areas. 


\subsection{How did release time, professional development, professional support and role development affect the SENCo role?}

The three areas to emerge out of the qualitative data analysis of the changes in SENCo conditions and processes were conditions of service in the school, the SENCo processes within schools and professional learning.

The project provided release time, encouraged establishment of job descriptions and impacted on the number of additional SENCo roles. These changes in the conditions of service for SENCos within their schools, was a major theme in the data.

The SENCos comments about release time showed that it was being used in many different ways to support their role. Sharing practise and up-skilling each other, as well as the traditional SENCo tasks were impacted upon. Whether this release time was to continue after the project was uncertain but, the principals of the schools expressed a continued commitment to maintain the positions and some form of release time. What this change did reveal was commitment to meeting project objectives.

What was unexpectedly surprising was that the SENCos indicated that the initial 3 (and later 2 release days) per term was excessive. While they valued the time to undertake learning about various aspects of the SENCo role they were reluctant to be absent from their classes sp frequently. This is worth noting because teacher workload was seen as an important issue in considering release time for the SENCo positions during the initial EPF application and during steering group meetings. The perception of those establishing the project was that release time was needed to add value to the position but the SENCos were indicating the release time was necessary for the SENCo tasks but that release time in itself held no value. Perhaps it was because these SENCos were committed and dedicated teachers who held the best interests of the students as their core work and this may well have reflected their commitment to their primary role as classroom teachers. 
At the beginning of the project, seventy four percent of the SENCos had a job description for their role as SENCo distinct from their other roles (Figure 8), while at the end of the project eighty percent had a SENCo job description. While this was only a six percent increase it was a significant step within those schools it affected because these schools had had SENCos for some time but job descriptions had not been given any priority. This was seen by the RTLB as something that was inherently important although it had not been a high priority to actually achieve in some schools (RTLB L, personal communication, May 29, 2009). The developing community of practice had some power in pulling practice into conformity: the discussion and consensus among the SENCo drove some of the change so, in effect, professional peer support played a part in changing priorities and initiating change. Spillane (2002) identified that communities of practice provide an essential part of intelligent activity where mutual understanding drove practice.

The reduction in the additional roles held by SENCo at the end of the project suggests that as the project unfolded a greater appreciation for the role developed within school management structures. The number of SENCos with one or two other positions in the school decreased by seven percent, while the number of SENCos with 3 or 4 other positions decreased by twenty three percent and the number of SENCos who had 5 to 7 additional roles in the school decreased by sixteen percent (to 0 ) over the course of the project. Initially the RTLB team thought that having SENCos who were on the senior management team (SMT) would raise the profile of the position and allow changes to happen more rapidly. However they quickly realised that these SENCos were busy with their other roles and the SENCo position was often an 'add on' job rather than a solely dedicated position. As Abbott (2007) found:

[it] ...showed that the responsibilities, skills and attributes expected of the SENCO were numerous and that it was a core position, yet carried a substantial teaching load, that the role was strongly managerial and that there was fragmented support in practical terms. (p.391)

It appeared that the RTLB came to understand that the move away from SMT SENCos was a means of valuing the position in its own right. From the schools perspective this was a change in 
thinking and a surprise to a number of RTLB (RTLB D, personal communication, March 4, 2010). Therefore, having SMT step into these positions was a way of getting them off the ground in order to meet the requirements of the EPF. However, once those involved in the project realised the value of the position and the commitment required they were able to locate staff within the school interested in pursuing this role. Perhaps this is a reflection on the number of additional roles teachers assume as well as their classroom positions within schools, often with no recognition. It is likely the role could be avoided by staff who are already struggling to fulfil their workloads, especially when they do not see any recognition for undertaking such a role. The project offered the recognition. As one SENCo (J) stated, “The PD gives me space to think about the SENCo role away from other responsibilities as a classroom teacher” (personal communication, 6 April 2009).

The project encouraged the creation of special needs committees and special needs registers. These changes in the SENCo processes within schools, was another major theme identified by the qualitative data.

One of the aims that the RTLB had for the project was the creation of special needs committees. This was because it provides collaborative support, guidance and a means of readily implementing knowledge and skills within the school. Kugelmass (2004) discussed how collaboration and compromise are essential to the advancement and preservation of 'inclusive culture'.

Of particular interest in this study was whether each school had a special needs committee. At the beginning of the project thirty two percent of the SENCos had established a full special needs committee (Figure 5) while at the end of the project eighty five percent had a full special needs committee. This is a fifty three percent increase and it was one of the key aspects that the RTLB identified as an area to develop within schools. Establishing the momentum to change the way special needs is perceived within schools and having a team to oversee it was vital to getting significant change. However, it will only be as these committees get established and develop their own roles in schools that their success or failure of special education will be measurable. At the end of the project the RTLB cluster expressed some concern that these committees need to be 
more operationally efficient and effective - for example, making the SENCos part of a supportive team that could work collaboratively to meet the individual needs of the students in an inclusive manner (RTLB L, personal communication, May 11, 2010). The RTLB had allocated funds and additional training to support the development of these committees and there was a growing realisation for ongoing support within the schools to make these work effectively (RTLB A, personal communication, May 11, 2008). It seemed probable that to get this working well across the region, RTLB may have to support the establishment of the committees by assuming a membership responsibility and provide guidance until each committee is firmly established within the school culture and then it may be able to operate independently.

A second development was the special needs register. The number of SENCos who had set entry criteria for the special needs register moved from twenty one percent at the beginning of the project to ninety percent at the end of the project. This suggests that SENCos were feeling more confident in determining what the criteria for entry were and what role the special needs register played in the position they had developed. Again the RTLB were surprised with this result. They had initially hypothesised that as the SENCos became more confident, set criteria would decrease, however they saw this unexpected result as a positive outcome of the intervention (RTLB L, personal communication, May 11, 2010). The SENCo were more aware of what the role was, how to collect data how to support students and record their progress. As one of the SENCos (K) stated about the value of the PD, "It's sharing ideas so that we are learning from each other. It's sharing best practice, I leave the PD days with new tools” (personal communication, 6 April 2009).

The ultimate value of the special needs register was not in the development of the criteria but in the process of discussion around inclusive practise ecological assessment. It is important to note that the emphasis at the PD days was on looking at problem situations rather than problem students and working towards inclusive interventions that were based on ecological analysis. Ecological assessment stemming from an inclusive paradigm is an important consideration underlying the planning and organization of the PD (personal communication, 12 August 2009). 
Crowne (2005) discusses the British system in terms which echo our current New Zealand situation:

But with the present pressure on schools coming from the potentially conflicting government agendas of inclusion and standards, the SENCO role is changing.... If this is the case, then surely SENCOs should be viewed as agents for change who aim at improving teaching and learning of all pupils, but especially those with diverse and different needs? (p.67)

With newly introduced national standards and a review of special education practises, it is possibly that teachers may well have a dilemma: maintaining inclusive practices and balancing this with the need to identify and remediate deficit students (Daniels \& Garner, 1999). This underscores the importance of the SENCo role which can provide inclusive based knowledge, support structures, skills and strong processes in place to balance the competing demands.

The project initiated and maintained changes in the PD available to SENCos, which in turn affected the SENCo role. This inclusive based PD provided the second major theme within the data.

SENCo access to PD increased by sixty nine percent. Thirty one percent of the SENCos said they had had access to PD specific to their role (Figure 6), within the last 2 years. At the end of the project $100 \%$ of the SENCos had engaged in PD specific to their role as SENCo. This was not surprising since a function of the project was to provide the PD. It is important to note the high level of commitment as evidenced by the attendance numbers for the PD days. Because the RTLB had such a strong commitment to inclusive education they considered this PD as vital. As Beattie, Jordan and Algozzine (2006) stated: "Professional development that empowers both special education and general education teachers and encourages them to work together is critical to successful inclusion” (p186). They suggested the best way to provide students with great education is to give them great teachers, and indeed Darling-Hammond (2003) showed the single most important impact on student achievement was teacher quality. It was important to note that the RTLB cluster moved away from determining and organising the PD was needed encouraging 
SENCo driven PD arrangements. For this reason, the PD was not pre-organised, although the temptation to do this was strong. The RTLB's felt a strong sense of responsibility for providing a good programme but also for utilizing the EPF grant.

Initially the PD days were plotted out in advance, until the RTLBs realised that while they could predict what may be useful for the SENCos they could not hope to be successful if they failed to allow the SENCos the right to drive their own PD based on their own perceived needs. Therefore SENCos were actively involved in the process of selecting what form and content the PD would take (RTLB C, personal communication 14th May 2008).

Effective PD is about empowering participants to have the knowledge and tools to enable growth and change while contributing to the decision-making processes (Arenas, Bleau, Eckvahl, Gray, Hamner \& Powel, 2009). Parmar (2003) defines empowerment as a process in which one realizes their inner strength and their capacity to sway change within their own group. Empowerment is an involved process where the persons self knowledge, experiences and interaction with others leads to growth and change (Parmar, 2003). Effective PD for the SENCos provided time for reflection, new experiences, knowledge and interactions with others in the same role and a safe environment for challenging ideas and assumptions so that real growth and change could occur.

In order to develop empowerment within the SENCos they need to drive the programme, however this did not imply RTLB had a limited role. Bay and Parker-Katz (2009) recommended that SENCos receive extensive guidance and support from experienced special education teachers. They stress the value of skills, practices and tools, while highlighting the need for a professional learning community which can mentor members.

Part of the PD involved providing the SENCos the opportunity for SENCos to learn about community agencies. Therefore the number of agencies they could identify increased on average by four agencies from the beginning of the project to its end. This was an important issue because as Barnes (2008) discussed the importance of multi-agency activity involving SENCos in working to support vulnerable children, whether through individual key workers or collaborative 
teams. This has become a community of practice focus in that SENCos now actively hold and share this information among the group.

With regard to the notion of communities of practice, before the project commenced only $6 \%$ of the SENCos met specifically with another SENCo to discuss SENCo matters as part of a community of practice. However by the end of the project $100 \%$ of the SENCos networked with other SENCos regularly. Campbell (210) showed how the newcomers to a community are connected to their identity within the group and what they bring with them. Fuller (2005) found that communities of practice are established to build capacity in "developing the collective ability - dispositions, skills, knowledge, motivation and resources - to act together to bring about positive change” (4). While Timperley et al. (2007) found that those involved in communities of practice are supported and encouraged to consider new ideas and implications for their theories, understandings and practices. One SENCo stated, "It is important to think about our role and this is allowing SENCos to not just get together but to share all our skills. This matches what was noted throughout the study where the increased networking went hand in hand with the development of the collective ability. As SENCo (F) said, It is supportive too, because we're isolated in our own school sometimes and you think you're doing okay but it is good to talk to staff from other schools. Often we didn't have someone to sound off - now we have that support. (personal communication, 16 September 2009)

Professional development was a major theme within the project. It was evident that the RTLB cluster would remain actively involved in providing this form of PD for SENCos within their region for at least the next 2 years and probably for much longer. The SENCos are committed to continuing their community of practice and considering the possibility of a group internet forum hosted by the RTLB team.

\subsection{How did the project impact on the service provided to students with special educational needs within the region?}

The study identified two changed practices that benefited students in the parent interview school. These were the development of partnerships with parents (as evidenced by the increased 
awareness of the parents) along with the increased identification of students in an inclusive environment experiencing difficulties.

There was a change in parental awareness of the SENCo role over the course of the project. In both families, the ability to identify the SENCo increased by one hundred percent. Both of the families showed a more in-depth grasp of the processes around the identification, planning and monitoring of their child's needs.

The special needs processes within the school changed during the project. By the end of the project the number of students on the special needs register had increased thirty five percent showing a better process of identification and monitoring, this had grown from a clearer understanding of the role and the processes needed to support the role. It is important to stress that simply identifying students with needs does not necessarily equate to a better service. It may lead to a more grounded deficit approach. However, the emphasis of the project was on the elements of the environment not the problem within the child, and finding inclusive ways to accommodate differences effectively was the priority.

\section{$5.5 \quad$ Reflections}

The strongest evidence of how the initiative impacted on the regional SENCo service was demonstrated through, the RTLB cluster with region wide principal support, effectively initiating and supporting the development of SENCo positions within the region. There was a seventy four percent increase in the number of SENCos in the region studied. Prior to the project there were 5 SENCos within the region and the project directly enabled all of the 19 schools to create these positions. It is unlikely that this would have happened without this intervention and it appeared partly due to the financial support, peer pressure among schools, requirements of the EPF and the opportunity taken up by schools to focus on this area of special needs and gain some support in so doing.

It is worth noting that the RTLB cluster successfully gained EPF support for this project (under the new National Government this funding pool has ceased). This required gaining support from 
all of the 19 principals within the region, some of whom had to walk away from their own proposals to support the project. The RTLB clearly identified one key lead principal who supported the ideas behind the application and then in conjunction with that individual worked to get the principals to accept the project ideas. Without this support the project may have floundered (RTLB D, personal communication, November 4, 2008).

Through the project, the SENCos were allocated funding for release time and PD. this was organised for them by the RTLB who organised the 8 days PD over the 2 years. The steering committee was comprised of; 2 principals, a GSE manager, 1 SENCo and 3 RTLB oversaw the administration of the EPF. The direction, gleaned from the SENCos themselves was fed back to this group for approval, however once the direction and speakers were agreed upon the RTLB cluster had the full responsibility for organising and running the PD. This included the contracting of speakers, booking or facilities and catering needs. This required a high level of skill in many areas relating to; sourcing, organising and promoting PD. It is possible that not all RTLB clusters would have the necessary skills to achieve this, or possibly access to the standard of speakers that were available within a reasonable range of this region. It is worth noting that two other RTLB clusters within the wider area have implemented their own form of SENCo professional support and development after learning about (and in one cases) being involved in this project.

The final interview, although gathering important data, did not exhaust the issue. Furthermore, since this was an exploratory study other issues arose which need to be investigated in future studies. These include the inclusive practises used in schools, the SENCos own perceptions of status and self efficacy.

Three of the SENCos involved in this project successfully gained positions as RTLB during the term of the project (two locally and one in another district). This was an achievement because it demonstrated their empowerment and was unplanned outcome. Up skilling the SENCos had increased both their knowledge and skills but also sparked their interest in special needs education and had given them the opportunity to learn about other roles and career opportunities. 
The RTLB had a vision to have the SENCos take over ownership of the PD and eventually (before the end of the 2 years) manage the days themselves. It became apparent to the RTLB cluster, early in the second year that this was not realistic. As RTLB A (2009) said, "They are too busy and scattered a population, this isolation makes it hard for them to network and coupled with their workload makes taking this responsibility on virtually impossible” (personal communication, 8 April 2010). RTLB accepted that if this was to work long term they would have to remain as a support mechanism to organise the mechanics around the PD. Although 2 SENCos did manage workshops at one of the PD days but most were not enthusiastic about being actively involved in such a manner.

Another facet of the project was the way the literature shaped the RTLB practise concerning ownership of PD. Initially it was planned that the RTLB cluster should arrange the PD days for the 2 years, and while this would have been an easier option, it was not consistent with best practice (McDonald \& Melchior, 2008). Even though the RTLB had a very clear idea of what the SENCos required for PD, the direction and therefore ownership needed to come from the SENCos themselves. "Those joint discussions about what they knew and where they needed to go were as important as the professional development itself” (SENCo D, personal communication, 8 April 2010).

There were some concerns expressed about sustaining the SENCo positions due to staffing changes within schools. This was one reason the RTLB favoured the development and maintenance of special needs committees, so that the process and knowledge was not dependant on one person. However, the SENCos who changed during the study made a smooth transition into their role and were actively supported by others in the group. This included using their support time to allow visits and help in setting up processes. The RTLB also took on the role of supporting new SENCos when the opportunity arose.

This evidence suggests that a key element in sustaining expertise within the SENCo role is the provision of a wider, collaborative community of support. In this way capability is built in the system rather than isolated individuals. 
The RTLB cluster also noted the difficulties transferring the ideas and practises back on the job. There was a desire on the part of RTLB to implement the ideas and initiatives discussed at the PD days. However this was a slow process and at times the SENCos became the holders of knowledge rather than the gatekeepers to it. What worked well was when the RTLB worked collaboratively with the SENCos in accessing and providing school based PD at the teaching level. This school based PD was based around the ideas developed at the SENCo PD days coupled with the driving motivation coming from the specific SENCo and special needs committee. The RTLB cluster has also (towards the end of the project) accessed training for themselves in specific programmes to support the SENCos introducing ecological, inclusive programmes within the schools. These programmes were introduced on the PD days. It is envisioned that if the special needs committees become the driving force of special education change within the schools, this will become an internal process and therefore more effective because it is being driven from within the school rather than externally.

Another problem was the need for relief teachers on PD days within this area. Each PD day took 19 teachers out of schools within this region, and there were very few other relievers to cover other absences. This was a major logistical consideration and PD days needed to be timetabled on the principals' calendar at the very beginning of the year to avoid problems arising over hiring relievers.

\subsection{Summary}

This study aimed to evaluate the outcomes of the SENCo project through identifying the affects of an RTLB led initiative to create and support the development of SENCO positions within schools in this specific region. The overall impact of the initiative on the regional SENCo service was considerable leading to a better managed, collaborative special education service within the region.

The three areas to emerge out of the qualitative data analysis of the changes in SENCo conditions and processes were conditions of service in the school, the SENCo processes within schools and professional learning. The study also identified two changed practices that benefited students. 
These were the development of partnerships with parents and the increased identification of students experiencing difficulties. 


\section{Chapter 6: Implications and Recommendations}

\subsection{Introduction}

Historically New Zealand's education system either ignored students with special education needs or placed them into special settings. The international human rights movement, mainstreaming, Special Education 2000 and the Tomorrow Schools policy were steps toward inclusive practices within our schools. However, as discussed, the research clearly indicates that the tools to implement shifts in paradigm are found through; professional development, communities of practice, collaborative-consultative approaches, teacher/school change and the management and facilitation of the transfer of learning. This study provided a rare opportunity to assess the use of these tools through the evaluation of an RTLB project which provided a wrap around SENCo service to all of the schools within its region.

The findings of this project have been discussed in light of the three key research questions concerning; the impact on the regional SENCo service, the affect on the SENCo role and the impact on the service provided to students with special educational needs within the region. In this chapter, these findings are reviewed. Then the implications and recommendations for special education within schools are discussed, outlining suggestions that could be useful to Boards of Trustees, the Ministry of Education and future researchers.

\subsection{Implications}

The findings reveal that the project, through release time, PD, professional support and role development, impacted on the regional SENCo service as well as on the students with special educational needs within the region. These findings have implications for the way the role of SENCo is incorporated into the New Zealand school system.

This research raises some possibilities for improving special education practices within the New Zealand setting. It suggests that SENCos need to be provided with opportunities, resources, 
support, encouragement and recognition in their professional development pursuits. They need to know that their efforts are being supported by their colleagues, principals and school boards. Boards of Trustees, principals, teachers and RTLB need to understand that the process and theory of communities of practice and professional development are communicated to those trying to set up SENCo positions in schools.

The following limitations have implications that need to be considered in interpreting the findings:

- This was a small-scale study, although the project included all of the school's from this area.

- Being a quasi-experimental study there was no control group and therefore where changes were measured it is impossible to categorically say whether these were directly caused by the intervention or not. Of course with social research this is often the case.

- The only other New Zealand based SENCo study known was undertaken by Storer (2002) which investigated current practise of a sample of SENCo from across New Zealand. This study adds to that knowledge by looking at the deliberate creation of and support for these positions. It would have been useful to have found this research project earlier so that the researcher could have considered the possibility of using some of the forms that were created to compare the outcomes between Storer's study and this one. However it is not easy to access 1 paper research projects.

- Correlations only show relationships not causes. In most scientific inquiries, we seek the cause of something. It would be nice to be able to say that if we change a specific practice within Special Education then we will get a certain outcome. However life is complicated and there are numerous variables in working with educational systems and people. While we can find links and relationships we can not say definitively that there is any causation between the measured variables or than we would necessarily see the same relationships within another population. 
- The data collected was not based on a five point scale which would have allowed a greater analysis.

- The researcher wanted to conduct two case studies of separate schools to look in more detail on the impact of the project on students and their outcomes. This did not work out. Leaving limited information about the impact on students. It would have been ideal to undertake case studies in all of the 19 schools, and to have selected a wide range of parent participants.

- It would have been useful to have used an established psychometric tool (measuring selfefficacy, anxiety and personality and preferably with five-point scales for analysis) for measuring further constructs over the course of the intervention.

- There are some tools within the literature that have been used to measure SENCos perceptions of their role and self efficacy and it would have been valuable to have replicated their use here within the New Zealand situation. It would also have been useful to have used forms that Storer's (2002) study created to compare the outcomes for this area against that national sample.

- Because the intervention took place over 2 years there was a change in the personnel involved in the project. This impacted on the questionnaire that was used, it is not possible to tell if all of the answers would have remained the same had the personnel remained the same.

\subsection{Recommendations}

It is clear from the results of this study that RTLB can create and support the development of SENCo positions within schools. This raises the possibility of whether a similar project could be successfully run within a different area. It is important to remember that this project received 
considerable funding through the EPF process which is now no longer available. It also had the backing of the principals from the entire area, assisted by the support of a key principal who acted as the go-between the local Principals Association and the RTLB cluster. It has also been noted that this project was conducted within a region with a low socio-economic status and a high level of need. This in some part helped shape the need for this form of intervention. However, similar initiatives have taken shape recently in neighbouring areas and it would be worthwhile studying their processes and outcomes.

\section{Recommendation 1.}

Additional information is required and similar projects need to be assessed to further inform this field of research.

Furthermore, it would seem that there are major advantages in having SENCo positions within the schools. The data available to management and Board of Trustees has greatly increased by having one person responsible for overseeing the special education needs with the school. It also allows for a more streamlined approach to the processes and data collection in subsequent programmes to support the learning of children with the schools as well as allowing parents a better understanding of what is happening and a say in the process.

While inclusive practice was at the foundation of this initiative, it became sidelined somewhat in this study as the roles and perspectives were explored. It would have been useful to have examined more closely changes in the type of interventions promoted and used by SENCos within these schools to see if there was a significant move towards more inclusive practise. It would also have been interesting to look at the SENCos philosophies and to see if there were any changes in their beliefs over the time of this study.

There is much scope for future research within this area. We are ten years on from the Wiley report however little data exists about the use of SENCos within New Zealand schools. This is coupled with the currently changing face of education within New Zealand and its implications 
for students with special educational needs. There is a need for schools to retain a focus on individual's needs within an environment of increasing comparative assessment.

\section{Recommendation 2.}

Additional research needs to be undertaken to ascertain what happens to practices and beliefs during such a process.

While there are some fairly major limitations to the study and the results gleaned from it, it does seem to be a clear link between the ability of the school to maintain a SENCo position and the school's ability to maintain its processes for students with special educational needs.

The RTLB cluster noted that it made a considerable difference to their work, having one person within the school whom they could contact about students with special educational needs, and one person who was responsible for putting through referrals to their service that they could contact regarding screening the child, gathering additional information and becoming part of the IEP process. The only school within this study which did not achieve this change in perception was one where the SENCo was employed part-time within the school and did not have the time available to work collaboratively within the school to be part of the day to day special needs processes. In all of the other schools in the study the RTLB's found that not only the workload in relation to gathering information about referrals was reduced but also the level of discussion around needs and inclusive practices was enhanced through this project. The RTLB also noted an increase in the number of SENCos that were supporting new colleagues in other schools. (RTLB A, personal communication, September 3, 2010).

\section{Recommendation 3.}

Schools need to consider appointing a full time SENCo to oversee special needs within the school. 
It would be interesting to follow what happens with this group of SENCos in the long term. A longitudinal study of this kind would be able to answer questions about the long term implications and outcomes that may arise. Do the systems put in place lead to more inclusive classroom practices within the region and better outcomes of the students? Is this fledgling community of practice maintained and do the SENCos take up the mantle of change agents within their schools? It would also be worthwhile to look at the other two clusters who have initiated their own versions of this project. Undertaking case studies for schools which create SENCo positions would shed further light on what works and what doesn't at the school level and the outcomes for students with special educational needs.

\subsection{Further research questions}

- Does having a dedicated SENCo positon within a school lead to better outcomes for students?

- Do Boards of Trustees have a comprehensive understanding of the role of SENCos within schools?

- What are the long term outcomes of this project for SENCos?

- What are the long term outcomes of this project for schools?

- What are the long term outcomes of this project for students?

- What models of the SENCo role are operating within New Zealand schools?

6.5

Summary

The 2000 Wylie Report (2000) recommended the use of SENCo positions as an integral part of schools 'special-needs systems'. Wylie recommended that the SENCo, “could work with school staff, Resource Teachers: Learning and Behaviour, and district centre staff to identify individual student's needs, plan programmes, arrange support, professional development and resource materials to support other teachers at the school in their work with special needs” (p.88). The SENCo position was considered as an integral part of the schools special-needs system and 
responsible for overseeing and reporting on: resources, personnel, programmes and equipment provided to students within special education.

The RTLB led project built on the recommendations of the Wylie Report. It created SENCo positions, and generated a programme that enabled them developing knowledge, resources and skills while networking both together and with outside agencies alongside supporting staff within their schools.

This study found that the effects of an RTLB led initiative to create and support the development of SENCo positions within a region of New Zealand provided a positive impact on the regional SENCo service. This was achieved through creating SENCo positions and providing the resources (release time, professional support and role development) which afforded effective systems to support inclusive practices within schools which in turn led to a better service for students with special educational needs within the region.

Given the current climate of educational change within New Zealand this project offers a model of increasing effective inclusive practice through utilizing resources to support the Wiley report suggestion of nurturing SENCo positions within our schools. This study demonstrates that RTLB can assist regional schools in working collaboratively to increase inclusive practice, through the effective use of SENCos within their schools, in order to provide the best outcomes for their students.

The research clearly indicates that further investigation is needed to understand the role of the SENCo within New Zealand schools. Is there a place for SENCos in our post Special Education 2000 schools? Does release time, PD, professional support and role development affect the SENCo role and does a SENCo service impact on the service provided to students with special educational needs? 


\section{References}

Abbott, L. (2007). Northern Ireland Special Educational Needs Coordinators creating inclusive environments: An epic struggle. European Journal of Special Needs Education, 22(4), 391307.

Ainscow, M. (2000). The next step for special education. British Journal of Special Education. 27, (2), 76-80.

Arenas, J., Bleau, J., Eckvahl, S., Gray, H., Hamner, P., \& Powel,K. (2009). Empowering faculty to facilitate distance education. Academic Leadership the Online Journal, 7(1).

Ballard, K. (2003). Inclusion, exclusion, poverty, racism and education : An outline of some present issues. Dunedin: University of Otago.

Barnes, P. (2008). Multi-agency working: What are the perspectives of SENCos and parents regarding its development and implementation? British Journal of Special Education, 35(4), 230-240.

Bay, M., \& Parker-Katz, M. (2009). Perspectives on induction of beginning special educators. Teacher Education and Special Education, 32, 17-32.

Beattie, J., Jordan, L., \& Algozzine, B. (2006). Making inclusion work: Effective practices for ALL teachers. Thousand Oaks, CA: Corwin Press/Sage Publications.

Billett, S. (1998). Ontogeny and participation in communities of practice: A socio-cognitive view of adult development. Studies in the Education of Adults, 30 (1) 21-34.

Bines, H. (2001). A longer road to inclusion. Support for learning, 16(2), 92-93.

Bronfenbrenner, U. (1979). The ecology of human development: Experiments by nature and design. Cambridge, MA: Harvard University Press.

Brown, Thomson, Anderson, Moore, Walker, Glynn, Macfarlane, Medcalf \& Ysseldyke. (2000). Resource teachers learning and behaviour: An ecological approach to special education. Australasian Journal of Special Education. 24 (1), 5-20.

Brown, C. \& Wills, R. (2000). Special Education 2000 - Getting it right together? Paper presented to International Special Education Congress, Manchester, 2000, 24-28 July.

Burstein, N., Sears, S., Wilcoxen, A., Cabello, B., \& Spagna, M. (2004). Moving toward inclusive practices. Remedial and Special Education, 25(2), 104-116. 
Campbell, M. (2010). A framework for analysis of learning in professional settings.Providing a competitive advantage; Proceedings on the 13th Annual NZACE Conference. Palmerston North

Campbell, D., \& Fiske, D. (1959). Convergent and discriminent validation by the multitratmultimethod matrix. Psychological Bulletin, 56, 81-105.

Cassell, C., Symon, G. (1994) Qualitative research in work contexts, In C. Cassell, and G.

Creswell, J. (1994). Research design: Qualitative and quantitative approaches. Thousand Oaks, CA: Sage.

Cole, C.(2002). The academic progress of students across inclusive and traditional settings. ISEAS Cable, 23(4).

Cole, B.A. and Johnson, M. (2004) SENCOs and the revised code of practice' Unpublished paper, The University of Sheffield and Keele University.

Cole, B. (2005). Mission impossible. Special education needs, inclusion and the reconceptualization of the role of the SENCO in England and Wales. European Journal of Special Needs Education, 20(3), 287-307.

Colver, A \& Robinson, A. (1989). Establishing a register of children with special needs. Archives of Disease in Childhood, 64, 1200-1203.

Coolican H (1999). Research methods and statistics in psychology (3rd Ed). London: Hodder and Stoughton Educational.

Crowne, E. (2003). The SENCO handbook working within a Whole-School Approach. London : David Fulton Publishers.

Crowne, E. (2005). What do special educational needs coordinators think they do? Support for Learning, 20(2), 61-68.

Creswell, J. W. (1994). Research design: Qualitative and quantitative approaches. Thousand Oaks, CA: Sage.

Creswell, J., \& Clark, V. P. (2007). Designing and conducting mixed methods research. London: SAGE Publications.

Daniels, H. \& Garner, P. (Eds) . (1999). Inclusive education: supporting inclusion in education systems. London:. Kogan Page Limited:

Darling-Hammond, L. (2003). Wanted: A national teacher supply policy for education: The right way to meet the "highly qualified teacher”. Education Policy Analysis Archives, 11(3). 
Department of Education (1987). Draft review of special education. Wellington: Government Printer.

Department of Education. (1988). Administering for excellence. Effective administration in education (The Picot Report). Wellington: Government Printer.

Department for Education and Skills (DfES) (2003). Making a difference: A guide for special educational needs. London:DfES..

Deschenes, S., Cuban, L., \& Tyack, D. (2001). Mismatch: Historical perspectives on schools and students who don't fit them. Teachers College Record, 103(4), 825-547.

Dey, I. 1993 Qualitative Data Analysis:A User-friendly Guide for Social Scientists. New York: Routledge.

Education Counts. (n.d.). Special Education (EEPSE) Pilot study findings. Retrieved from http://www.educationcounts.govt.nz/publications/special_education/eepse_pilot_study_find ings.

Farmer \& J.W. Rojewski (Eds.) (2001). Research pathways: Writing professional papers, theses, and dissertations in academic and technical education (pp. 223-245). Lanham, MD: University Press of America.

Feagin, J., Orum, A., \& Sjoberg, G. (Eds.), (1991). A case for case study. Chapel Hill, NC : University of North Carolina Press.

Fielding, N., \& Fielding, J. (1986). Linking data. Articulation of qualitative and quantitative methods in social research. California: SAGE.

Fine, M., \& Asch, A. (Eds). (1988). Women with disabilities: Essays in psychology, culture, and politics. Philadelphia, PA: Temple University Press.

Frankfort-Nachmias, C., \& Nachmias, D. (1992). Research methods in the social sciences (4th ed.). New York: St. Martin's Press.

Fryer, D. (1991). Qualitative methods in occupational psychology: Reflections upon why they are so useful but so little used. The Occupational Psychologist, 4 (Special issue on qualitative methods), 3-6.

Fuller, A, Hodkinson, H., Hodkinson, P. and Unwin, L. (2005) Learning as peripheral participation in communities of practice: a reassessment of key concepts in workplace learning, British Educational Research Journal, 31, (1), 49-68. 
Gable, R. A., Korinek, L., \& McLaughlin, V. (1997). Collaboration in the schools: Ensuring success. In J. Choate (Ed.., Successful inclusive teaching (2nd ed.) (pp.450-471). Boston: Allyn \& Bacon.

Gartner, A., \& Lipsky, D. (1987). Beyond special education: Toward a quality system for all students. Harvard Educational Review, 57(4), 367-395.

Gartner, A. \& Lipsky, D.K. (1992). Breaking the yoke of special education. National Learning Differences Network Newsletter and reprinted in The Special Edge. 7(1), September/October 1992. Sacramento, California: California Department of Education. Gerber R 1998. How do workers learn in their work? The Learning Organisation, 5:168175.

Gibbs, G. (2002). Qualitative Data Analysis: Explorations with NVivo, Buckingham:Open University Press.

Glynn, T. (1998). A collaborative approach to teacher development: New initiatives in special education. In T. Glynn (Chair). Developing and delivering a national support initiative for learning and behaviour: Politics, partners, players and payers. Symposium conducted at the Australian Teacher Education Association Twenty-eighth Annual Conference, Melbourne, Australia.

Glesne, C., \& Peshkin, A. (1992). Becoming qualitative researchers: An introduction. White Plains, NY: Longman.

Guskey, Thomas R. "Does it Make a Difference? Evaluating Professional Development." Educational Leadership v. 59, no. 6 (Mar. 2002) p. 45-51.

Greaves, A. (2003). Special Education 2000: Rhetoric or reform? ACE Papers, 5(12).

Guzmán N, (1997). Leadership for successful inclusive schools: A study of principal behaviours. Journal of Educational Administration. 35(5), 439 - 450.

Hall, J., (1997). Social devaluation and special education. Jessica Kingsley Publishers: London.

Hamel, J., Dufour, S., \& Fortin, D. (1993). Case study methods. Newbury Park, CA: Sage Publications.

Harré, R. (1997). He lived to tell the tale. Journal of Narrative and Life History, 7 (1-4), 331-334.

Haskell, E.H. (2001). Transfer of learning: Cognition, instruction, and reasoning. New York: Academic Press.

Huberman, M. (1993). The lives of teachers. New York: Teachers College Press. 
Hunt, A.(2000). The Lost Years: From Levin Farm Mental Deficiency Colony to Kimberly Centre, Levin. Mangere Hospital and Training School Jubilee Organising Team, Mangere Hospital and Training School Twenty-five years, 1963-1988, Auckland, 1988

Hutchinson, N. (2001). Inclusion of exceptional learners in canadian schools: A practical handbook for teachers. Toronto: Prentice Hall.

Karagiannis, A., Stainback, S., \& Stainback, W. (1996). Historical overview of inclusion. In S. Stainback \& W. Stainback (Eds.), Inclusion: A guide for educators (17-28). Baltimore: Brookes.

Karten, T. J. (2005). Inclusion strategies that work! Research-based methods for the classroom. Thousand Oaks, CA: Corwin Press.

Kearney, A., \& Poskitt, J. (2001). Special Education 2000 professional development: A catalyst for change? New Zealand Principal, 16(1), 18-20.

Ki Te Aoturoa. (n.d). Inquiry-based practice. Retrieved on 20 January 2010 from http://instep.net.nz/inquiry_and_evidence_based_practice/inquiry_based_practice

Korthagen, F\& Kessels, J. (1999). Linking theory and practice: changing the pedagogy of teacher education. Educational Researcher, 28(4), 4-17.

Kugelmass, J. (2004). The inclusive school: sustaining equity and standards. New York: Teachers College Press.

Lave, J., \& Wenger, E. (1998). Communities of practice: learning, meaning, and identity. England: Cambridge University Press.

Layton, L. (2005). Special education needs coordinators and leadership: a role too far? Support for Learning, 20(2), 53-60.

Liberty, K. (2009). Reforming Learning for Children with Learning Differences in New Zealand. In Reforming Learning Concepts, Issues and Practice in the Asia-Pacific Region (Eds) Chihung Ng and Peter D. Renshaw. Netherlands : Springer.

Lincoln, YS. \& Guba, EG. (1985). Naturalistic Inquiry. Newbury Park, CA: Sage Publications.

Lindsay, J. (2003). Inclusive education: a critical perspective. British Journal of Special Education, 30(1), 3-12.

Lipsky, D.K. \& Gartner, A (1992). Achieving full inclusion: Placing the student at the center of educational reform. In W. Stainback \& S. Stainback (Eds.), Controversial Issues Confronting Special Education. New York: Allyn and Bacon. 
Lipsky, D.K. \& Gartner, A. (1997). Inclusion and school reform: transforming America's classrooms. Brookes: Baltimore.

Luster, J. \& Ouder,C. (1994). Special Educators' Language: Do we understand each other? A paper presented at the Annual Meeting of the Mid-South Educational Research Association. Nashville. TN. November 10, 1994.

MacArthur, J., Kelly, B., Higgins, N., Phillips, H., McDonald, T., Morton, M. \& Jackman, S. (2005). Draft Building Capacity in Education for Students with Moderate and High Needs. Dunedin: Donald Beasley Institute.

McAlpine, D. (1999). Meeting the needs of students on the margin. Address to Special Education 2000 Research Conference, Auckland.

McDonald, L. (2009). Teacher change: A dynamic interactive approach. International Journal of Learning, 6 (10), 623-636.

Macdonald, L. \& Melchior, L. (2007). Investing in transfer of learning: Dancing the talk. New Zealand Annual Review of Education: Te arotake a tau o tea o o te maturanga i Aotearoa 17:2007 73-91.Wellington: School of Education Studies, Victoria University of Wellington.

Maharey,S. (2006). Launch of the new draft curriculum. Speech notes for the "Launch of the New Draft Curriculum" at Karori Normal School, Wellington retrieved 18 November 2009 from http://www.beehive.govt.nz/node/26639

Mertens, D.M. (2005). Research methods in education and psychology: Integrating diversity with quantitative and qualitative approaches. (2nd ed.) Thousand Oaks: Sage.

Myers, D. G. (2009)._Exploring Social Psychology (5th ed.). New York: McGraw-Hill.

Miller, F. A. \& Katz, J. H. (2002). The Inclusion Breakthrough: Unleashing the Real Power of Diversity. San Francisco: Berrett-Koehler Publishers

Miles, M.B. \& Huberman, A.M. (1994) Qualitative data analysis: an expanded sourcebook. London: Sage.

Ministry of Education. (1991) Special education in New Zealand: Statement of intent. Wellington: Ministry of Education.

Ministry of Education , (2004). EEPSE Pilot Study Findings. Retrieved 21 October 2009 from http://educationccounts.govt.nz/publications/special_education/eepse_pilot_study_findings 
Ministry of Education (1995). Special education policy guidelines. Wellington: Ministry of Education.

Ministry of Education (1996). Special education 2000. Wellington: Ministry of Education. Ministry of Education (n.d). Retrieved April 3. 2009 from http://www.minedu.govt.nz/NZEducation/EducationPolicies/Schools/PolicyAndStrategy/Pl anningReportingRelevantLegislationNEGSAndNAGS/TheNationalEducationGoalsNEGs.a spx).

Ministry of Social Development. (2003). The New Zealand Disability Strategy retrieved 15 April 2010 from http://www.odi.govt.nz/resources/publications/nzds/index.htm

Ministry of Education. (2007). RTLB Policy and Toolkit. Retrieved April 3, 2009 from http://www.tki.org.nz/r/governance/rtlb/policy_e.php

Mitchell, D. \& Mitchell, J. (1985). Out of the shadows: A chronology of significant events in the development of services for exceptional children and young persons in New Zealand: 1850 - 1983. Wellington: Department of Education.

Mitchell, D. (1999) Special education in New Zealand : A decade of change. In, M. Thrupp (Ed.). A decade of reform in New Zealand Education : Where to now? (Pp199 - 210). Hamilton: School of Education, University of Waikato, Hamilton, NZ

Moore, D., Anderson, A., Timperley, H., \& Glynn, T. (1999). Caught between stories: Special education in New Zealand. Wellington: NZCER.

Moran, A. (2007). Embracing inclusive teacher education. European Journal of Teacher Education 30(2), 119-133.

Morgan, G,\& Smircich, L. 1980. The case for qualitative research. Academy of Management Review, 5, 491-500.

Morse, J. M. (2003). Principles of mixed methods and multimethod research designs. In A. Tashakkori \& C.Teddlie (Eds.) Handbook of mixed methods in social \& behavioral research (pp. 189-208). Thousand Oaks, CA: Sage Publications.

Morris, J. (1991). Pride against prejudice: Transforming attitudes to disability. Philadelphia: New Society Press.

Myers, D. G. (2009). Exploring social psychology (5th ed.). New York: McGraw-Hill

Namey E, Guest G, Thairu L, Johnson L, (2007). Data reduction techniques for large qualitative data sets in Handbook for Team-based Qualitative Research. Guest and MacQueen (eds.). Lanham, MD: AltaMira Press 
Nirje, B. (1976). The normalisation principle and its human management implications. In R. J. Flynn \& K.E Nitch. Normalisation, Social Integration and Community Services. Baltimore, MD: University Park Press

Norwich, B. \& Lewis, A. (2001). A critical review of evidence concerning teaching strategies for pupils with special educational needs. British Educational Research Journal, 27(3), 313329.

NZCER. (n.d.). SENCo newsletter retrieved from http://www.nzcer.org.nz/pdfs/csbkgrnd.pdf National Union of Teachers (NUT). (n.d). Special educational needs co-ordinators qualified teacher status - guidance to divisions retrieved from http://www.nut.org.uk/search/node/(SENCO)

OECD (2003), Students with Disabilities, Difficulties and Disadvantages, Statistics and Indicators for Curriculum Access and Equity, Paris: OECD

Oliver, P. (2003) The student's guide to research ethics. Open University Press: Maidenhead. Parmar, A. (2003). Ocean in a drop of water: Empowerment, water and women. Canadian Woman Studies, 23(1), 124-128.

Patton, M.Q.(1990). Qualitative evaluation and research methods. London: SAGE Publications. Pearson, S. (2008). Deafened by silence or by the sound of footsteps? An investigation of the recruitment, induction and retention of special education needs coordinators (SENCOs) in England. Journal of Research in Special Educational Needs, 8(2), 96-110.

Polgar S. and Thomas S.A. (1995) Introduction to Research in the Health Sciences. London. Churchill Livingstone

Pyecha, J. (1988). A case study of the application of noncategorical special education in two states. Chapel Hill, NC: Research Triangle Institute.

Ryan, G., \& R. Bernard (2000). Data management and analysis methods. In Norman Denzin and Yvonna Lincoln, eds. Handbook of Qualitative Research. Pp. 769-802. Thousand Oaks, Calif.: Sage.

Reschly, D., \& Ysseldyke, J. E. (2002). Paradigm shift: The past is not the future. In A. Thomas \& J. Grimes (Eds.), Best practices in school psychology IV (pp. 3-20). Bethesda, MD: National Association of School Psychologists.

Schwandt, T. A. (1994). Constructivist, interpretivist approaches to human inquiry. In N. K. Denzin \& Y. S. Lincoln (Eds.), Handbook of qualitative research (pp. 118-137). Thousand Oaks, CA: Sage. 
Spillane, J. (2002). Local theories of teacher change: The Pedagogy of District Policies and Programs. Symon (Eds.), Qualitative methods in organizational research (p.p.1-13), Thousand Oaks, CA: Sage Publications.

Teachers College Record. 104 (3).

Skerrett, A. (2008). Racializing educational change: Melting pot and mosaic influences on educational policy and practice. Journal of Educational Change, 9(3).

Skrtic, T. (1991). Behind Special Education. New York: Love Pub Co.

Smith M.J. (1988). Contemporary communication research methods. Belmont, CA: Wadsworth, Inc.

Stainback, W., Stainback, S., \& Bunch, G. (1989). Introduction and historical background. In S. Stainback, W. Stainback, \& M. Forest (Eds.). Educating all students in the mainstream of regular education (3-13). Baltimore : Paul H. Brookes.

Szwed, C. (2007). Managing from the middle? Tensions and dilemmas in the role of the primary school special educational needs coordinator. School Leadership and Management, 27(5), 337-351.

Tashakkori, A., \& Teddlie, C. (2003). Handbook of mixed methods in social and behavioural research. London Cassell. types and software tools. NewYork: Falmer Press,

Tellis, W. (1997). Introduction to case study. The qualitative report, 3(2).

Tennant, G. (2007). IEPs in mainstream secondary schools: An agenda for research. Support for Learning, 22(3), 203-208.

Thorndike, R. (1997). Measurement and evaluation in psychology and education (6 ${ }^{\text {th }}$ ed.). Upper addle River, NJ: Prentice-Hall.

Tilly W. D. III. (2002). Best practices in school psychology as a problem-solving enterprise. In

A. Thomas \& J. Grimes (Eds.) Best practices in school psychology ,4th ed.(21-36).

Bethesda, MD: National Association of School Psychologists.

Timperley, H., Wilson, A., Barrar, H., \& Fung, I. (2007). Teacher professional development and learning: Best evidence synthesis iteration (BES). Wellington : Ministry of Education.

Trochim, W. (2005). Research methods: The concise knowledge base. Cincinnati, OH: Atomic Dog Publishers.

Victoria University. (n.d.). Human ethics policy. Retrieved 11 April 2009 from http://policy.vuw.ac.nz/Amphora! policy.vuw.ac.nz POLICY 000000000744.pdf 
Villegas-Reimers, E. 2003. Teacher Professional Development: An International Review of the Literature. Paris: UNESCO, International Institute for Educational Planning.

Wedell, K. (2001). Points from the SENCo-forum. British Journal of Special Education, 28(2), 98.

Wedell, K. (2008). Dilemmas in the quest for inclusion. British Journal of Special Education, 32(1), 3-11.

Wenger, E. (1998). Communities of practice: Learning, meaning, and identity. Cambridge, UK: Cambridge University Press.

Wenger, E., McDermott, R., and Snyder,W. (2002). Cultivating communities of practice: A guide to managing knowledge. Boston: MA: Harvard Business School Press.

Wylie, C. (2000). Picking up the pieces: Review of special education 2000. Wellington: NZCER

Yin, R. (1993). Applications of case study research. Beverly Hills, CA: Sage Publishing.

Yin, R. (1994). Case study research: Design and methods (2nd ed.). Beverly Hills, CA: Sage Publishing. 


\section{Appendices}

\section{Appendix A}

\section{Ethical Approval}

$25^{\text {th }}$ August 2009

Lisa Collinson

MEd Student

Victoria University of Wellington Faculty of Education

C/- School of Educational Psychology and Pedagogy

Donald Street

Wellington

\section{Dear Lisa}

RE: Ethics application SEPP/2009/29: RM 16643

I am pleased to advise you that your ethics application 'A mixed method study on the effects of a systems level intervention, that provides a wrap around senco service to all of the state schools in the w with the requested amendments, has been approved by the Victoria University of Wellington Faculty of Education Ethics Committee. Please note that the approval for your research to commence is from the date of this letter.

Good luck with your research.

Yours Sincerely

Dr Sue Cornforth

Co-Convener

Victoria University of Wellington Faculty of Education Ethics Committee 


\section{Appendix B}

\section{Participant Information and consent form}

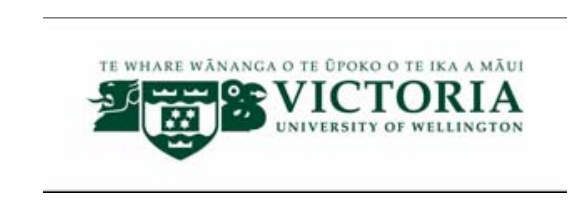

PRINCIPAL INFORMATION SHEET

\section{Participant Information Sheet for a mixed method study on the developing role of the Special Education Needs Coordinator.}

\section{Researcher:}

Lisa Collinson: School of School of Educational Psychology and Pedagogy, Victoria University of Wellington.

\section{Supervisors:}

Lex McDonald - Head of School of Educational Psychology and Pedagogy and Liz Manins - Academic Staff.

I am a Masters student in Education at Victoria University of Wellington. As part of this degree I am undertaking a research project leading to a thesis. The project I am undertaking is examining the effects of a systems level intervention, that provides a wrap around SENCO service to all of the state schools in the The University requires that ethics approval be obtained for research involving human participants and this study has ethics approval from the Victoria University College of Education Ethics Committee.

The purpose of this study is to investigate the systems level intervention through EPF (enhancing programming funding) to improve the SENCO (special education needs coordinator) service 
(outcomes for students) within the region through RTLB (Resource teacher of Learning and Behaviour) collaboratively supporting SENCO’s work. This intervention includes: assisting in setting up special needs committees, gaining release time for SENCO's, negotiating and arranging professional development, providing a reporting system for SENCO's, developing interagency collaboration and fostering support networks among the SENCO's. As well as this an indepth case study of two of the schools represented within this programme will be undertaken.

Special Education 2000 brought a great change in the delivery of special education in New Zealand. It encouraged the use of SENCOs in schools, but did not provide resources or training for these positions. As you are aware within the $ـ$ all of the schools have become part of an RTLB led EPF programme to provide a wrap around service for training and developing SENCOs ability to be effective and therefore improve outcomes for students. The outcomes of this programme would provide useful information to Schools about how best to effectively support special education.

This study will involve your SENCO being interviewed in his/her role of SENCO on a maximum of three occassions for no more than forty-five minutes each. If your school is selected to be part of the case study I will need access through your SENCO to your special needs register data, this should take no longer than two hours over the course of the study. Up to six families will be selected from each of the two case study schools and consent will be obtained from them to be involved in the study. These families will be requested to complete a questionaire and to be interviewed once for no more than forty-five minutes. Any other data obatined from school's special needs register will not include individual names or identifying data. I will also access any data collected by the project subject to informed consent.

Should any participants feel the need to withdraw from the project, they may do so without question at any time (before data collection and analysis is complete) by contacting either myself or either of my supervisors.

Information collected will form the basis of my research project and will be put into a written report on an anonymous basis. It will not be possible for you to be identified personally or for the 
school to be identified. All material collected will be kept confidential. No other person besides my supervisors (Liz Manins and Lex McDoanld) and myself will see the raw data. The thesis will be submitted for marking to the School of Educational Psychology and Pedagogy and deposited in the University Library. It is intended that one or more articles will be submitted for publication in scholarly journals. The completed thesis will be available on an electronic repository.

If you have any questions or would like to receive further information about the project, please contact me at 06) 3686639 or either of my supervisors, Liz Manins or Lex McDonald, at the School of Educational Psychology and Pedagogy at Victoria University, P O Box 600, Wellington, phone 04-463 9500.

\section{$\underline{\text { Lisa Collinson }}$}




\section{te Whare Wananga o te Opoko o te iKa a mãu

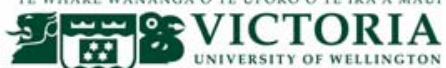 \\ a. University of wellington \\ PRINCIPAL CONSENT TO PARTICIPATE IN RESEARCH}

Title of project: A mixed method study on the effects of a systems level intervention, that provides a wrap around SENCO service to all of the state schools in the

I have been given and have understood an explanation of this research project. I have had an opportunity to ask questions and have them answered to my satisfaction. I understand that I may withdraw myself (or any information I have provided) from this project (before data collection and analysis is complete) without having to give any reasons.

I understand that any information I provide will be kept confidential to the researcher and the supervisors, the published results will not use my name or the name of my school, and that no opinions will be attributed to me in any way that will identify me or my school. I understand that any tape recording of interviews will be electronically wiped at the end of the project unless I indicate that I would like them returned to me.

I would like any tape recordings of my interview returned to me at the conclusion of the project. YES/NO

I understand that I will have an opportunity to check the transcripts of the interview before publication.

I understand that the data I provide will not be used for any other purpose or released to others.

I would like to receive a summary of the results of this research when it is completed. YES /NO

I agree to take part in this research

signed:

Date:

Print name of participant (please print clearly) 


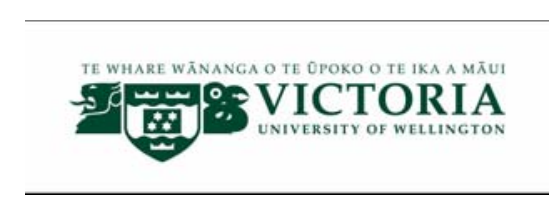

\section{SENCO INFORMATION SHEET}

\section{Participant Information Sheet for a mixed method study on the developing role of the Special Education Needs Coordinator.}

\section{Researcher:}

Lisa Collinson: School of School of Educational Psychology and Pedagogy, Victoria University of Wellington.

\section{Supervisors:}

Lex McDonald - Head of School of Educational Psychology and Pedagogy and Liz Manins - Academic Staff.

I am a Masters student in Education at Victoria University of Wellington. As part of this degree I am undertaking a research project leading to a thesis. The project I am undertaking is examining the effects of a systems level intervention, that provides a wrap around SENCO service to all of the state schools in the . The University requires that ethics approval be obtained for research involving human participants and this study has ethics approval from the Victoria University College of Education Ethics Committee.

The purpose of this study is to investigate the systems level intervention through EPF (enhancing programming funding) to improve the SENCO (special education needs coordinator) service (outcomes for students) within the region through RTLB (Resource teacher of Learning and Behaviour) collaboratively supporting SENCO's work. This intervention includes: assisting in setting up special needs committees, gaining release time for SENCO's, negotiating and arranging professional development, providing a reporting system for SENCO's, developing interagency collaboration and fostering support networks among the SENCO’s. As well as this an indepth case study of two of the schools represented within this programme will be undertaken. 
This will involve you being interviewed in your role of SENCO on a maximum of three occassions for no more than forty-five minutes each. If your school is selected to be part of the case study I will need access through you to your special needs register data, this should take no longer than two hours over the course of the study.

Should any participants feel the need to withdraw from the project, they may do so without question at any time (before data collection and analysis is complete) by contacting either myself or either of my supervisors.

Information collected will form the basis of my research project and will be put into a written report on an anonymous basis. It will not be possible for you to be identified personally. All material collected will be kept confidential. No other person besides my supervisors (Liz Manins and Lex McDoanld) and myself will see the raw data. The thesis will be submitted for marking to the School of Educational Psychology and Pedagogy and deposited in the University Library. It is intended that one or more articles will be submitted for publication in scholarly journals. The completed thesis will be available on an electronic repository.

If you have any questions or would like to receive further information about the project, please contact me at 06) 3686639 or my supervisor, Liz Manins, at the School of Educational Psychology and Pedagogy at Victoria University, P O Box 600, Wellington, phone 04-463 9500.

\section{$\underline{\text { Lisa Collinson }}$}




\section{TE WHARE WÃNANGA OTE OPOKO O TE IKA A MÃUI \\ 5 菌国 VICTORIA \\ 20. University of Wellington \\ SENCO CONSENT TO PARTICIPATE IN RESEARCH}

Title of project: A mixed method study on the effects of a systems level intervention, that provides a wrap around SENCO service to all of the state schools in the

I have been given and have understood an explanation of this research project. I have had an opportunity to ask questions and have them answered to my satisfaction. I understand that I may withdraw myself (or any information I have provided) from this project (before data collection and analysis is complete) without having to give any reasons.

I understand that any information I provide will be kept confidential to the researcher and the supervisor, the published results will not use my name, and that no opinions will be attributed to me in any way that will identify me. I understand that any tape recording of interviews will be electronically wiped at the end of the project unless I indicate that I would like them returned to me.

I would like any tape recordings of my interview returned to me at the conclusion of the project. YES/NO

I understand that I will have an opportunity to check the transcripts of the interview before publication.

I understand that the data I provide will not be used for any other purpose or released to others.

I would like to receive a summary of the results of this research when it is completed. YES /NO

I agree to take part in this research

signed:

Date:

Print name of participant (please print clearly) 


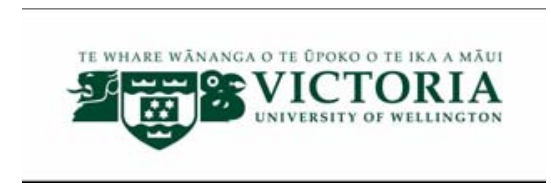

RTLB INFORMATION SHEET

\section{Participant Information Sheet for a mixed method study on the developing role of the Special Education Needs Coordinator.}

\section{Researcher:}

Lisa Collinson: School of Educational Psychology and Pedagogy, Victoria University of Wellington.

\section{Supervisors:}

Lex McDonald - Head of School of Educational Psychology and Pedagogy and Liz Manins - Academic Staff.

I am a Masters student in Education at Victoria University of Wellington. As part of this degree I am undertaking a research project leading to a thesis. The project I am undertaking is examining the effects of your systems level intervention, that provides a wrap around SENCO service to all of the state schools in the . The University requires that ethics approval be obtained for research involving human participants and this study has ethics approval from the Victoria University College of Education Ethics Committee.

The purpose of this study is to investigate the systems level intervention through EPF (enhancing programming funding) to improve the SENCO (special education needs coordinator) service (outcomes for students) within the region through RTLB (Resource teacher of Learning and Behaviour) collaboratively supporting SENCO's work. This intervention includes: assisting in setting up special needs committees, gaining release time for SENCO's, negotiating and arranging professional development, providing a reporting system for SENCO's, developing 
interagency collaboration and fostering support networks among the SENCO's. As well as this an indepth case study of two of the schools represented within this programme will be undertaken.

This will involve you being interviewed on a maximum of three occassions for no more than forty-five minutes each. I would also like to accept your offer to attend the steering committee meetings for this project. I will also need to access (subject to consent from those involved) the data collected by you during the study.

Should any participants feel the need to withdraw from the project, they may do so without question at any time (before data collection and analysis is complete) by contacting either myself or either of my supervisors.

Information collected will form the basis of my research project and will be put into a written report on an anonymous basis. It will not be possible for you to be identified personally. All material collected will be kept confidential. No other person besides my supervisors (Liz Manins and Lex McDoanld) and myself will see the raw data. The thesis will be submitted for marking to the School of Educational Psychology and Pedagogy and deposited in the University Library. It is intended that one or more articles will be submitted for publication in scholarly journals. The completed thesis will be available on an electronic repository.

If you have any questions or would like to receive further information about the project, please contact me at 06) 3686639 or my supervisor, Liz Manins, at the School of Educational Psychology and Pedagogy at Victoria University, P O Box 600, Wellington, phone 04-463 9500.

\section{$\underline{\text { Lisa Collinson }}$}




\section{TE WHARE WÃNANGA OTE OPOKO O TE IKA A MÃUI \\ 5 菌国 VICTORIA \\ 20. University of Wellington \\ SENCO CONSENT TO PARTICIPATE IN RESEARCH}

Title of project: A mixed method study on the effects of a systems level intervention, that provides a wrap around SENCO service to all of the state schools in the

I have been given and have understood an explanation of this research project. I have had an opportunity to ask questions and have them answered to my satisfaction. I understand that I may withdraw myself (or any information I have provided) from this project (before data collection and analysis is complete) without having to give any reasons.

I understand that any information I provide will be kept confidential to the researcher and the supervisor, the published results will not use my name, and that no opinions will be attributed to me in any way that will identify me. I understand that any tape recording of interviews will be electronically wiped at the end of the project unless I indicate that I would like them returned to me.

I would like any tape recordings of my interview returned to me at the conclusion of the project. YES/NO

I understand that I will have an opportunity to check the transcripts of the interview before publication.

I understand that the data I provide will not be used for any other purpose or released to others.

I would like to receive a summary of the results of this research when it is completed. YES /NO

I agree to take part in this research

signed:

Date:

Print name of participant (please print clearly) 


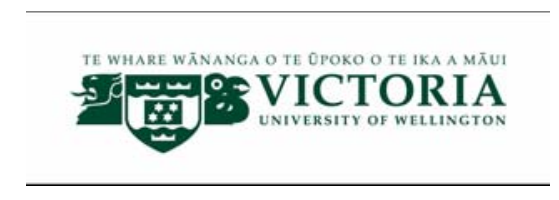

PARENTAL INFORMATION SHEET

Participant Information Sheet for a mixed method study on the developing role of the
Special Education Needs Coordinator.

\section{Researcher:}

Lisa Collinson: School of School of Educational Psychology and Pedagogy, Victoria University of Wellington.

\section{Supervisors:}

Lex McDonald - Head of School of Educational Psychology and Pedagogy and Liz Manins - Academic Staff.

I am a Masters student in Education at Victoria University of Wellington. As part of this degree I am undertaking a research project leading to a thesis. The project I am undertaking is examining the effects of a systems level intervention, that provides a wrap around SENCO service to all of the state schools in the . The University requires that ethics approval be obtained for research involving human participants and this study has ethics approval from the Victoria University College of Education Ethics Committee.

The purpose of this study is to investigate the special education needs coordinator service within the region.

As part of this study two case studies will be undertaken within two schools in the region. Your child's school has been selected a s one of these schools and we would like to invite you to be part of this study. It will involve you completing a questionaire and being interviewed once (for 
no more than forty-five minutes). It will also involve data ragarding your child being accessed through the schools special needs register.

Should any participants feel the need to withdraw from the project, they may do so without question at any time (before data collection and analysis is complete) by contacting either myself or either of my supervisors.

Information collected will form the basis of my research project and will be put into a written report on an anonymous basis. It will not be possible for you to be identified personally. All material collected will be kept confidential. No other person besides my supervisors (Liz Manins and Lex McDoanld) and myself will see the raw data. The thesis will be submitted for marking to the School of Educational Psychology and Pedagogy and deposited in the University Library. It is intended that one or more articles will be submitted for publication in scholarly journals. The completed thesis will be available on an electronic repository.

If you have any questions or would like to receive further information about the project, please contact me at 06) 3686639 or either of my supervisors, Liz Manins or Lex McDonald, at the School of Educational Psychology and Pedagogy at Victoria University, P O Box 600, Wellington, phone 04-4639500.

\section{$\underline{\text { Lisa Collinson }}$}




\section{te whare Wananga o te Opoko o te iKa a mãuI \\ 5 T) \\ Le vniversity of wellington \\ PARENTAL CONSENT TO PARTICIPATE IN RESEARCH}

Title of project: A mixed method study on the effects of a systems level intervention, that provides a wrap around SENCO service to all of the state schools in the

I have been given and have understood an explanation of this research project. I have had an opportunity to ask questions and have them answered to my satisfaction. I understand that I may withdraw myself (or any information I have provided) from this project (before data collection and analysis is complete) without having to give any reasons.

I understand that any information I provide will be kept confidential to the researcher and the supervisors, the published results will not use my name, and that no opinions will be attributed to me in any way that will identify me. I understand that any tape recording of interviews will be electronically wiped at the end of the project unless I indicate that I would like them returned to me.

I understand that consent is sort for data to be collected from the school's special needs register regarding my

child for whom I have guardianship.

I would like any tape recordings of my interview returned to me at the conclusion of the project. YES/NO

I understand that I will have an opportunity to check the transcripts of the interview before publication.

I understand that the data I provide will not be used for any other purpose or released to others.

I would like to receive a summary of the results of this research when it is completed. YES /NO

I agree to take part in this research

signed:

Date:

Print name of participant (please print clearly) 


\section{Appendix C}

\section{Interview questions}

\section{CONFIDENTIAL}

\section{SENCO cluster project interview}

The purpose of this interview is to get a baseline measurment of the present situation with SENCOs in the We will repeat the interview at the end of the project. The data from all the nineteen completed interviews will be complied into one report that will be used to measure any change that takes place as a result of this project.

\section{We will not identify any schools or SENCOs from the individual survey or within any report produced as a result of the survey.}

It is important that it doesn't take anymore than 10-15 minutes to complete the interview. We ant to find out what you can tell us without particular reference to other staff, policies or records.

\section{QUESTIONS:}

1. Do you have release time to do the job or SENCO?

YES / NO

If yes, how many hours per week are you released for?

2. How is any release time funded? (ex. SEG, satffing, bulk grnat etc) comment

3. What other positions do you hold within the school? comment

4. In the SENCO position what data do you record for the school regarding students with special needs? 
comment

5. How are students identified for special needs support? YES / NO comment

6. Are there set criteria for students referred to SENCO? YES / NO comment

7. Are students requiring extention recorded on your special needs register?YES / NO

8. Is there a special needs committee in place? YES / NO If yes, who is on the committee (job positions)

Comment

9. What professional development have you had access to regarding the SENCO position? comment

10. How would you define your role as SENCO?

comment

11. Do you have a SENCO job description? YES / NO

12. How would you like to see your SENCO role developed? comment

13. What skills and knowledge would you like to develop to assist with your SENCO role?

comment

14. Which agencies in the community have you been involved with as a SENCO? comment 
15. Are there any SENCOs that you meet with to discuss your role/students?YES / NO comment

Do you give permission for the infomration from this interview to be used in the data gathering process for a Masters thesis that will study the effect of this project? YES / NO

Thank you for participating in this interview.

\title{
Lisa Collinson
}

RTLB

\author{
Interview date \\ Interview time \\ Interview Place \\ SENCO name \\ School \\ Interviewer
}




\section{CONFIDENTIAL}

SENCO cluster project parent questionaire

We will not identify any schools, students or school staff from the individual survey or within any report produced as a result of the survey.

It is important that it doesn't take anymore than 10-15 minutes to complete the interview.

\section{QUESTIONS:}

1. How many schools has your child attended?

2. Have they been on a special needs register at all schools attened?

3. How old was your child when placed on a special needs register?

4. Why was your child placed on the special needs register?

5. Do you know what SENCO stands for?

6. Who do you contact at the school about you child's special needs?

7. What things have been done by the school to help your child?

8. What could the school do that you would find helpful?

Thank you for participating in this interview.

\section{Lisa Collinson}

Interview date

RTLB

Interview time

Interview Place

Parent name

School 


\section{Appendix D}

\section{Outline of the professional development days}

The eight professional development day outlines.

\section{SENCO Professional Development Day 1}

Introductory day

This was an introductory day, where the main aim was to allow the SENCos a chance to meet each other in a non-threatening way that set the tone for the entire programme. It commenced with muffins and coffee with an opportunity for the SENCos to mix and talk. Then the structured programme began with an experienced \& an inexperienced SENCO both doing a presentation on their roles and challenges. The plan was to affirm the newly appointed SENCos who may have been concerned about working alongside some very experienced SENCOs while also showing good practice at both the beginning and experienced level. The local Resource Teacher of Literacy (RT:Lit) attended and the school principals were involved for an hour. 


\section{SENCO Professional Development Day 2}

\section{POLICY AND PROCEEDURE}

Policy \& Procedure with assistance from Carolyn Grace, MoE.

Special Education in the New Zealand Education Context

Special Education Defined

Education Policy

Vision of Special Education 2000

Key Components of SE 2000 Resourcing Framework

Moderate Needs Initiatives

New Zealand Disability Strategy (2001)

Special Education Today

Funding Proportion

The National Administration Guidelines are statements for school administration of desirable principles of conduct or administration.

Special Needs Register

Role of the SENCO

Three components: Managing task, Documenting tasks \& Teaching tasks

Why a systematic Approach?

\section{SENCO Professional Development Day 3}

Social work agencies available in the with an introduction from Jayne Cameron, community liaison CYFS. 


\title{
SENCO Professional Development Day 4
}

Effective use of TAs and curriculum adaptation - Massey University. All principals were brought in for $1 / 2$ hour of the TA session

\author{
3 March 2009, 8.30am-3.00pm
}

SENCO Cluster Professional Development Day

“Effective Use of Teacher Aides \& Curriculum Adaptation.”

Effective Use of Teacher Aides - Alison Kearney/Angela Ward

Principals join SENCOs - Alison Kearney/Angela Ward

RTLB referrals - RTLB

Curriculum Adaptation - Alison Kearney/Angela Ward

Goal setting - RTLB

\section{SENCO Professional Development Day 5}

GSE - the different support available to schools

\section{SENCO cluster}

Professional development day $3^{\text {rd }}$ June 2009

\section{Outcomes for the day}

Understanding of the GSE service provision, including SLT and ORRS

Review of individual school special needs area and future planning

Awareness of whole school professional development opportunities

Focus on the future of the SENCO project

Brief introduction to the GSE service - referrals \& consent issues (GSE Manager)

Communication service (SLT’s GSE)

ORRS (Tracey Rae)

Next steps - activity for Principals \& SENCOs

Introduction to Principals \& SENCOs about cluster wide professional development

RTLB referral form

RTLB presentations regarding possible cluster wide professional development 


\title{
Professional Development Day 6
}

Skills for Effective Facilitation

\begin{abstract}
Karen Shephard
Training for

SENCOs

19 August 2009

\section{$\underline{\text { Session Objectives }}$}

To provide a brief overview of facilitation principles and skills

To recognised the skills participants already have in facilitation

To recognised the ways participants could improve their facilitation of meetings
\end{abstract}

Keys to Facilitation
Agreed Purpose
Role and responsibility clarity
Clear process
PREPARATION
Facilitation Skills
Listening
Questioning
Clarifying and Paraphrasing
Building a bridge (negotiating)
Keeping the 'we' going
What helps?
Appropriate humour
Honesty
Ground rules
Clear purpose
Clear roles

Clear facilitator permission
Clear timeframe
What also helps
Konouring contributions
Being adaptable
Sticking to planned process
Negotiation
When in doubt check it out e.g
What are we doing?
What we want?
What we need?
How are we doing?
Where would you scale your facilitation skills today?
What will you do to develop and enhance these skills?
Where would you like to scale yourself in 6 months time?




\section{SENCO Professional Development Day 7}

Workshop sessions run by RTLB and SENCOs, looking again at some of the core activities of SENCOs such as procedures, IEPS, registers, etc.

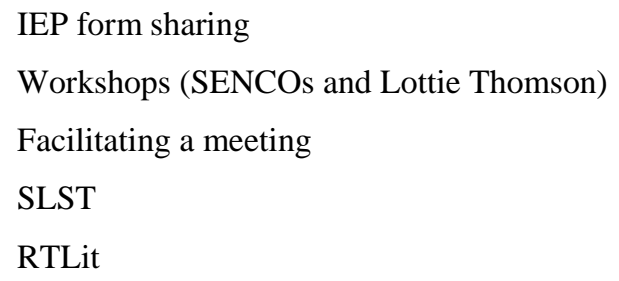

\section{SENCO Professional Development Day 8}

Mark Sweeney Making a difference in an educational consultancy role

SENCOs essentially operate in what is known as a collaborative-consultative teacher model and this workshop will offer strategies and skills which will assist them in this role with particular emphasis on the fact that they have expectations for delivering outcomes without the direct authority to require their implementation. Building and maintaining effective relationships is central to success in the Senco role and the workshop will use the 'umbrella' of strategic communication capabilities as a key tool for relationship management and the building of influence. The workshop will be active and interactive and will offer a rich array of practical strategies and tools that fit with the reality of the SENCO role and school situations.

The workshop will focus specifically on core capabilities in the following areas

Role clarity - understanding the realities of the role of a 'collaborative support teacher'. 5 dimensions to the consultative-collaborative role will be identified and Sencos will be encouraged to examine these and reflect on how they operate in their positions.

Relationship management - connecting and communicating effectively with others. Core strategies for building and maintaining effective relationships will be presented. Sencos will be offered a range of practical tools which can be easily utilised.

Influence building - creating commitment and 'buy-in'. The relationship management component will also focus on the building of influence - a key strategy for effectiveness in the role.

Collaborative problem solving skills. The course will present a powerful and highly practical listening/problem solving framework which Sencos can use in a range of situations where issues need to be positively resolved. 
Appendix E

The RTLB milestone report format 


\section{SENCO Cluster Development Project}

As this project is now over the half way mark it is time to reflect on where each of the schools are at regarding development of special needs procedures and to determine what would be the next steps in its development. We have listed in the left hand column some suggestions about what could be in place within a school regarding special needs structures. (It is not intended that schools should have all these things or that this is supposed to be some form of exhaustive list that may represent some mythical ideal school. There is room for you to add to this list if you want to do so.)

The process we would like you to follow is:

- We would like the Principal and SENCO to work together, going through the list in the left hand column ticking off what they already have in their school and adding any additional processes they have in place.

- Then together the Principal and SENCO go through the right hand column ticking the processes they would want to introduce into their school by the end of Term 1, 2010. Please write in any that may not be in the list.

- Then finally the SENCO and Principal record in the centre column what they need to do or what assistance they need to achieve what they have recorded in the previous step.

We will then:

- Collect all the sheets from the SENCOs and take them away for photocopying.

- We will return the originals to the SENCOs so they can work with their Principal to put in place the changes they want. 
- We will collate the data in a format that ensures no individual school can be identified, and then report the data back to the Principals about the present state of development of special needs processes within our cluster.

- The first part of this process will be repeated in term 1, 2010 so we can report back to the Principals in an appropriate format on the extent of change brought about by the EPF project. 
School:

Date:

\begin{tabular}{|c|c|c|}
\hline $\begin{array}{l}\text { Present level of Special Needs } \\
\text { development within the school }\end{array}$ & $\begin{array}{l}\text { Assistance and action required to reach } \\
\text { goals indicated in column } 3\end{array}$ & $\begin{array}{l}\text { Intended level of Special Needs } \\
\text { development within the school }\end{array}$ \\
\hline $\begin{array}{l}\text { Policy } \\
\text { A Special Needs Policy is written. } \\
\text { Special Needs Policy signed by the } \\
\text { BOT representative. } \\
\text { The BOT receives a regular report } \\
\text { regarding the schools activities } \\
\text { regarding the Special Needs Policy. } \\
\square \text { The staff have received professional } \\
\text { development from a Special Needs } \\
\text { committee representative about the } \\
\text { Special Needs policy. }\end{array}$ & & $\begin{array}{l}\text { Policy } \\
\square \text { A Special Needs Policy is written. } \\
\text { Special Needs Policy signed by the } \\
\text { BOT representative. } \\
\text { The BOT receives a regular report } \\
\text { regarding the schools activities } \\
\text { regarding the Special Needs Policy. } \\
\square \text { The staff have received professional } \\
\text { development from a Special Needs } \\
\text { committee representative about the } \\
\text { Special Needs policy. }\end{array}$ \\
\hline
\end{tabular}




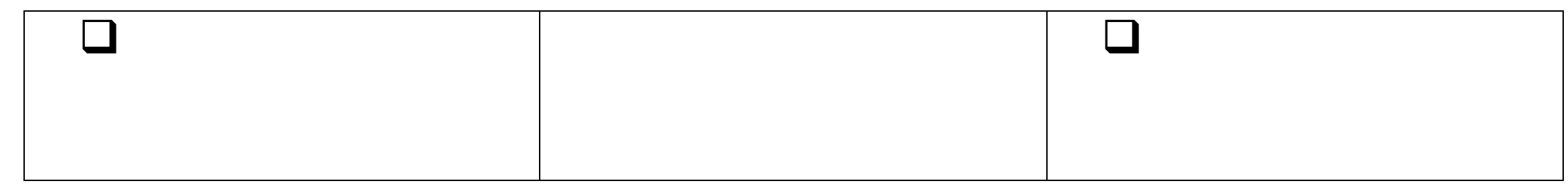




\begin{tabular}{|c|c|c|}
\hline $\begin{array}{l}\text { Present level of Special Needs } \\
\text { development within the school }\end{array}$ & $\begin{array}{c}\text { Assistance and action required to reach } \\
\text { goals indicated in column } 3\end{array}$ & $\begin{array}{l}\text { Intended level of Special Needs } \\
\text { development within the school }\end{array}$ \\
\hline $\begin{array}{l}\text { SENCO } \\
\text { A SENCO is appointed. } \\
\text { SENCO job description written and } \\
\text { agreed to by Principal and SENCO. } \\
\text { SENCO has designated release } \\
\text { time each term. } \\
\text { Release time each term for the } \\
\text { SENCO is set at__ days. } \\
\square \text { At the end of the EPF project the } \\
\text { school will be able to still fund the } \\
\text { same level of SENCO release time. } \\
\square \text { The SENCOs appraisal includes } \\
\text { discussion about their role in } \\
\text { special needs within the school. } \\
\square \text { SENCO has professional }\end{array}$ & & $\begin{array}{l}\text { SENCO } \\
\text { A SENCO is appointed. } \\
\text { SENCO job description written and } \\
\text { agreed to by Principal and SENCO. } \\
\text { SENCO has designated release time } \\
\text { each term. } \\
\text { Release time each term for the } \\
\text { SENCO is set at __ days. } \\
\text { At the end of the EPF project the } \\
\text { school will be able to still fund the } \\
\text { same level of SENCO release time. } \\
\text { The SENCOs appraisal includes } \\
\text { discussion about their role in } \\
\text { special needs within the school. } \\
\square \text { SENCO has professional }\end{array}$ \\
\hline
\end{tabular}




\begin{tabular}{|c|c|c|}
\hline $\begin{array}{l}\text { development that is specifically for } \\
\text { the requirements of this role. }\end{array}$ & & $\begin{array}{l}\text { development that is specifically for } \\
\text { the requirements of this role. }\end{array}$ \\
\hline $\begin{array}{l}\text { Present level of Special Needs } \\
\text { development within the school }\end{array}$ & $\begin{array}{c}\text { Assistance and action required to reach } \\
\text { goals indicated in column } 3\end{array}$ & $\begin{array}{l}\text { Intended level of Special Needs } \\
\text { development within the school }\end{array}$ \\
\hline $\begin{array}{l}\text { Special Needs Register } \\
\square \text { A special needs register is } \\
\text { maintained. } \\
\text { A student's placement on the } \\
\text { special needs register is based on } \\
\text { an agreed set of criteria. } \\
\square \text { The SENCO has ready access to } \\
\text { assessment data from class teachers } \\
\text { for children on the Special Needs } \\
\text { Register. }\end{array}$ & & $\begin{array}{l}\text { Special Needs Register } \\
\text { A special needs register is } \\
\text { maintained. } \\
\text { A student's placement on the } \\
\text { special needs register is based on an } \\
\text { agreed set of criteria. } \\
\square \text { The SENCO has ready access to } \\
\text { assessment data from class teachers } \\
\text { for children on the Special Needs } \\
\text { Register. }\end{array}$ \\
\hline
\end{tabular}




\begin{tabular}{|l|l|}
\hline Data about the Special Needs \\
Register, such as the number of \\
students and the reasons for \\
inclusion on the register, is reported \\
to the BOT. \\
$\square$ Data about the number of students \\
$\begin{array}{l}\text { on the special needs register and } \\
\text { the reasons for being on the register } \\
\text { feeds into the school's budgeting } \\
\text { process. } \\
\text { Data about the effectiveness of } \\
\text { special needs programmes feeds } \\
\text { into the school's budgeting process. }\end{array} \mid \begin{array}{l}\text { Register, such as the number of } \\
\text { students and the reasons for } \\
\text { inclusion on the register, is reported } \\
\text { to the BOT. } \\
\text { Data about the number of students } \\
\text { on the special needs register and the } \\
\text { reasons for being on the register } \\
\text { feeds into the school's budgeting } \\
\text { process. } \\
\text { Data about the effectiveness of } \\
\text { special needs programmes feeds } \\
\text { into the school's budgeting process. }\end{array}$ \\
\hline
\end{tabular}




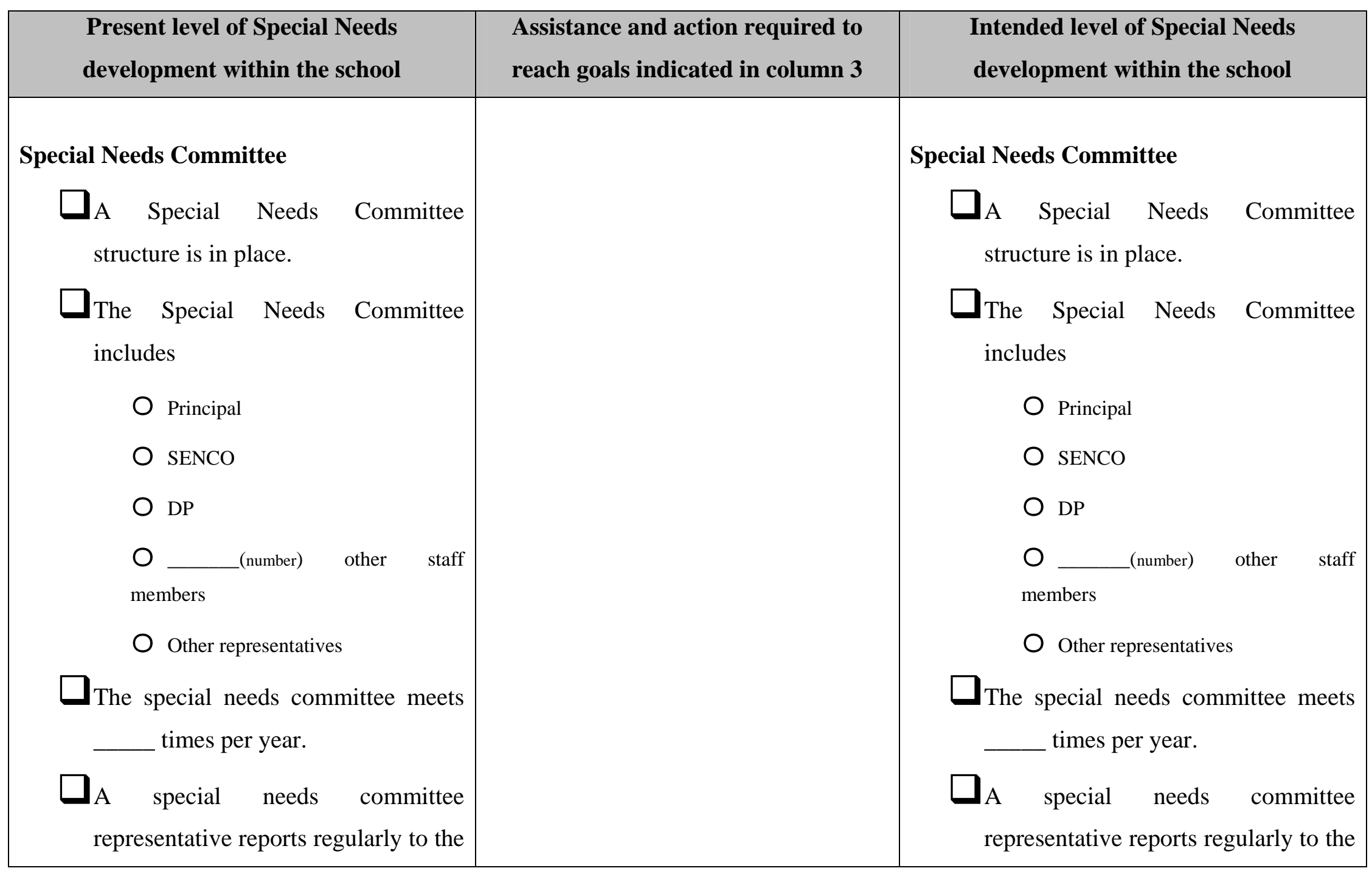




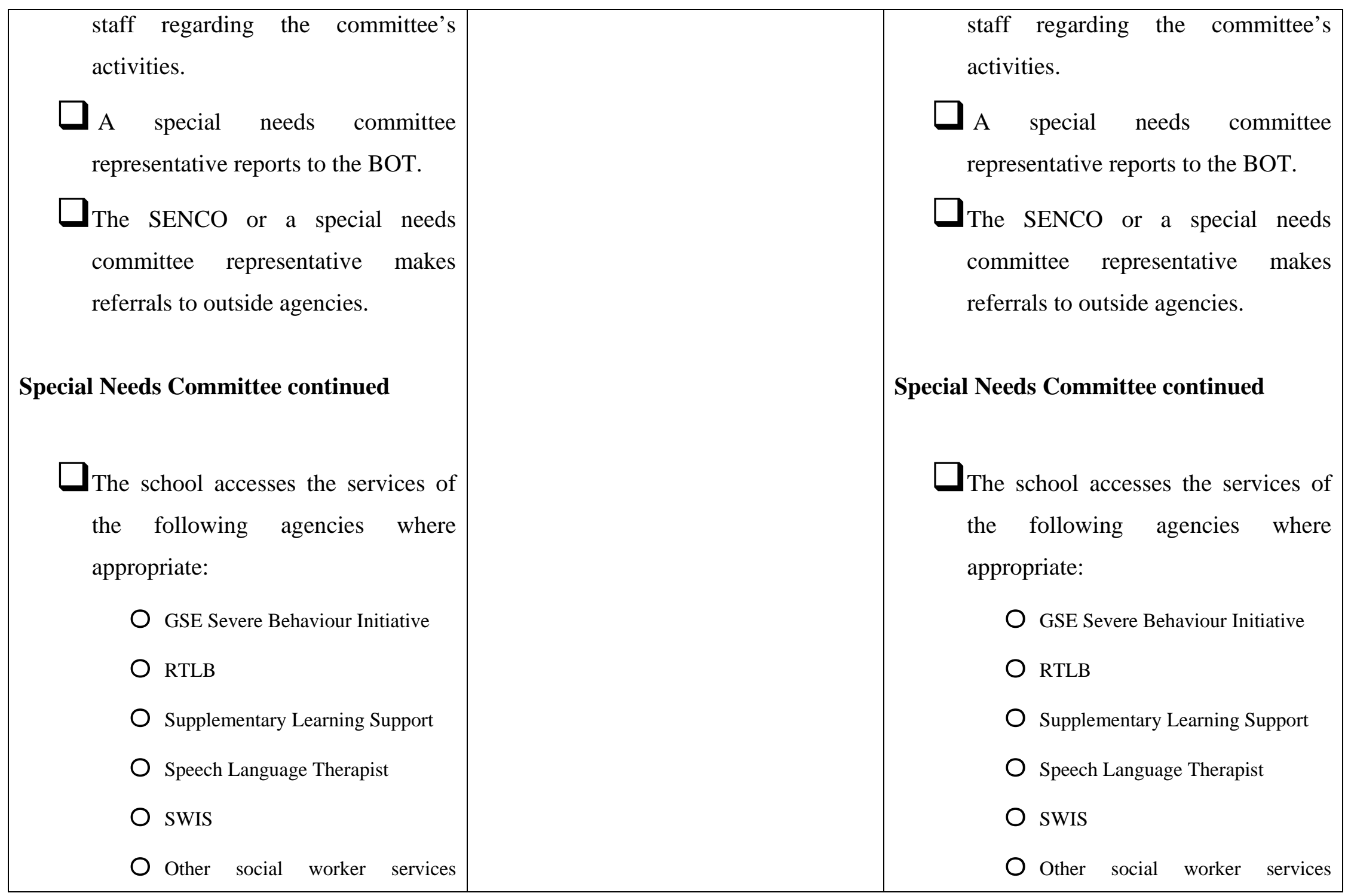




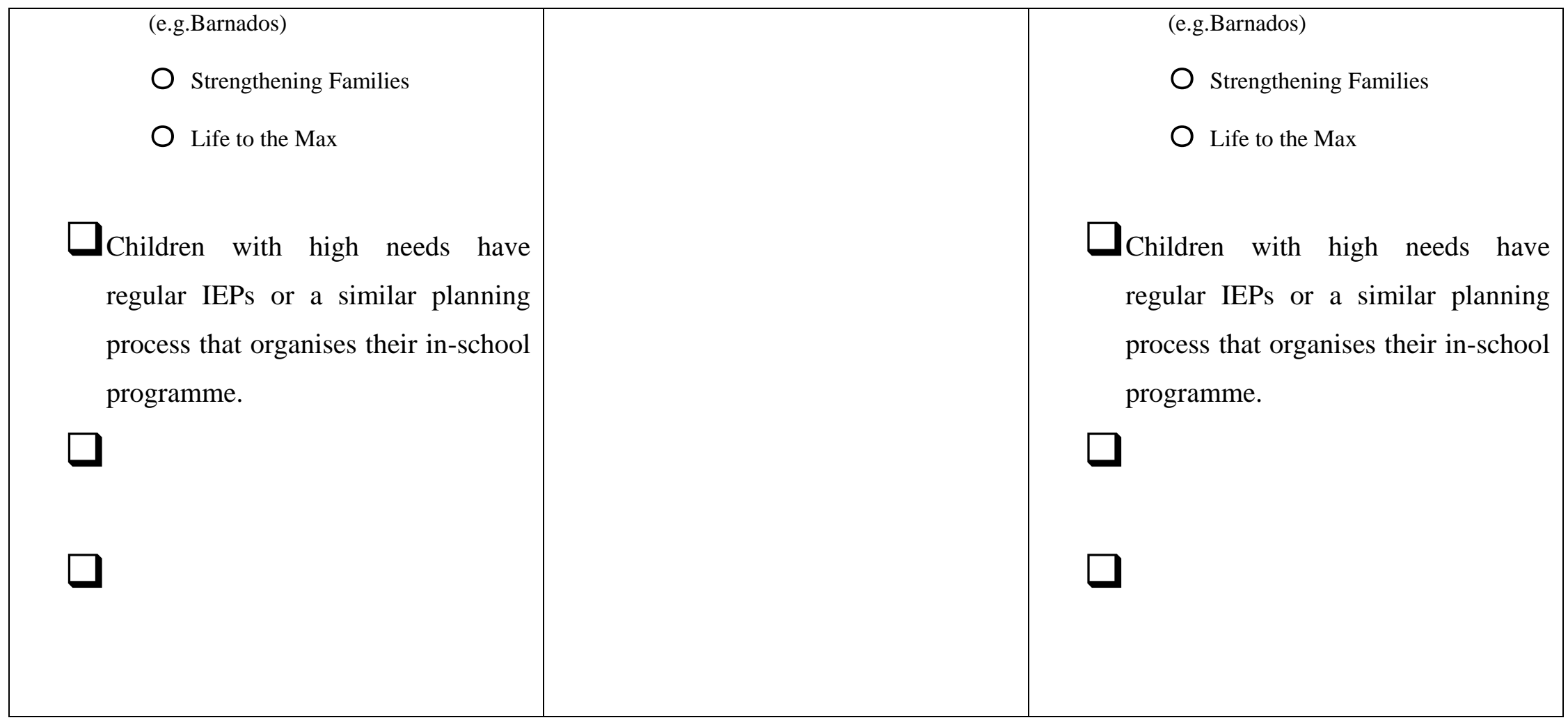

\begin{tabular}{|c|c|c|}
\hline $\begin{array}{c}\text { Present level of Special Needs } \\
\text { development within the school }\end{array}$ & $\begin{array}{c}\text { Assistance and action required to reach } \\
\text { goals indicated in column } 3\end{array}$ & $\begin{array}{c}\text { Intended level of Special Needs } \\
\text { development within the school }\end{array}$ \\
\hline $\begin{array}{c}\text { Teacher aides } \\
\square_{\text {Teacher } \quad \text { aides have a job }}\end{array}$ & $\begin{array}{c}\text { Teacher aides } \\
\text { Teacher }\end{array}$ & aides have a job \\
\hline
\end{tabular}




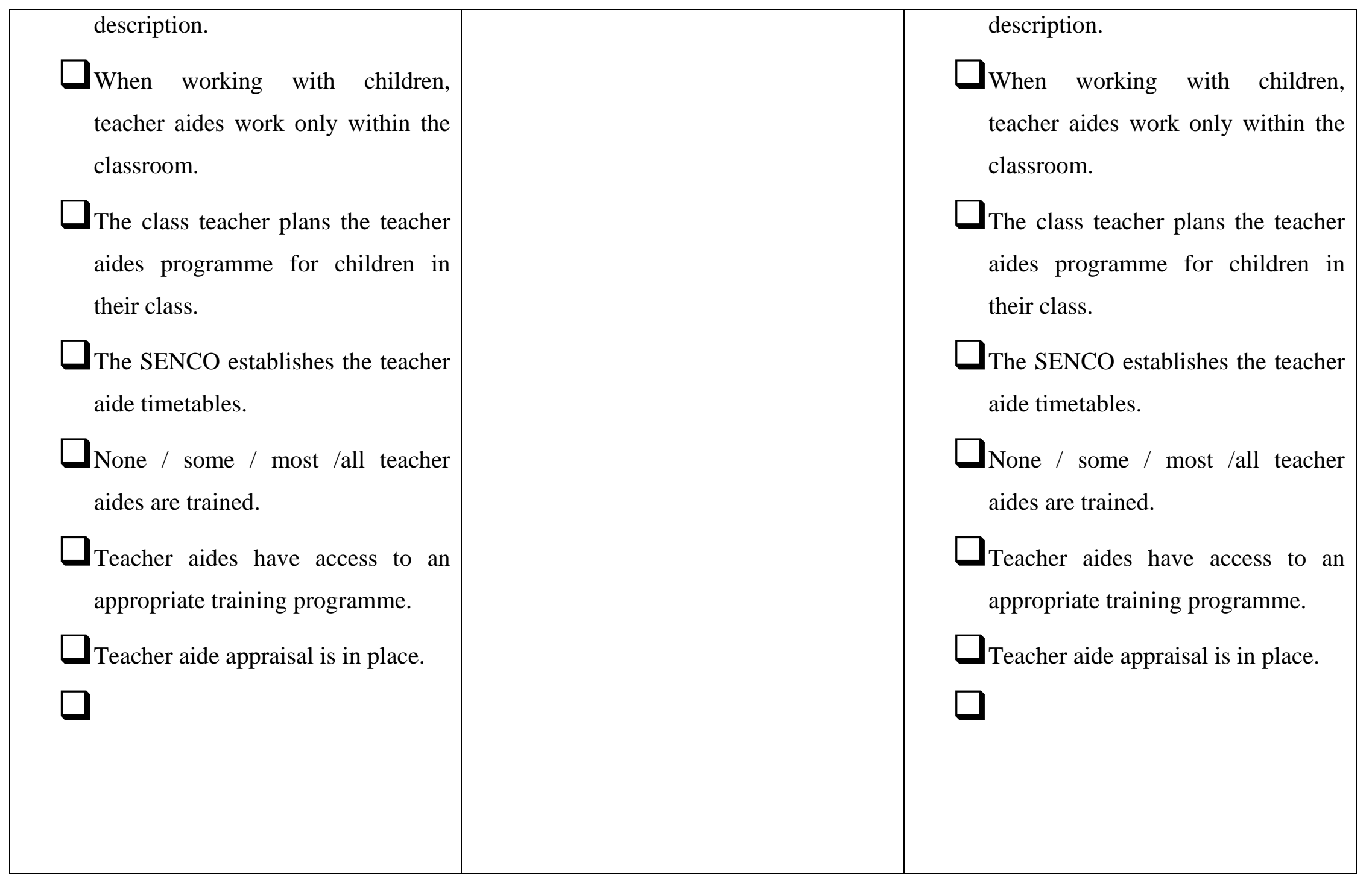

